Florida International University FIU Digital Commons

\title{
Reactions of 1,1-disubstituted-ethylenes and 1,4-Diphenyl-1,3-Butadienes with singlet oxygen and 4-Alkyl-1,2,4-triazoline-3,5-dione (RTAD)
}

Baishakhi Das

Florida International University

DOI: $10.25148 /$ etd.FI14062201

Follow this and additional works at: https://digitalcommons.fiu.edu/etd

Part of the Chemistry Commons

\section{Recommended Citation}

Das, Baishakhi, "Reactions of 1,1-disubstituted-ethylenes and 1,4-Diphenyl-1,3-Butadienes with singlet oxygen and 4-Alkyl-1,2,4-triazoline-3,5-dione (RTAD)" (2006). FIU Electronic Theses and Dissertations. 2735.

https://digitalcommons.fiu.edu/etd/2735 
FLORIDA INTERNATIONAL UNIVERSITY

Miami, Florida

REACTIONS OF 1,1-DISUBSTITUTED-ETHYLENES AND 1,4-DIPHENYL-1,3BUTADIENES WITH SINGLET OXYGEN AND 4-ALKYL-1,2,4-TRIAZOLINE-3,5DIONE (RTAD)

A thesis submitted in partial fulfillment of the requirements for the degree of MASTER OF SCIENCE in

CHEMISTRY

by

Baishakhi Das

2006 
To: Interim Dean Mark D. Szuchman

College of Arts and Sciences

This thesis, written by Baishakhi Das, and entitled Reactions of 1,1-Disubstitutedethylenes and 1,4-Diphenyl-1,3-butadienes with singlet oxygen and 4-alkyl-1,2,4triazoline-3,5-dione (RTAD), having been approved in respect to style and intellectual content, is referred to you for judgment.

We have read this thesis and recommend that it be approved.

David Becker

Rudolf Jaffé

Kevin O'Shea, Major Professor

Date of Defense: March 29, 2006

The thesis of Baishakhi Das is approved.

Interim Dean Mark D. Szuchman College of Arts and Sciences

Interim Dean Stephan L. Mintz University of Graduate School

Florida International University, 2006 


\section{DEDICATION}

I dedicate my thesis to the memory of my father Jaladhar Das who always inspired me in higher education. 


\section{ACKNOWLEDGMENTS}

I sincerely appreciate my committee members - Drs. David Becker and Rudolf Jaffé for their comments and guidance. I wish to thank Dr. Stanislaw Wnuk for his support. I would like to thank Dr. Watson Lees for helping me. My sincere gratitude goes to my major professor Dr. Kevin E. O'Shea for his patience, optimism, guidance, advice, and having confidence on me.

I would also like to thank my professor Joydev Mandol who inspired me to pursue a career in Chemistry. I gratefully appreciate his guidance and support. I thank my labmates Roberto, Weihua, Tielian, Sandra, Adriana, Sabrina and Chris for their friendship and assistance.

My love goes to my mother Prova Das and my brother Manojit Das for their understanding and unconditional love. Finally, I thank my husband Dr. Subrata D. Nath. Without his support, understanding and love the completion of this work would not have been possible. 


\section{ABSTRACT OF THE THESIS}

REACTIONS OF 1,1-DISUBSTITUTED-ETHYLENES AND 1,4-DIPHENYL-1,3-

BUTADIENES WITH SINGLET OXYGEN AND 4-ALKYL-1,2,4-TRIAZOLINE-3,5-

DIONE (RTAD)

by

Baishakhi Das

Florida International University, 2006

Miami, Florida

Professor Kevin E. O'Shea, Major Professor

A study of the reaction pathways of 1,1-diphenylethylene; methyleneindan;

fluorenene; trans, trans-1,4-diphenyl-1,3-butadiene; cis, trans-1,4-diphenyl-1,3-

butadiene and cis, cis-1,4-diphenyl-1,3-butadiene with singlet oxygen and the singlet oxygen mimic, 4-alkyl-1,2,4-triazoline-3,5-dione (RTAD) has been undertaken. Comparisons of the reactivity and reaction mechanisms among the isomers and electrophiles have been conducted. Singlet oxygen exhibits significantly lower reactivity compared to RTAD. RTAD reacts with 1,1diphenylethylene to produce $4+2 /$ ene and $4+2 / 4+2(2: 1)$ adducts but with methyleneindan to give a complex mixture including the ene adduct. Reactions of isomeric 1,4-diphenyl-1,3-butadienes with RTAD produce $4+2$ adducts. The results of the studies provide fundamental mechanistic information which is important to a better understanding of the detrimental and beneficial reactions of ${ }^{1} \mathrm{O}_{2}$ in biological systems and the environment. 
I.

1.1 Background. 1

1.2 Reaction Mechanisms of ${ }^{1} \mathrm{O}_{2}$ and MTAD ...................................... 5

1.3 Reaction probes for mechanistic study................................... 9

II.

2.1 Characterization of 1,1-Diphenyl-ehylene 12

2.2 Synthesis and Characterization of Methyleneindan via Wittig Reaction......15

2.3 Synthesis and Characterization of Fluorenene via Wittig Reaction...........19

2.4 Characterization of E,E-1,4-Diphenyl-1,3-butadiene......................... 23

2.5 Synthesis and Characterization of E,Z-1,4-Diphenyl-1,3-butadiene.........23

2.6 Synthesis and Characterization of Z,Z-1,4-Diphenyl-1,3-butadiene........ 31

III.

3.1 Singlet oxygen reactions with 1,1-Disubstituted-ethylenes and 1,4Diphenyl-1,3-butadienes

3.1.1 The reaction of 1,1-Diphenyl-ethylene with singlet oxygen...........36

3.1.2 The reaction Methyleneindan with singlet oxygen.....................40

3.1.3 The reaction Fluorenene with singlet oxygen......................... 43

3.1.4 The reaction E,E-1,4-Diphenyl-1,3-butadiene with singlet oxygen...45

3.1.5 The reaction $E, Z-1,4-D i p h e n y l-1,3$-butadiene with singlet oxygen... 48 3.1.6 The reaction $Z, Z-1,4-D i p h e n y l-1,3$-butadiene with singlet oxygen....51

3.2 Reactions of 4-Methyl-1,2,4-triazoline-3,5-dione (MTAD) with 1,1Disubstituted-ethylenes and 1,4-Diphenyl-1,3-butadienes

3.2.1 Reaction of 4-Methyl-1,2,4-triazoline-3,5-dione (MTAD) with 1,1- Diphenyl-ethylenes....................................................... 55

3.2.2 Reaction of 4-Methyl-1,2,4-triazoline-3,5-dione (MTAD) with

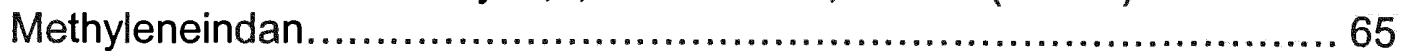

3.2.3 Reaction of 4-Methyl-1,2,4-triazoline-3,5-dione (MTAD) with Fluorenene. 69

3.2.4 Reaction of 4-Methyl-1,2,4-triazoline-3,5-dione (MTAD) with

E,E-1,4-Diphenyl-1,3-butadiene.

3.2.5 Reaction of 4-Methyl-1,2,4-triazoline-3,5-dione (MTAD) with

E,Z-1,4-Diphenyl-1,3-butadiene. 80

3.2.6 Reaction of 4-Methyl-1,2,4-triazoline-3,5-dione (MTAD) with Z,Z-1,4-Diphenyl-1,3-butadiene. 86 
Conclusions

References.

Appendix... 


\section{LIST OF FIGURES}

FIGURE

PAGE

Figure I $\quad{ }^{1}$ H NMR spectrum of 1,1-diphenyl-ethylene ........................13

Figure $\| \quad{ }^{13} \mathrm{C}$ NMR spectrum of 1,1-diphenyl-ethylene.......................14

Figure III $\quad{ }^{1} \mathrm{H}$ NMR spectrum of methyleneindan............................ 17

Figure IV $\quad{ }^{13} \mathrm{C}$ NMR spectrum of methyleneindan............................ 18

Figure $\mathrm{V} \quad{ }^{1} \mathrm{H}$ NMR spectrum of fluorenene..................................21

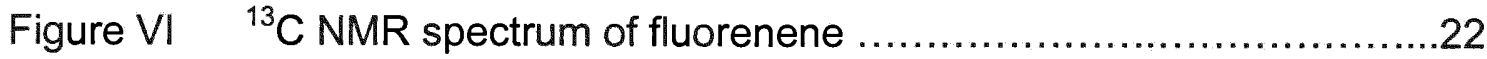

Figure VII $\quad{ }^{1} \mathrm{H}$ NMR spectrum of E,E-1,4-diphenyl-1,3-butadiene..............24

Figure VIII $\quad{ }^{13} \mathrm{C}$ NMR spectrum of E,E-1,4-diphenyl-1,3-butadiene.............25

Figure IX GC-MS spectrum of E,E-1,4-diphenyl-1,3-butadiene...............26

Figure $X \quad{ }^{1} \mathrm{H}$ NMR spectrum of E,Z-1,4-diphenyl-1,3-butadiene.................28

Figure XI $\quad{ }^{13} \mathrm{C}$ NMR spectrum of E,Z-1,4-diphenyl-1,3-butadiene...............29

Figure XII GC-MS spectrum of E,Z-1,4-diphenyl-1,3-butadiene.................30

Figure XIII ${ }^{1} \mathrm{H}$ NMR spectrum of Z,Z-1,4-diphenyl-1,3-butadiene................33

Figure XIV ${ }^{13} \mathrm{C}$ NMR spectrum of Z,Z-1,4-diphenyl-1,3-butadiene................34

Figure XV GC-MS spectrum of Z,Z-1,4-diphenyl-1,3-butadiene................35

Figure XVI $\quad{ }^{1} \mathrm{H}$ NMR spectrum of 1,1-diphenylethylene with ${ }^{1} \mathrm{O}_{2}$ in the Presence of TME.....................................................39

Figure XVII ${ }^{1} \mathrm{H}$ NMR spectrum of methyleneindan with ${ }^{1} \mathrm{O}_{2} \ldots \ldots \ldots \ldots \ldots \ldots . \ldots 42$

Figure XVIII ${ }^{1} \mathrm{H}$ NMR spectrum of fluorenene with ${ }^{1} \mathrm{O}_{2} \ldots \ldots \ldots \ldots \ldots \ldots \ldots \ldots . \ldots 44$

Figure $\mathrm{XIX} \quad{ }^{1} \mathrm{H}$ NMR spectrum of E,E-1,4-diphenyl-1,3-butadiene with ${ }^{1} \mathrm{O}_{2} \ldots \ldots 47$

Figure XX ${ }^{1} \mathrm{H}$ NMR spectrum of $\mathrm{E}, \mathrm{Z}-1,4$-diphenyl-1,3-butadiene with ${ }^{1} \mathrm{O}_{2}$ in presence of TME 
Figure $X X I{ }^{1} \mathrm{H}$ NMR spectrum of Z,Z-1,4-diphenyl-1,3-butadiene with ${ }^{1} \mathrm{O}_{2}$ in presence of TME

Figure XXII ${ }^{1} \mathrm{H}$ NMR spectrum of 1,1-diphenyl-ethylene with MTAD..............60

Figure XXIII ${ }^{13} \mathrm{C}$ NMR spectrum of 1,1-diphenyl-ethylene with MTAD............61

Figure XIV DEPT NMR spectrum of 1,1-diphenyl-ethylene with MTAD.........62

Figure XXV COSY spectrum of 1,1-diphenyl-ethylene with MTAD ...............63

Figure XXVI ${ }^{1} \mathrm{H}$ NMR spectrum of 1,1-diphenyl-ethylene + $\mathrm{MeOH}+\mathrm{MTAD} \ldots . .64$

Figure XXVII ${ }^{1} \mathrm{H}$ NMR spectrum of methyleneindan with MTAD .................66

Figure XXVIII ${ }^{13} \mathrm{C}$ NMR spectrum of methyleneindan with MTAD ...............67

Figure XXIX ${ }^{1} \mathrm{H}$ NMR spectrum of methyleneindan $+\mathrm{MeOH}+\mathrm{MTAD} \ldots \ldots \ldots \ldots 68$

Figure XXX ${ }^{1} H$ NMR spectrum of fluorenene with MTAD ........................70

Figure XXXI ${ }^{1} \mathrm{H}$ NMR spectrum of E,E-1,4-diphenyl-1,3-butadiene with

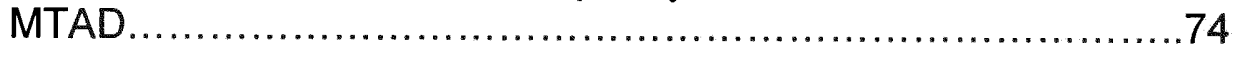

Figure XXXII ${ }^{13} \mathrm{C}$ NMR spectrum of E,E-1,4-diphenyl-1,3-butadiene with MTAD ......................................................... 75

Figure XXXIII DEPT NMR spectrum of E,E-1,4-diphenyl-1,3-butadiene with MTAD.

Figure XXXIV LC-MS spectrum of E,E-1,4-diphenyl-1,3-butadiene with

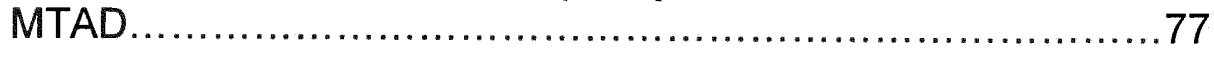

Figure XXXV ${ }^{1} H$ NMR spectrum of E,E-1,4-diphenyl-1,3-butadiene with MTAD : MeOH trapping

Figure XXXVI ${ }^{1} \mathrm{H}$ NMR spectrum of E,Z-1,4-diphenyl-1,3-butadiene with MTAD

Figure XXXVII ${ }^{13} \mathrm{C}$ NMR spectrum of E,Z-1,4-diphenyl-1,3-butadiene with MTAD.

Figure XXXVIII ${ }^{1} \mathrm{H}$ NMR spectrum of E,Z-1,4-diphenyl-1,3-butadiene with MTAD : $\mathrm{MeOH}$ trapping. .85 
Figure XXXIX $\quad{ }^{1} \mathrm{H}$ NMR spectrum of Z,Z-1,4-diphenyl-1,3-butadiene with MTAD.

Figure $X X X X \quad{ }^{13} \mathrm{C}$ NMR spectrum of Z,Z-1,4-diphenyl-1,3-butadiene with MTAD .............................................................89

Figure XXXXI $\quad{ }^{1} H$ NMR spectrum of Z,Z-1,4-diphenyl-1,3-butadiene with MTAD in presence of $\mathrm{MeOH}$................................. 90 
1.1 Background: The oxidation of organic and biological substrates in the presence of oxygen, light, and a photosensitizer has been the subject of extensive study over the past several decades ${ }^{1,2}$. Singlet oxygen $\left({ }^{1} \mathrm{O}_{2}\right)$ is the lowest electronic excited state of molecular oxygen, $22.4 \mathrm{Kcal} / \mathrm{mole}$ above the ground state. It is short lived in solution with lifetime of $10^{-3}-10^{-6}$ seconds depending on solvent and experimental conditions. Singlet oxygen is involved in a number of chemical, biological, biomedical and environmental processes, and thus its properties and reactions are of great interest to scientists. Several techniques have been developed which employ photooxidative processes for a variety of applications, from the treatment of skin disorders to the destruction of pollutants. The use of a photosensitizer in the presence of oxygen (Photodynamic Therapy, PDT) for the treatment of early stage superficial tumors is one of the advances in the medical field involving photooxidation ${ }^{3}$. A fundamental understanding of the reaction pathways and intermediates involved in these processes is crucial for assessing potential applications of singlet oxygen chemistry.

The reactivity of conjugated systems such as 1,4-diphenyl-1,3-butadienes and 1,1-diphenylethylenes with ${ }^{1} \mathrm{O}_{2}$ is expected to mirror a number of systems present in a variety of pigments and chromophores found in plants and animals. A better understanding of the mechanisms of the photooxidation of such conjugated systems will help to assess the role and impact of singlet oxygen reactions in the environment and living organisms. Photooxidation of conjugated diene systems in polymeric materials, such as terpenes, vitamins, paints, dyes 
etc. are detrimental to the degradation of these materials. Representative conjugated systems are illustrated below in $\beta$-carotene and vitamin $A$.

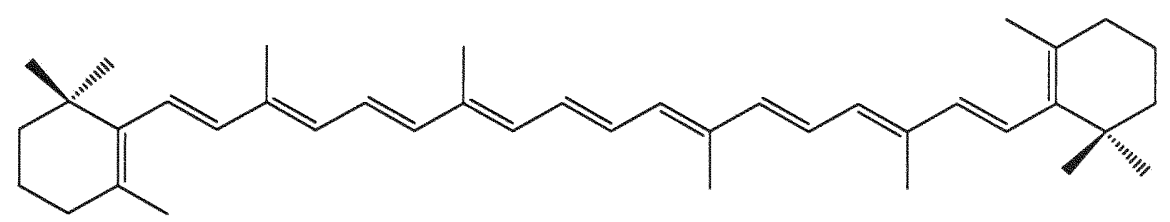

$\beta$-carotene (tetraterpene)

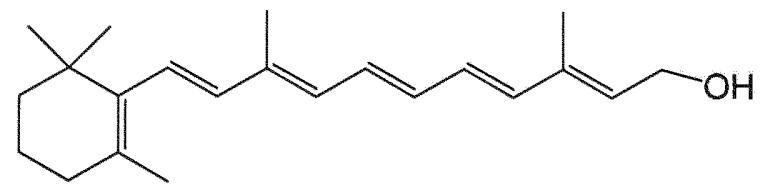

Vitamin A (retinol)

The reaction of organic polymers with molecular oxygen $\left(\mathrm{O}_{2}\right)$ is one of the most important processes of all polymer aging processes. This process can occur under comparatively mild conditions and is well known as autooxidation. Under sunlight irradiation, some photochemical oxidations occur in which ${ }^{1} \mathrm{O}_{2}$ may play a considerable role. Singlet oxygen oxidation of polymers has been previously discussed in several review papers ${ }^{19-30}$. Remarkably, however, the role of ${ }^{1} \mathrm{O}_{2}$ in the oxidation (or photooxidation) of polymers is still unclear. We have chosen 1,4-diphenyl-1,3-butadienes and 1,1-diphenyl-ethylenes to assess and better understand the role of ${ }^{1} \mathrm{O}_{2}$ in the initial step of oxidation (or photooxidation) of polymers. Our models resemble with polystyrene (PS) and polybutadiene (PBD) polymer models. 


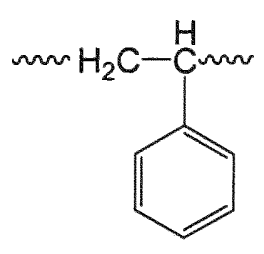

PS

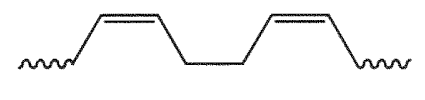

PBD

Polymers used in the form of plastics, fibers, and/or elastromers have a significant susceptibility to the thermal, photo-, environmental, and/or ${ }^{1} \mathrm{O}_{2}$ oxidation. In practice, only through the addition of a variety of stabilizers such as photostabilizers, antioxidants, thermal-stabilizers and/or ${ }^{1} \mathrm{O}_{2}$ interceptors, in amount 0.1 to $1.0 \mathrm{wt} \%$ the oxidation degradation of polymeric materials can be inhibited.

Photodynamic actions are the result of the photosensitized oxidation of biomolecules. Biomolecules and common functional groups susceptible to photosensitized oxidations include alcohols, aldehydes, amines, amino acids (especially cystein, histidine, methionine, tryptophan, and also lysine and arginine under certain conditions), carbohydrates, phospholipids, triglycerides, fatty acids, unsaturated fats, bilirubin, nitrogen heterocycles, pyrroles, indoles, imidazoles, purines, pyrimidines, nucleosides, nucleotides, nucleic acids, organic acids, phenols, proteins, steroids, thiols, sulfides, disulfides, unsaturated lipidsoluble biomolecules (cholesterol, vitamin D, $\beta$-carotene, sterols, tocopherols, and protaglandins), drugs, etc ${ }^{41}$. Illustrate below are vitamin $E$ (tocopherol) and indole: 


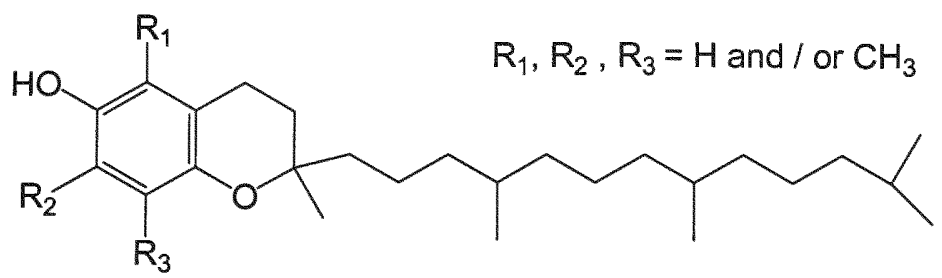

Tocopherol<smiles>c1ccc2[nH]ccc2c1</smiles>

Indole

Bilirubin forms covalent photoadducts with serum albumin on illumination both in vitro and in vivo during the phototherapy of hyperbilirubinemic infants; the sensitizer appears to couple at a specific region of the albumin molecule, probably at the bilirubin dark binding site ${ }^{31}$. Treatment typically involves simple photodynamic action by exposing the infant to artificial or solar irradiation.

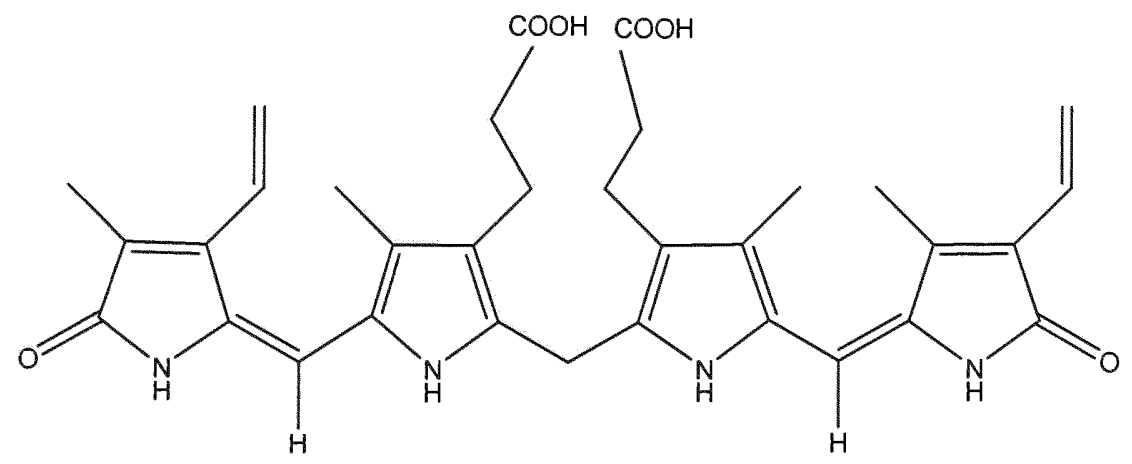

Bilirubin in the $E, E$ isomeric form

In addition to oxidation, dienes may isomerize in the presence of light, oxygen, or sensitizer ${ }^{5}$. We will use 1,4-diphenyl-1,3-butadienes and 1,1-diphenylethylenes as models for studying the reactions of ${ }^{1} \mathrm{O}_{2}$ with conjugated systems in an attempt to better understand the role of ${ }^{1} \mathrm{O}_{2}$ in biological and environmental systems. 


\subsection{Reaction Mechanisms of ${ }^{1} \mathrm{O}_{2}$ and MTAD:}

The typical reactions of singlet oxygen with olefins or dienes are usually [4+2], $[2+2]$ or "ene" products as shown below.

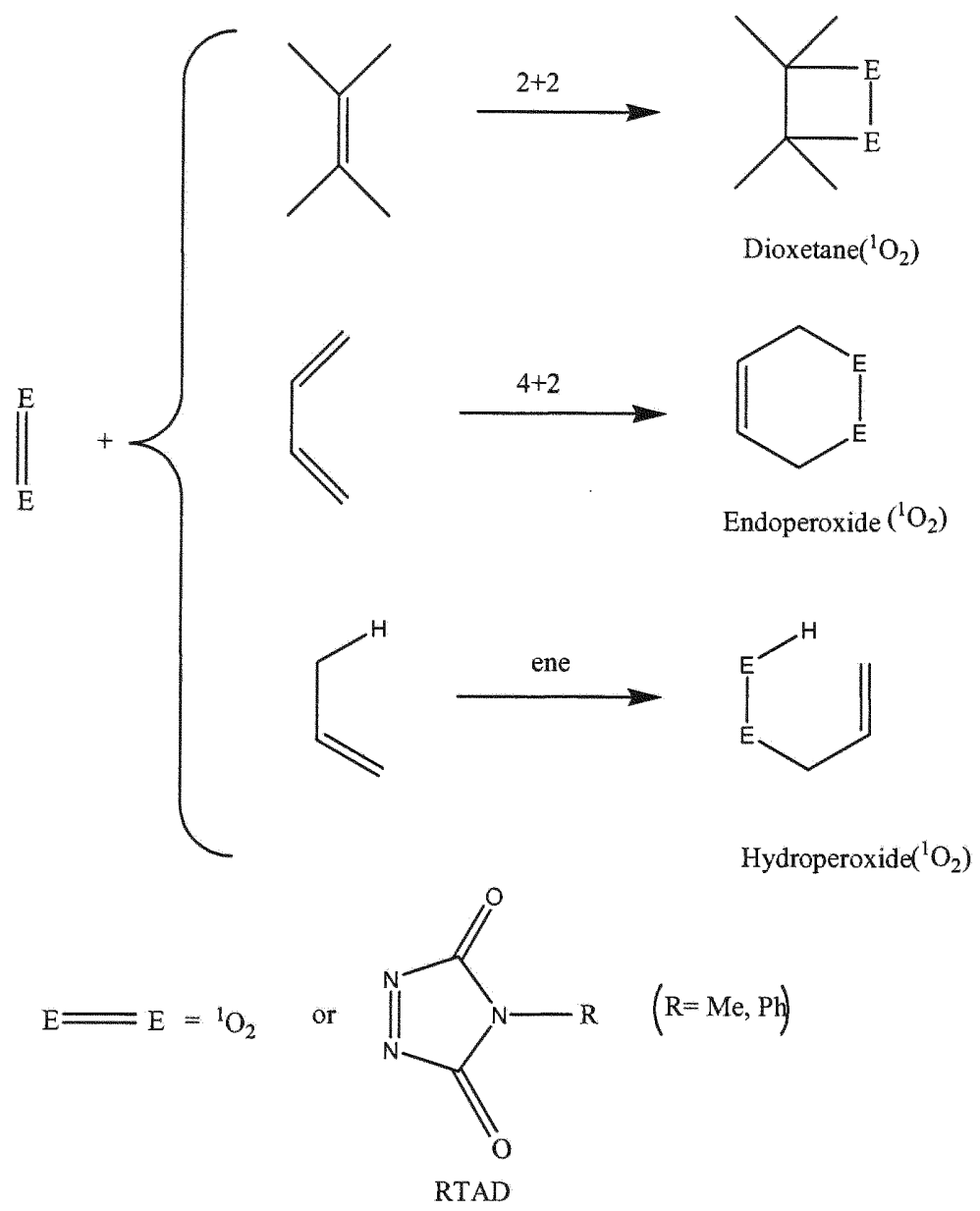

4-Alkyl-1,2,4-triazoline-3,5-dione (RTAD) exhibits reactivity analogous to that of singlet oxygen, typically [4+2], [2+2] or "ene" products. The products from RTAD are more stable than those formed with singlet oxygen and hence easier to isolate and characterize.

Both concerted and non-concerted mechanisms for [4+2], [2+2] or "ene" reactions of olefins and aromatics with the electrophiles, ${ }^{1} \mathrm{O}_{2}$, and $\mathrm{RTAD}$ have 
been reported ${ }^{1,2,5}$. Unsaturated fatty acids and olefins have been the subject of many investigations on photooxidation, and on their reactivity with singlet oxygen by the ene reaction ${ }^{32-39}$. The photooxidation of polystyrene (PS) is accompanied by extensive degradation and/or cross-linking. The coloration of PS during UV irradiation in the presence of air has been associated with ring opening oxidation of phenyl groups. It has been suggested that ${ }^{1} \mathrm{O}_{2}$ participates in these reactions via a dioxetane mechanism ${ }^{40}$ and ene-machanism in some cases ${ }^{2,41}$. The reaction of polybutadiene (PBD) with ${ }^{1} \mathrm{O}_{2}$ leads initially to the formation of allylic hydroperoxides. In addition, it has been suggested that endoperoxides may also result ${ }^{19,21,42-53}$.

O'Shea and Foote studied the reactions of singlet oxygen with $(E, E)$-, $(E, Z)$-, and $(Z, Z)-2,4$-hexadienes ${ }^{18}$. They observed cis-endoperoxide as major product and a complex mixture of hydroperoxides, acetaldehyde, and cis- and trans-2-butenal.
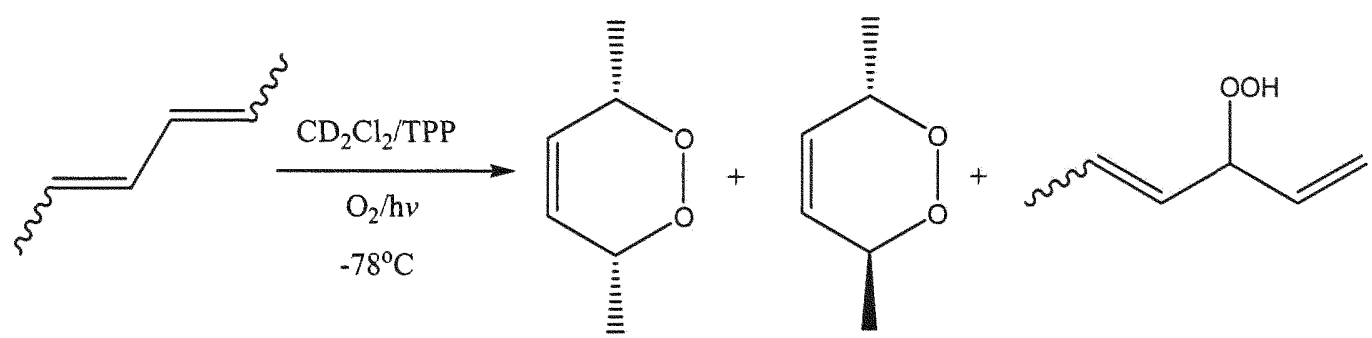

+ cis- and trans-2-butenal + acetaldehyde

They were also able to trap the intermediates by adding methanol. To rationalize their results they proposed the non-concerted reaction pathways and the formation of open zwitterion intermediates. 

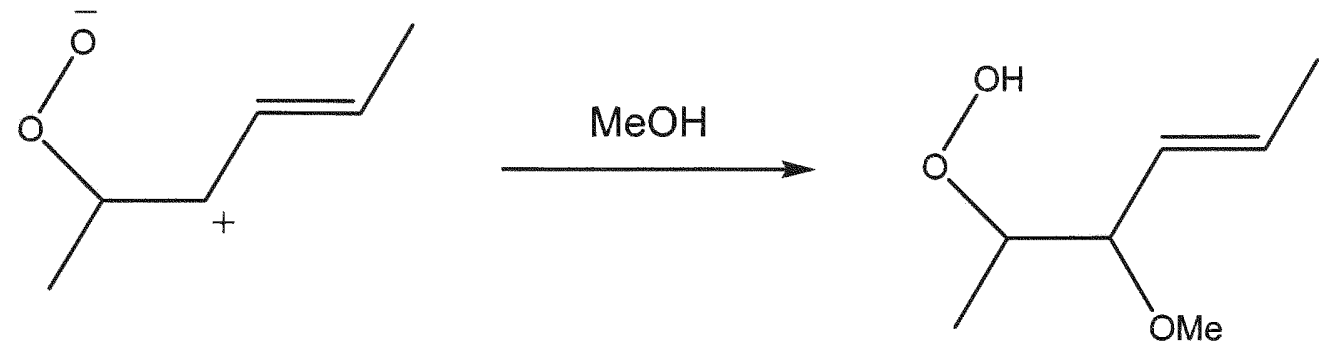

Jensen and Foote studied the reactions of RTAD with $(E, E)-,(E, Z)-$, and $(Z, Z)-2,4-$ hexadienes ${ }^{17}$. They observed the expected Diels-Alder products of RTAD with (E,E)-, and $(E, Z)-2,4$-hexadienes but the reaction of RTAD with $(Z, Z)$ 2,4-hexadiene yielded a mixture of two Diels-Alder products with major "wrong" stereoisomer. The solvent adducts and nonstereospecific products are rationalized via aziridinium imide $(\mathrm{Al})$ and/or open zwitterions.

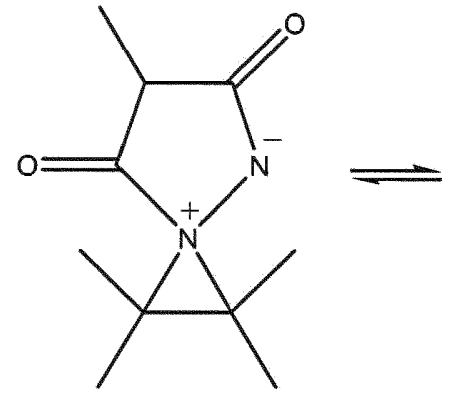

Al

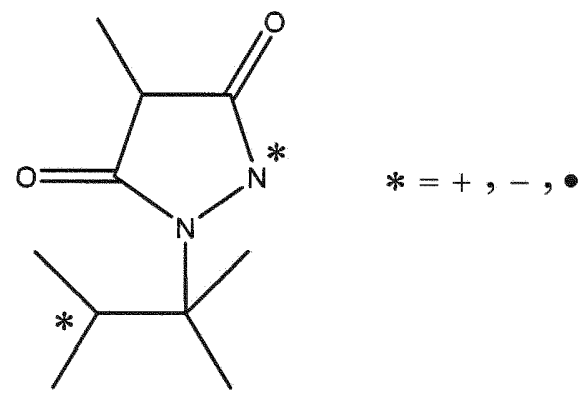

zwitterion

Singleton et al. studied the reactions of 2-methyl-2-butene, isobutene and tetramethylethylene (TME) with $R T A D^{9}$ and observed the unsymmetrical attack on the alkenes. They proposed a non-concerted mechanism involving biradicals and suggested zwitterionic species were "bystanders" to the observed reaction pathways. 
Kim and O'Shea studied the reactions of tetracyclopropylethylene (TCPE) with MTAD and observed meso-ionic, 5,5,6,6-tetracyclopropyl-3-methyl-5,6-dihydrooxazolo[1,2,4]-triazolium-2-olate and proposed non-concerted reaction processes $^{10}$.

We will probe the involvement of possible non-concerted reaction pathways involving 1,4-biradicals, peroxides, 1,4-zwitterions, charge transfer, and electron transfer mechanisms for reactions of ${ }^{1} \mathrm{O}_{2}$ and RTAD with 1,1diphenyl-ethylenes and isomeric 1,4-diphenyl-1,3-butadienes.

Some of the reaction probes were commercially available and others were made using standard synthetic techniques ${ }^{6,7,54}$. Disubstituted-ethylenes and isomeric 1,4-diphenyl-1,3-butadienes were subjected to control reactions related to the conditions of photooxidation. First the samples were irradiated in the absence of a sensitizer to establish contributions from direct photolysis. The samples were irradiated in the absence of $\mathrm{O}_{2}$ (argon purge) to assess the possibility for energy or electron transfer between sensitizer and disubstituted ethylenes and three isomers of 1,4-diphenyl-1,3-butadiene. Dark control experiments and methanol trapping studies were also conducted.

\section{Analysis:}

NMR and GC-Mass spectrometry were used as the primary tools to study the reactions of disubstituted-ethylenes and 1,4-diphenyl-1,3-butadiene with singlet oxygen and MTAD. Once the proper reactions conditions were established from the control reactions, detailed product studies were conducted using GC-MS, LC- 
MS spectrometry and NMR as ${ }^{1} \mathrm{H},{ }^{13} \mathrm{C}$, DEPT, and correlation spectroscopy (COSY, HETCOR). Disubstituted-ethylenes and 1,4-diphenyl-1,3-butadienes were subjected to the reaction conditions at different time intervals to establish percent conversion and to identify primary and secondary reaction products. A comparison of the reactivities of singlet oxygen and RTAD with disubstitutedethylenes and isomeric 1,4-diphenyl-1,3-butadienes is also presented.

\subsection{Reaction probes for mechanistic studies:}

$E, E, E, Z$ and $Z, Z-1,4$-diphenyl-1,3-butadienes were used as stereochemical probes. 1,1-diphenylethylene; 1-(1,3-dimethylphenyl)-1-phenylethylene; methyleneindan and fluorenene were selected to probe regiochemical and conformational effects. The structures of the substrates are given below:

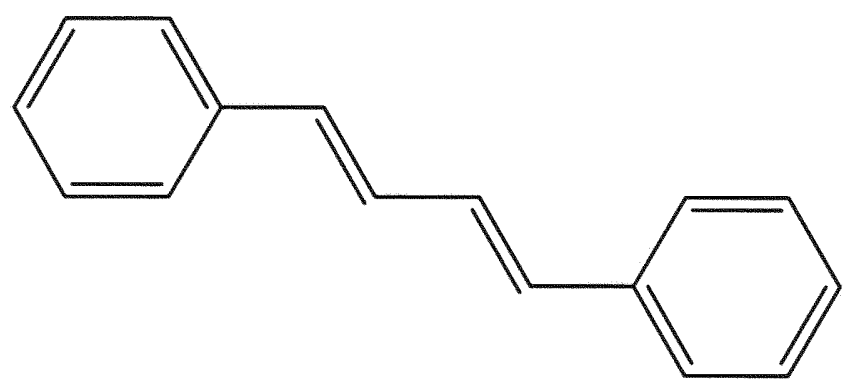

E,E-1,4-Diphenyl-1,3-Butadiene 


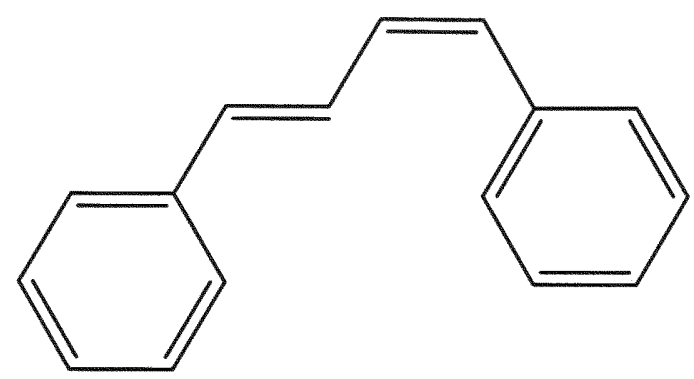

E,Z-1,4-Diphenyl-1,3-Butadiene

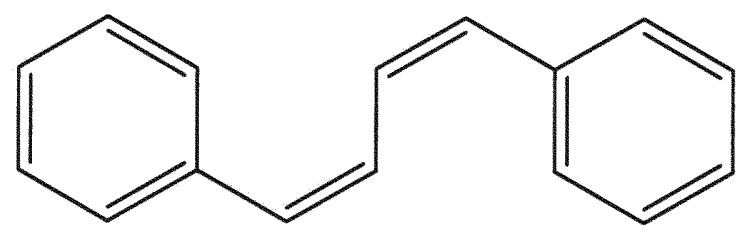

Z,Z-1,4-Diphenyl-1,3-Butadiene

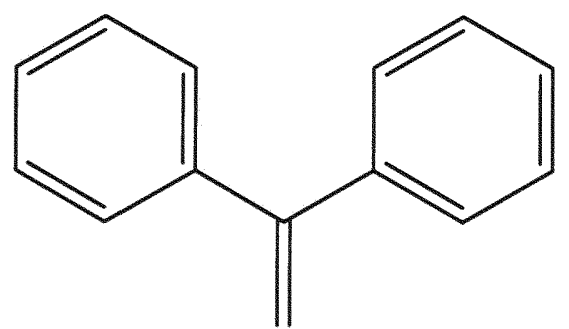

1,1-Diphenylethylene

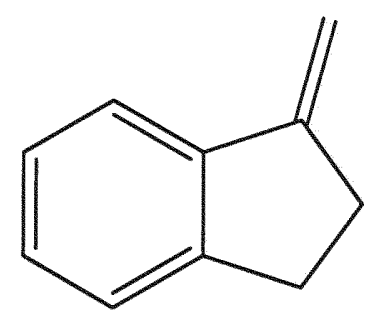

Methyleneindan

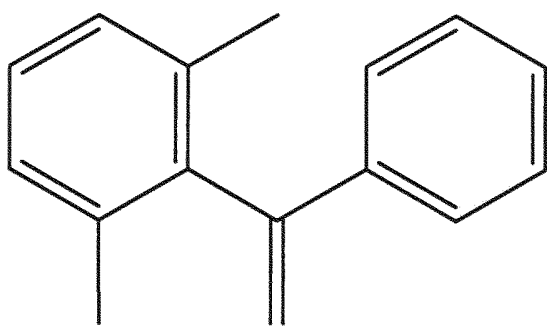

1,(1,3-Dimethylphenyl)-1-phenylethylene

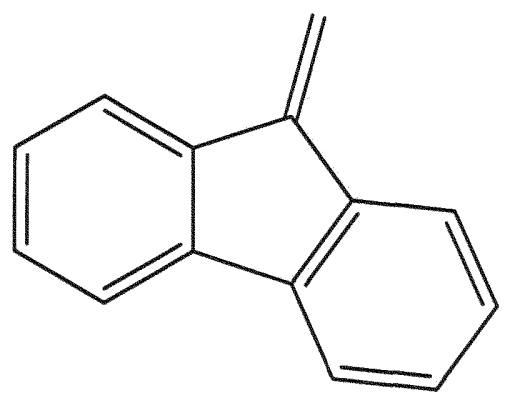

Fluorenene 
Expected reaction pathways of the reaction probes with electrophiles:

\begin{tabular}{|l|c|c|c|}
\hline Substrates & $4+2$ adduct & $2+2$ adduct & ene \\
\hline $\begin{array}{l}\text { Isomeric 1,4- } \\
\text { diphenyl-1,3- } \\
\text { butadiene }\end{array}$ & possible & possible & N/A \\
\hline $\begin{array}{l}1,1- \\
\text { diphenylethylene }\end{array}$ & unlikely & expected & N/A \\
\hline $\begin{array}{l}\text { 1-(1,3- } \\
\text { dimethylphenyl)-1- } \\
\text { phenylethylene }\end{array}$ & unlikely & expected & N/A \\
\hline methyleneindan & unlikely & expected & expected \\
\hline fluorenene & unlikely & expected & N/A \\
\hline
\end{tabular}

Singlet oxygen generation: Singlet oxygen is a reactive form of molecular oxygen. Singlet oxygen can be generated by a photosensitized reaction using visible light to excite a sensitizer and generate ${ }^{1} \mathrm{O}_{2}$ as follows:

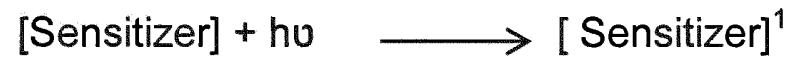

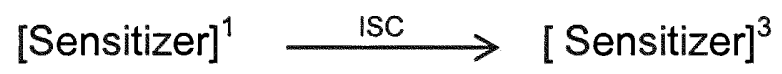

$$
\begin{aligned}
& {[\text { Sensitizer }]^{3}+{ }^{3} \mathrm{O}_{2} \longrightarrow[\text { Sensitizer }]+{ }^{1} \mathrm{O}_{2}}
\end{aligned}
$$

Photosensitization involves the absorption of light by a sensitizer to form `the singlet excited state (equation 1). The singlet excited state then undergoes intersystem crossing (ISC) to the triplet state (equation 2). The triplet state transfers its energy to ground state oxygen ${ }^{3} \mathrm{O}_{2}$ via an allowed process to form ${ }^{1} \mathrm{O}_{2}$ and ground state sensitizer (equation 3 ).

Materials: 1,4-Diphenylbutadiyne, 99\%; 1-indanone, 99+\%; trans,trans-1,4Diphenyl-1,3-butadiene, 98\%; Butyllithium 2M, solution in pentane; 2,3-Dimethyl- 
2-butene, 98\%; 2-Bromo-m-xylene, 98\%; 1,1-Diphenylethylene, 97\% were purchased from Aldrich, Chloroform-D (D, 99.8\%) from Cambridge Isotope Laboratories, Inc. Methyltriphenyl-phosphonium bromide, 98\%; Tetrahydrofuran, anhydrous, 99.9\%, inhibitor free from Sigma-Aldrich, Pyridinium chlorochromate, 98\% from Aldrich Chemical Company, Inc., Hexanes Reagent Grade ACS; Dichloromethane Glass Purified, Glass Distilled, HRGC/HPLC-Trace Grade from Pharmaco products Inc.

Equipment: GC-MS (Hewlett Packard, 6890 Series GC system, coupled with 5973 MS detector, J \& W DB-5ms, $30 \mathrm{~m}$ column, $0.25 \mathrm{~mm}$ diameter, $0.25 \mu \mathrm{m}$ coding; LC-MS (Finnegan Navigator $\mathrm{aQa}^{\mathrm{TM}}$, Scan AP+, 6.28e5, Cone Voltage 5, $300^{\circ} \mathrm{C}$ ); NMR (Bruker-Spectrospin 400, Ultrashield ${ }^{\mathrm{TM}}$, AVANCE 400); lamp (68806 Oriel model); Rayonet reactor

The following sections give detailed description of characterization and synthesis of these compounds.

\subsection{Characterization of 1,1-diphenylethylene:}

1,1-diphenylethylene was purchased from Sigma-Aldrich and used without further purification. It was characterized by ${ }^{1} \mathrm{H}$ and ${ }^{13} \mathrm{C}-\mathrm{NMR}$ (Bruker-400MHz NMR).

${ }^{1} \mathrm{H}$ NMR $(400 \mathrm{MHz}, \mathrm{CDCl} 3) \delta(\mathrm{ppm}): 5.58(\mathrm{~s}, 2 \mathrm{H}), 7.39-7.41(\mathrm{~m}, 10 \mathrm{H})$;

${ }^{13} \mathrm{C}$ NMR (ppm) : 114 (s), 127 (s), 128 (s), 129 (s), 142 (s), 150 (s). 

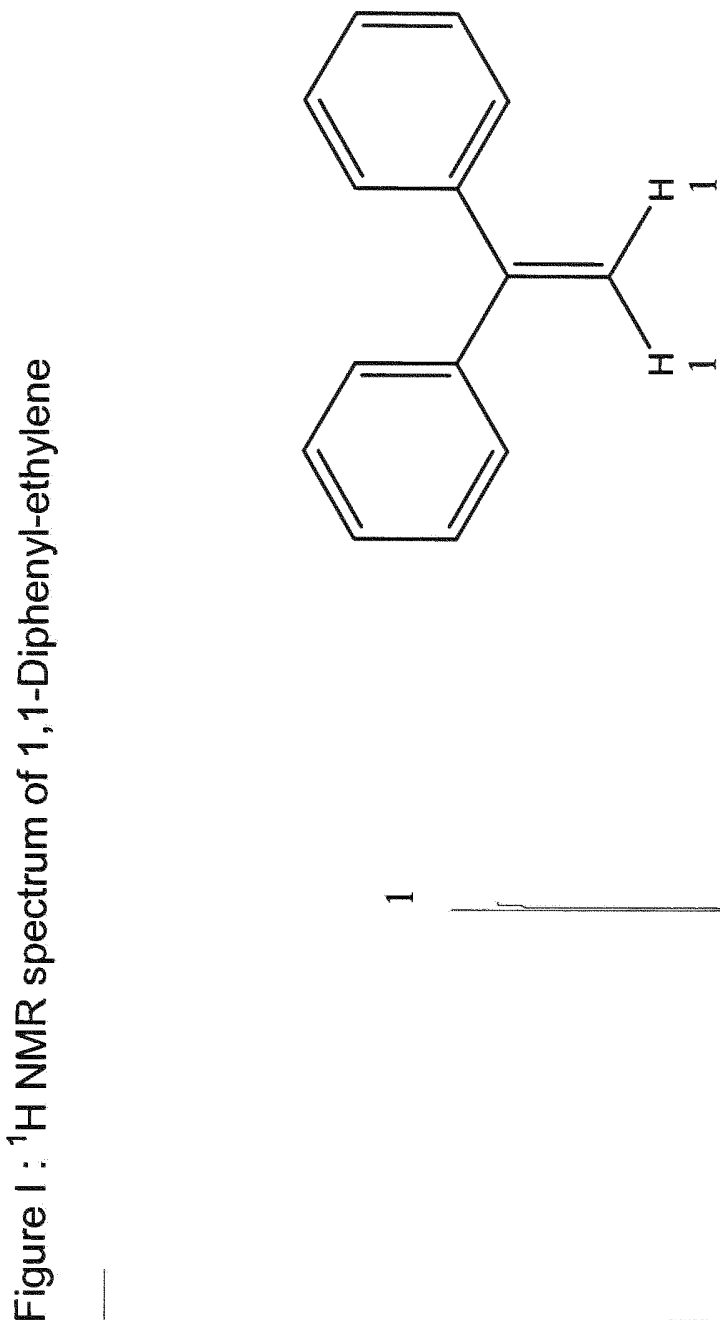

$-$

0

우

ì

$\stackrel{\infty}{\sim}$

พ

๓

$\stackrel{\varphi}{\oplus}$

-

$\dot{8}$

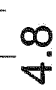

กั

$666^{\circ} 0$

0

$-0$

$\stackrel{+}{\circ}$

$\infty$

$0^{\circ}$

N 


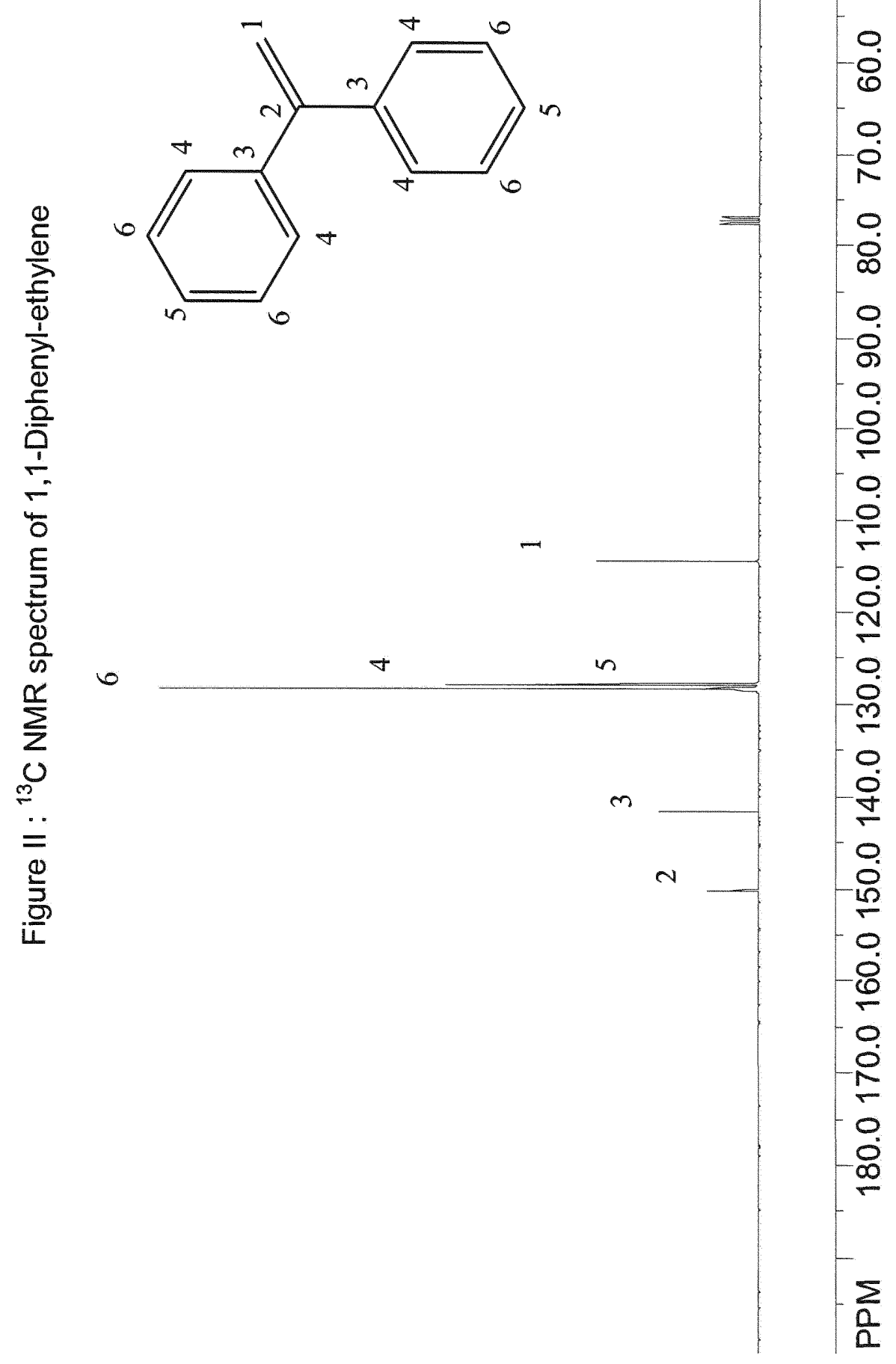




\subsection{Synthesis and Characterization of Methyleneindan via Wittig Reaction}

Methyleneindan was prepared from 1-Indanone and methyltriphenylphosphonium bromide via Wittig reaction. The yield was $88 \%$ of pure product.

Scheme: $\quad$ Synthesis of Methyleneindan

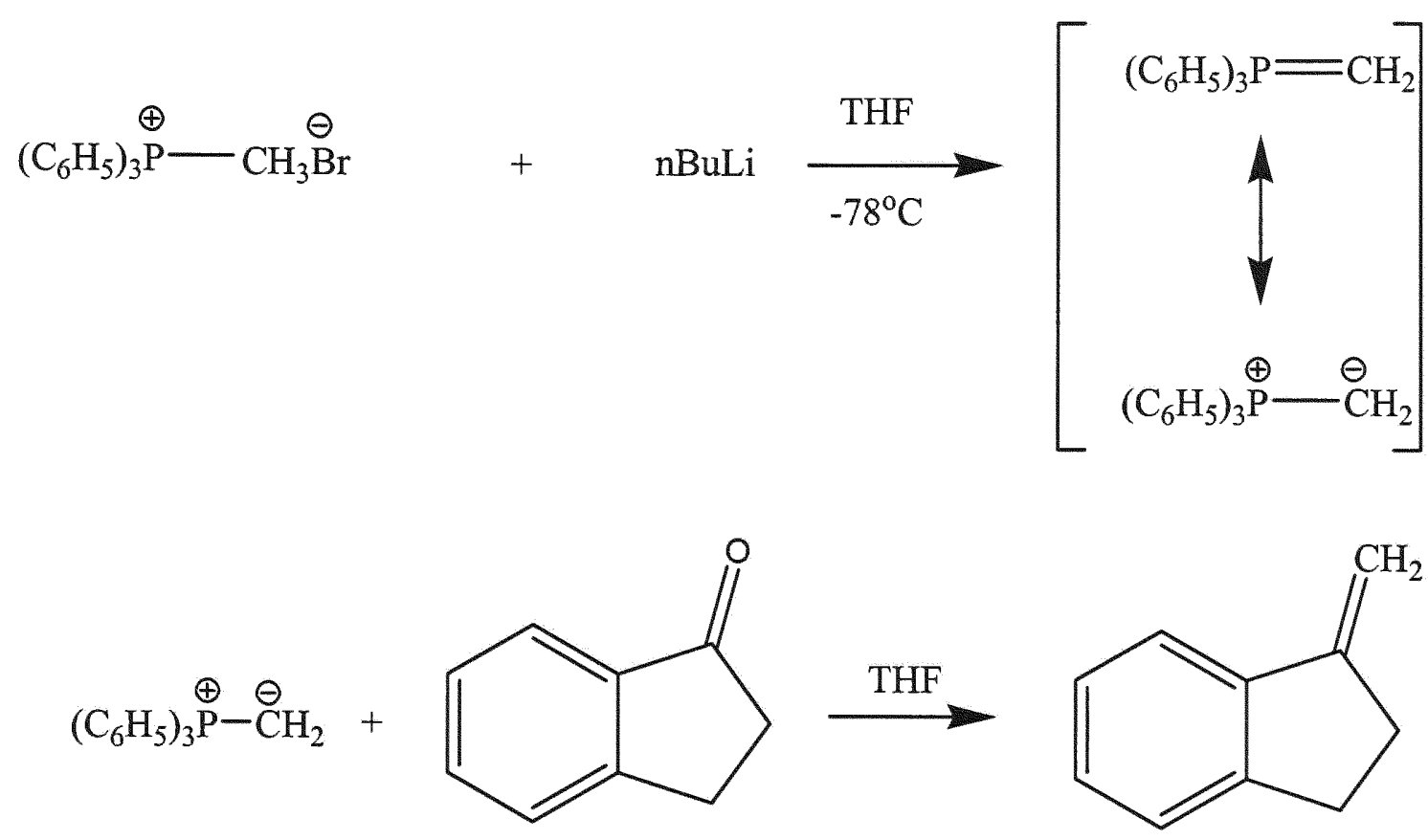

\section{Experimental:}

Methyltriphenylphophonium bromide (8.5062 g, 23.75 mmoles) of were weighed into a $100 \mathrm{~mL}$ 3-neck round bottom flask. A stirring bar and $25 \mathrm{mLs}$ of freshly distilled THF dried over $\mathrm{Na}$ was added. An addition funnel was placed in the center neck, the remaining opening were fitted with a septa/stoppers. The system was purged with a gentle stream of argon. A dry ice/acetone bath $\left(-78^{\circ} \mathrm{C}\right)$ was used to cool the reaction flask. $9.5 \mathrm{mLs}$ of $2.5 \mathrm{M} \mathrm{n}$-butyllithium in pentane was 
added dropwise via the addition funnel to the stirring mixture yielding a yellow color. An hour after the n-butyllithium was complete 1-indanone $(3.1390 \mathrm{~g}, 23.75$ mmoles in $25 \mathrm{mLs}$ dry THF) was added dropwise. The reaction was allowed to warm to room temperature and run overnight. Ice $(10 \mathrm{~g})$ was added to the round bottom flask the next day. Diethyl ether was added and crude reaction mixture was extracted with saturated $\mathrm{NaCl}$ solution. The organic phase was dried over $\mathrm{MgSO}_{4}$. The crude dried reaction mixture was transferred to a $100 \mathrm{ml}$ round bottom flask, and the solvent was removed on a rotovap. $25 \mathrm{mLs}$ of hexane$\mathrm{CH}_{2} \mathrm{Cl}_{2}(9: 1)$ mixture were added to the residue and stirred for one minute. The reaction mixture was purified by column chromatography using $1 \times 5$ inch silica (60-100 mesh) in hexane- $\mathrm{CH}_{2} \mathrm{Cl}_{2}(9: 1)$ mixture. The eluant was collected in small fractions and the process was monitored by TLC. $1.4704 \mathrm{~g}$ of $93 \%$ pure methyleneindan were obtained. Characterization was made by ${ }^{1} \mathrm{H},{ }^{13} \mathrm{C} N M R$ and GC-MS. 


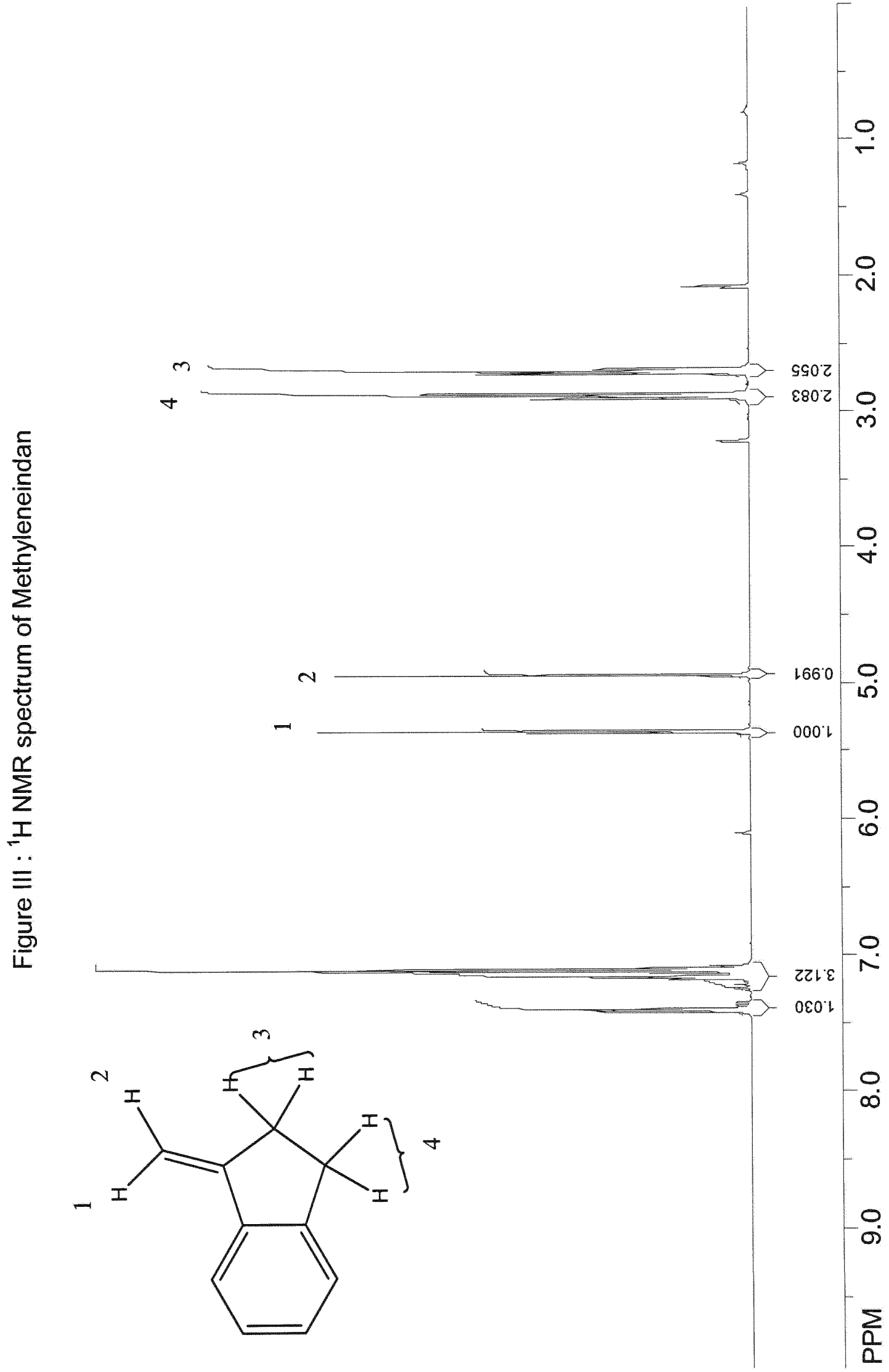



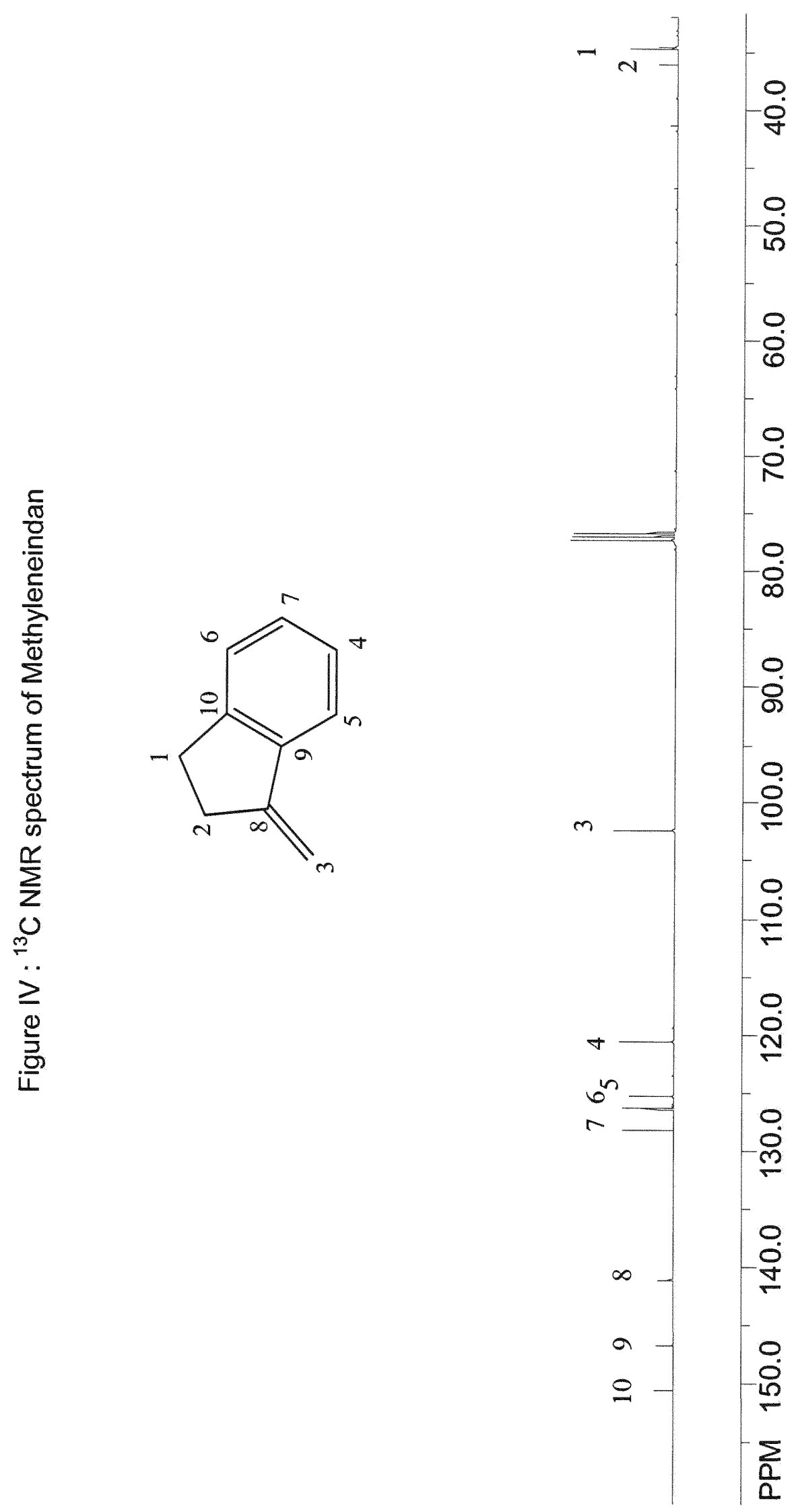


\subsection{Synthesis and Characterization of Fluorenene via Wittig Reaction}

Fluorenene was prepared from fluorenone and methyltriphenylphosphonium bromide via Wittig reaction. The yield was $80 \%$ of pure product.

Scheme: $\quad$ Synthesis of Fluorenene
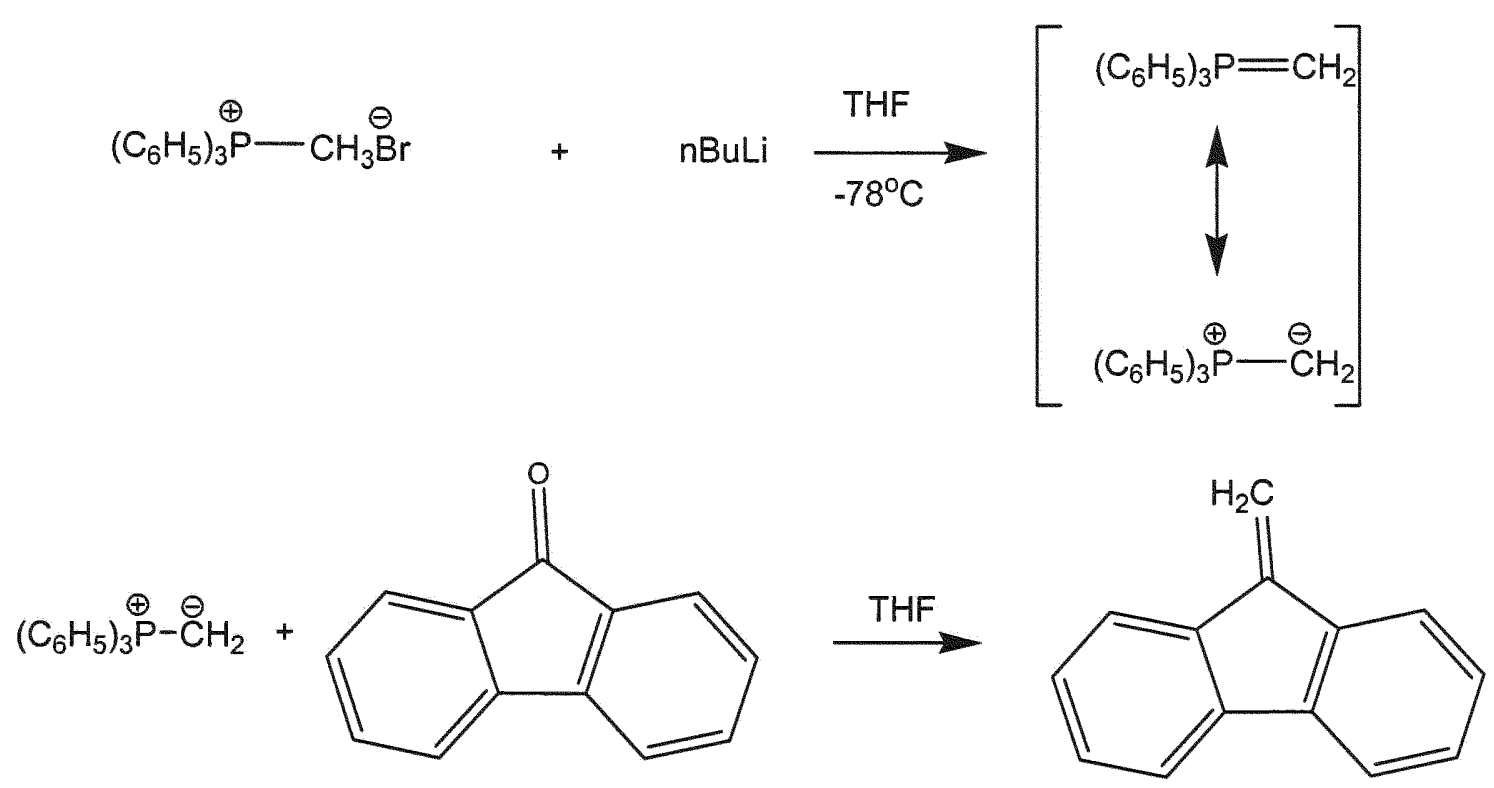

\section{Experimental:}

Methyltriphenylphophonium bromide $(5.95 \mathrm{~g}, 16.67 \mathrm{mmoles})$ were weighed into a $100 \mathrm{ml}$ 3-neck round bottom flask. A stirring bar and $50 \mathrm{ml}$ of freshly distilled THF dried over Na was added. An addition funnel was placed on the center neck. The remaining openings were sealed with seta/stoppers. The reaction was purged with argon. A dry ice/acetone bath $\left(-78^{\circ} \mathrm{C}\right)$ was used to cool the reaction solution. $\mathrm{n}$-butyllithium in pentane $(8.335 \mathrm{ml}$ of $2.5 \mathrm{M})$ were added dropwise to the stirring mixture. Fluorenone ( $3.0 \mathrm{~g}, 16.67 \mathrm{mmoles})$ were dissolved in dry THF. The 
dissolved 1-indanone was added dropwise. The reaction was left stirring with argon purging overnight.

Next day, ice $(10 \mathrm{~g})$ was added and resulting mixture was transferred to a separatory funnel. Diethyl ether was added and reaction solution was extracted with saturated $\mathrm{NaCl}$ solution. The organic phase was separated from the mixture and dried over $\mathrm{MgSO}_{4}$. The organic layer was transferred to a $100 \mathrm{ml}$ round bottom flask, and the solvent was removed on a rotovap. The product was purified by column chromatography. The column ( 1 X 2 inch, $60-100$ mesh silica) was filled with hexane. The crude fluorenene was dissolved in $2 \mathrm{mLs}$ hexane$\mathrm{CH}_{2} \mathrm{Cl}_{2}$ (9:1) mixture, and added to the column. The eluant was collected in small fractions and the process was monitored by TLC. $0.4704 \mathrm{~g}$ of $73 \%$ pure fluorenene were obtained. Characterization was made by ${ }^{1} \mathrm{H},{ }^{13} \mathrm{C}$ NMR and GCMS. 


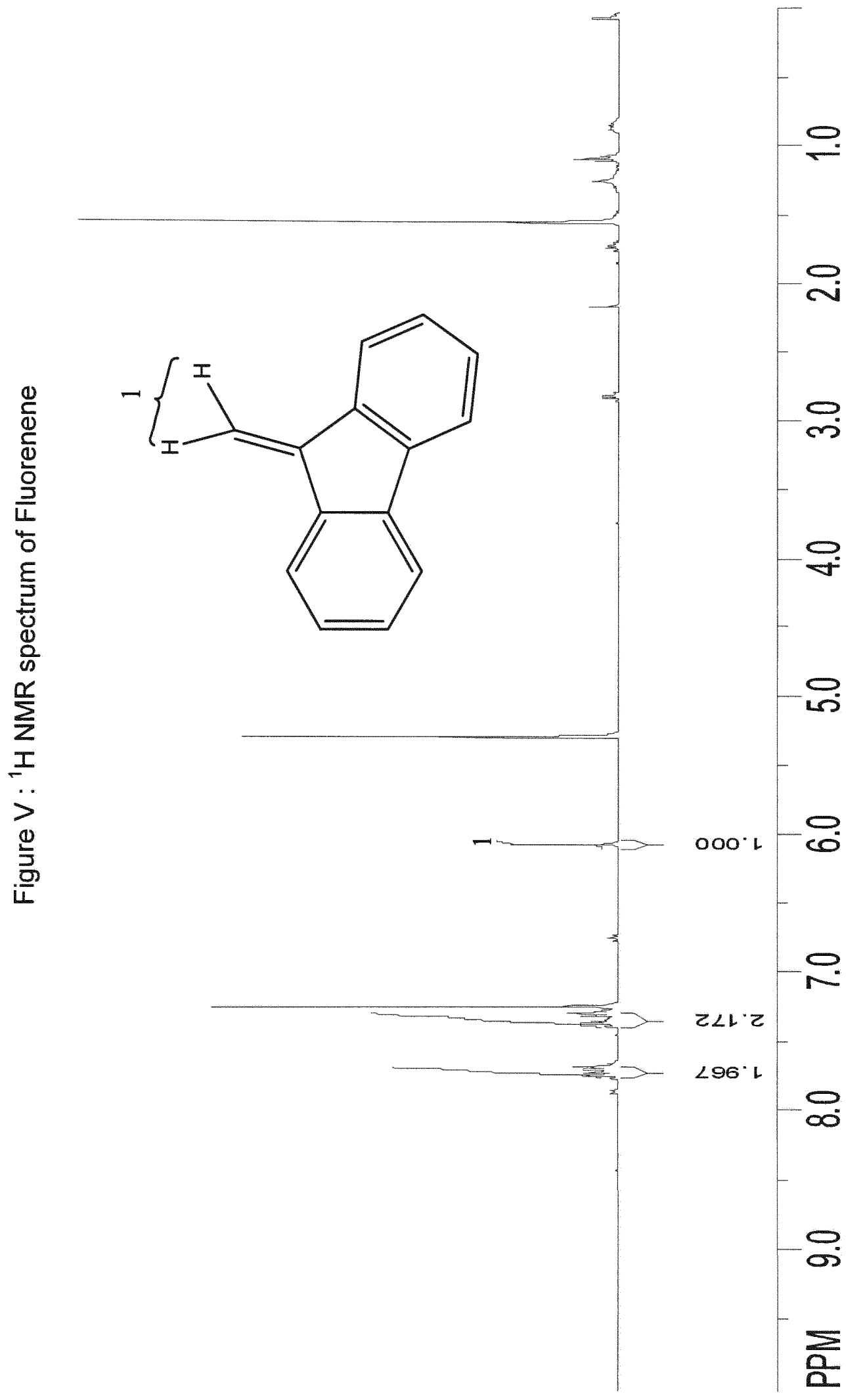



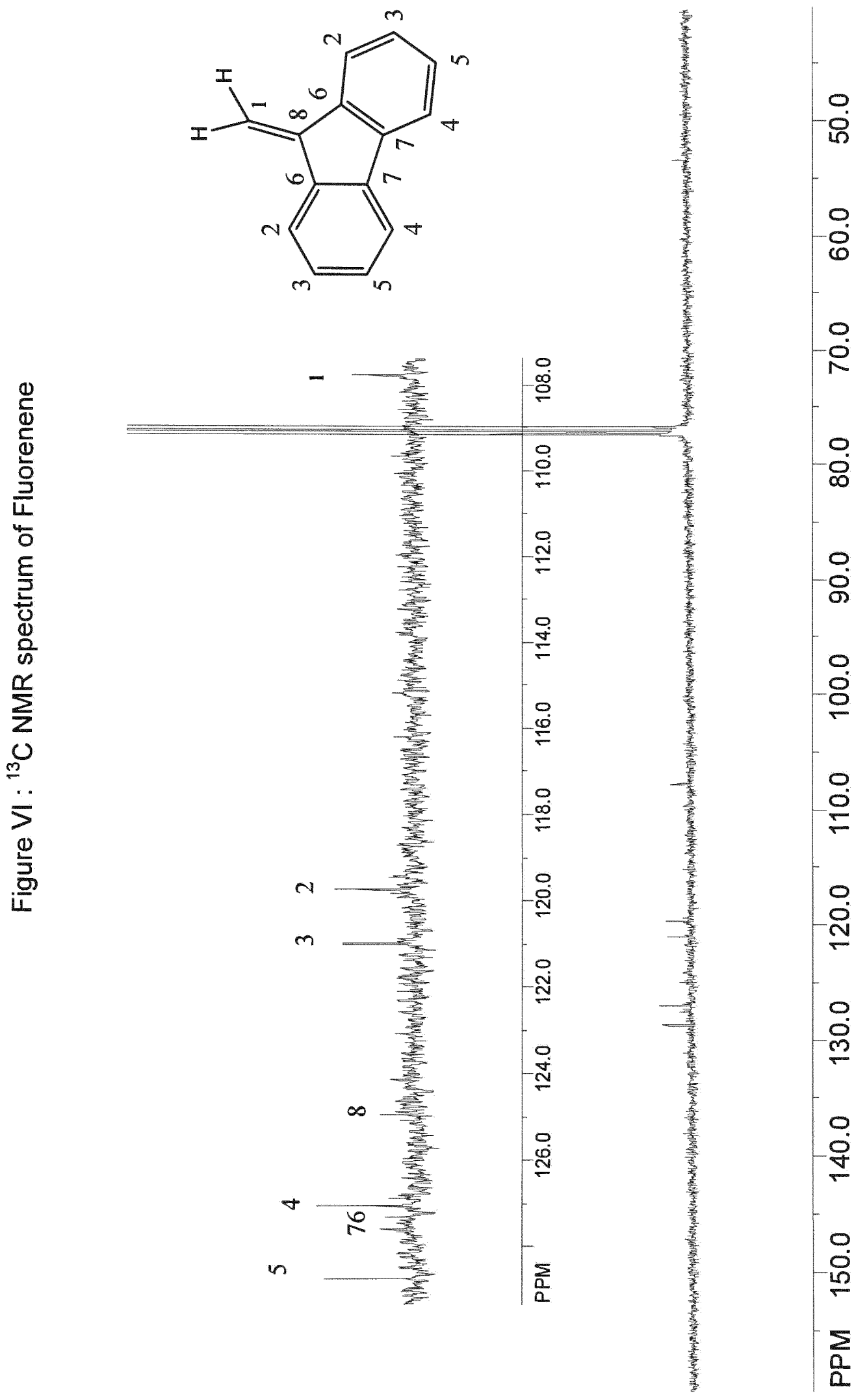


\subsection{Characterization of E,E -1,4-Diphenyl-1,3-butadiene}

E,E-1,4-Diphenyl-1,3-butadiene was commercially available. It was purchased from Sigma-Aldrich and characterized by ${ }^{1} \mathrm{H}$ and ${ }^{13} \mathrm{C}-\mathrm{NMR}$ (Bruker-400 $\mathrm{MHz}$ NMR).

${ }^{1} \mathrm{H} \mathrm{NMR}\left(400 \mathrm{MHz}, \mathrm{CDCl}_{3}\right) \delta(\mathrm{ppm}): 6.7$ (d of d, 2H), 7.0 (d of d, 2H) 7.20-7.50 $(\mathrm{m}, 10 \mathrm{H})$;

${ }^{13} \mathrm{C}$ NMR (ppm) : 126.5 (s), 127.5 (s), 128 (s), 129 (s), 133 (s), 137.5 (s).

2.5 Synthesis and Characterization of E, Z-1,4-Diphenyl-1,3-butadiene

E,Z-1,4-Diphenyl-1,3- butadiene was prepared from E,E-1,4-Diphenyl-1,3butadiene via photoisomerization reaction ${ }^{4,7}$. The yield was $75 \%$. Scheme :
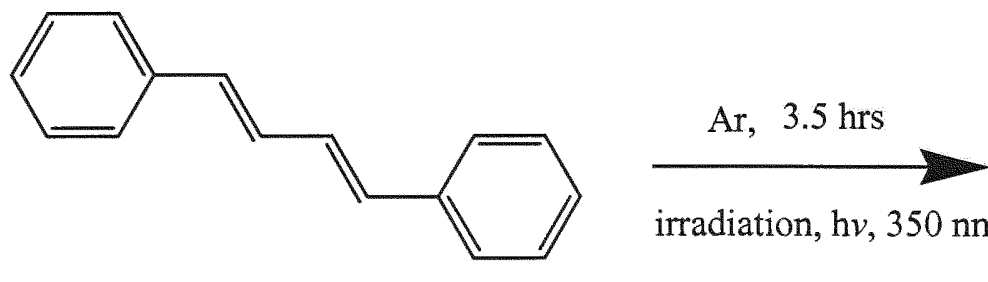

irradiation, $\mathrm{h} v, 350 \mathrm{~nm}$

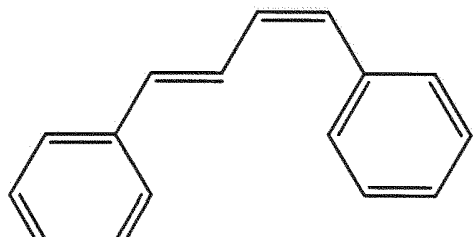



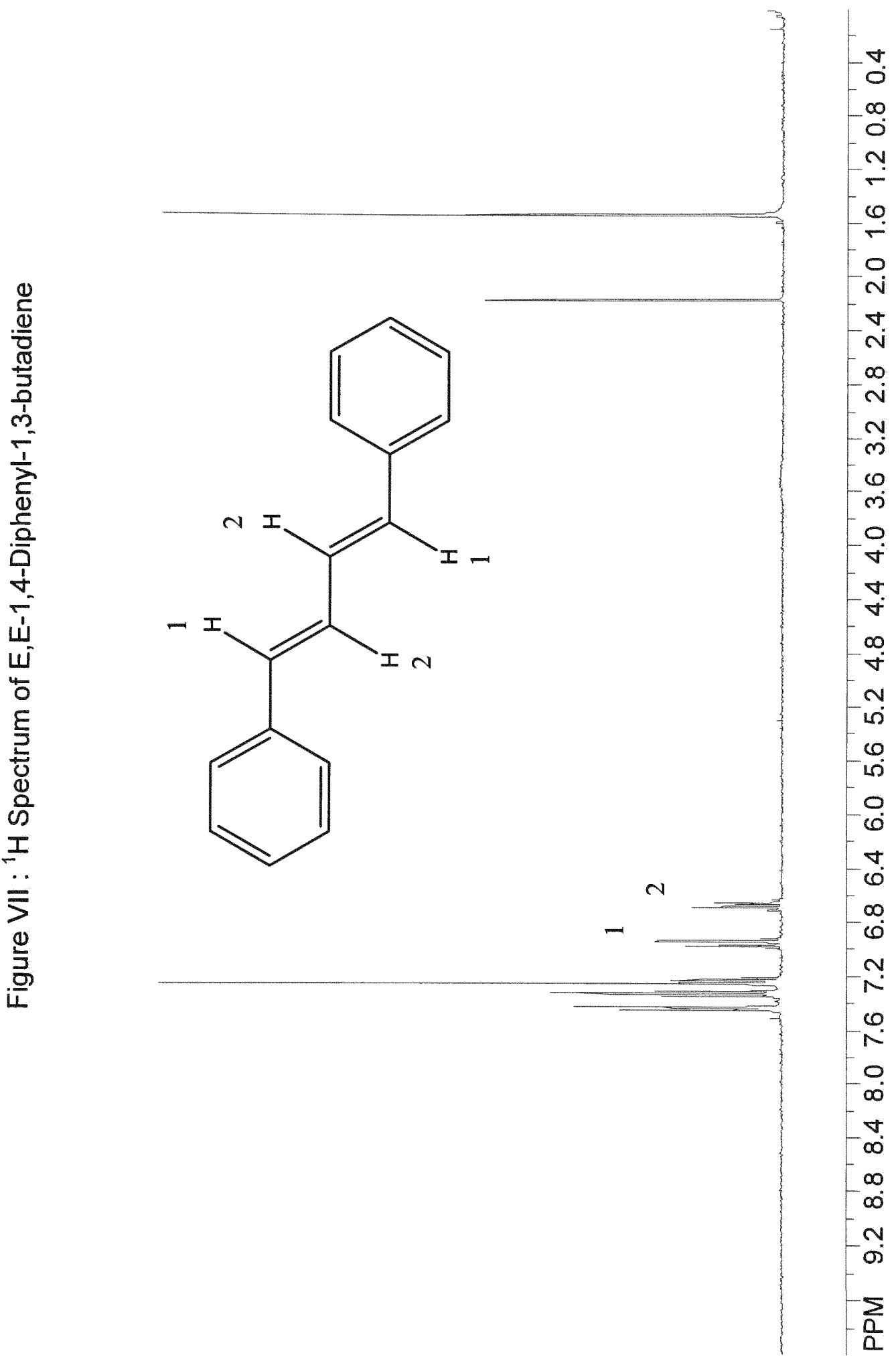

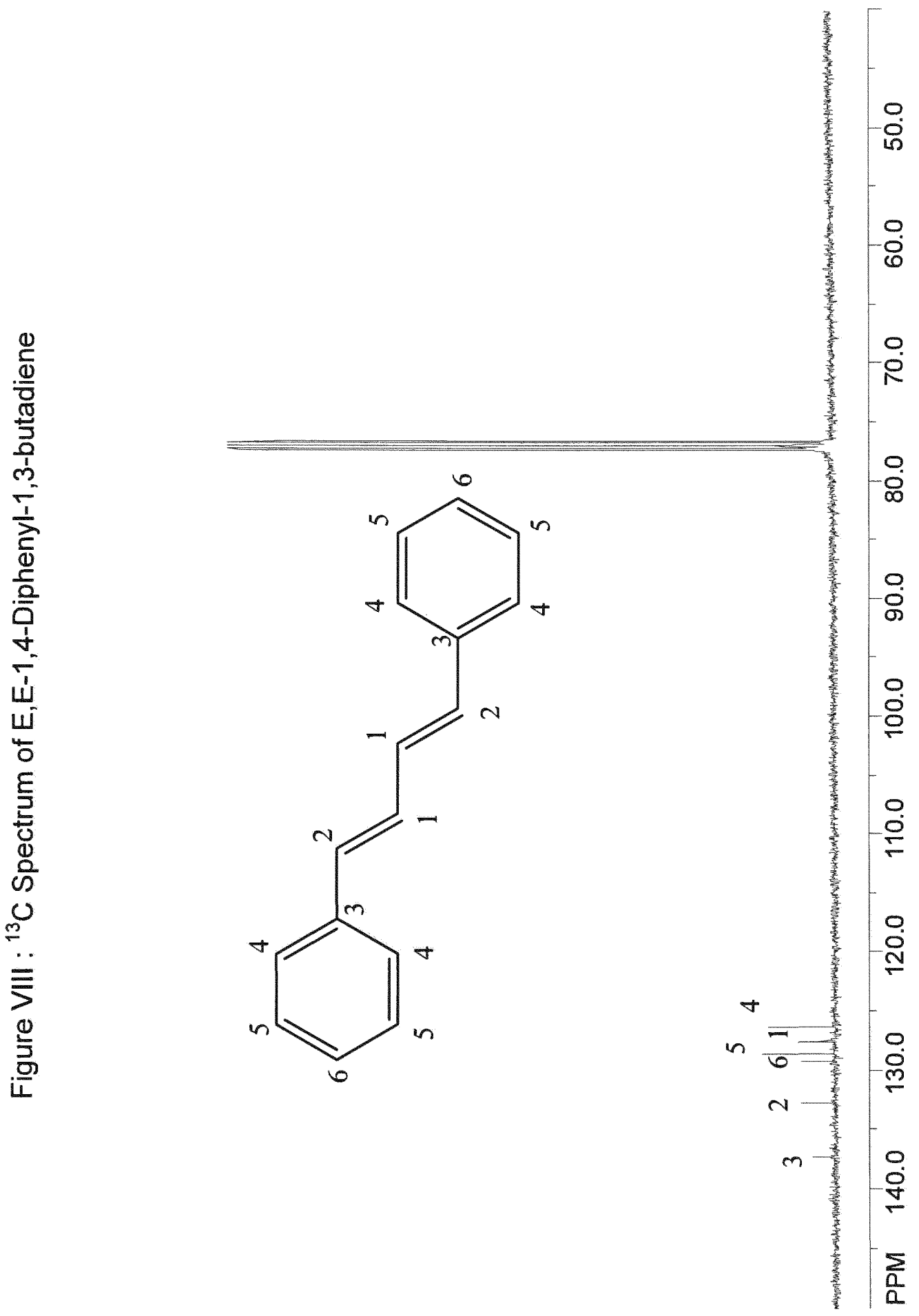
Figure IX : GC-MS spectrum of E,E-1,4-Diphenyl-1,3-butadiene

TIC: 14236.0

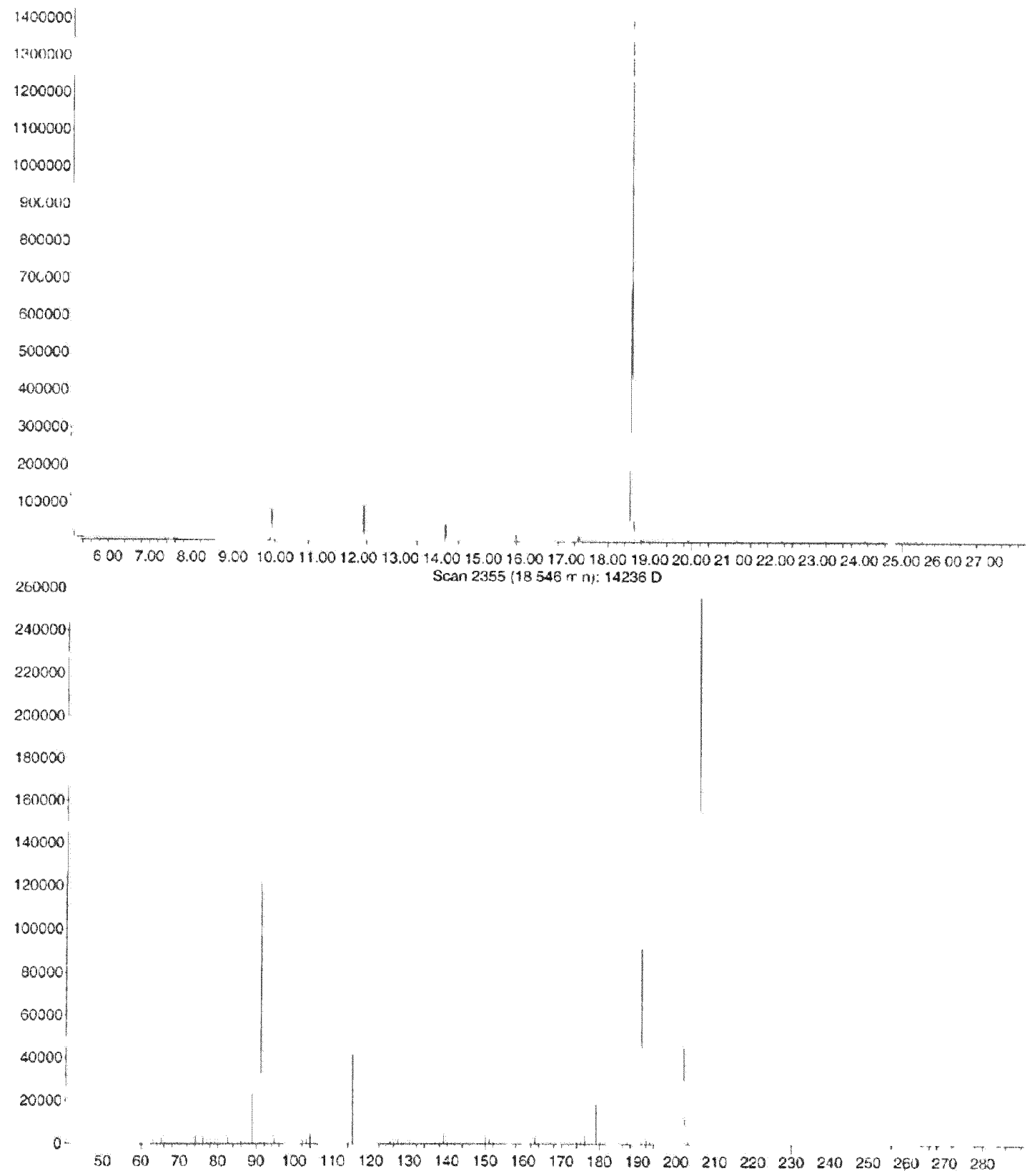




\section{Experimental:}

E,E-1,4-diphenyl-1,3-butadiene ( $0.2 \mathrm{gm}, 0.97$ mmoles) was transferred in a 100 $\mathrm{ml}$ pyrex tube along with $100 \mathrm{~mL}$ hexane. The solution was irradiated for 3.5 hours in Ar atmosphere using Rayonet reactor equipped with phosphor coated bulbs $(350 \mathrm{~nm})$. The resulting solution was transferred into a round bottom flask, rotovapped, and the crude product $(0.1 \mathrm{gm})$ was purified by column chromatography. 1X4 inch, 240-400 mesh silica column was run. The column was filled with hexane and eluant collected in small test tubes. The column was monitored by TLC. Pure E,Z-1,4-diphenyl-1,3-butadiene ( $0.05 \mathrm{gm}, 0.2427$ mmoles) was obtained. This was characterized by ${ }^{1} \mathrm{H}$ and, ${ }^{13} \mathrm{C}$ NMR (Bruker 400 $\mathrm{MHz}, \mathrm{CDCl}_{3}$ ) and GC-MS (Hewlett Packard 6890, 5973 Mass selective detector, DB-5 capillary column (MS), $0.25 \mathrm{~mm}, 30 \mathrm{~m}$ length).

${ }^{1} \mathrm{H}$ NMR $\left(400 \mathrm{MHz}, \mathrm{CDCl}_{3}\right) \delta(\mathrm{ppm}): 6.34(\mathrm{dd}, 1 \mathrm{H}), 6.44(\mathrm{~d}, 1 \mathrm{H}), 6.63(\mathrm{~d}, 1 \mathrm{H})$, 7.11-7.34 (m, 11H);

${ }^{13} \mathrm{C}$ NMR (ppm): 125 (s), 126 (s), 127 (s), 128 (s), 128.5(s), 129 (s), 131 (s), 132 $(\mathrm{s}), 135(\mathrm{~s})$

MS m/z 206(M), 77 (M-129). 


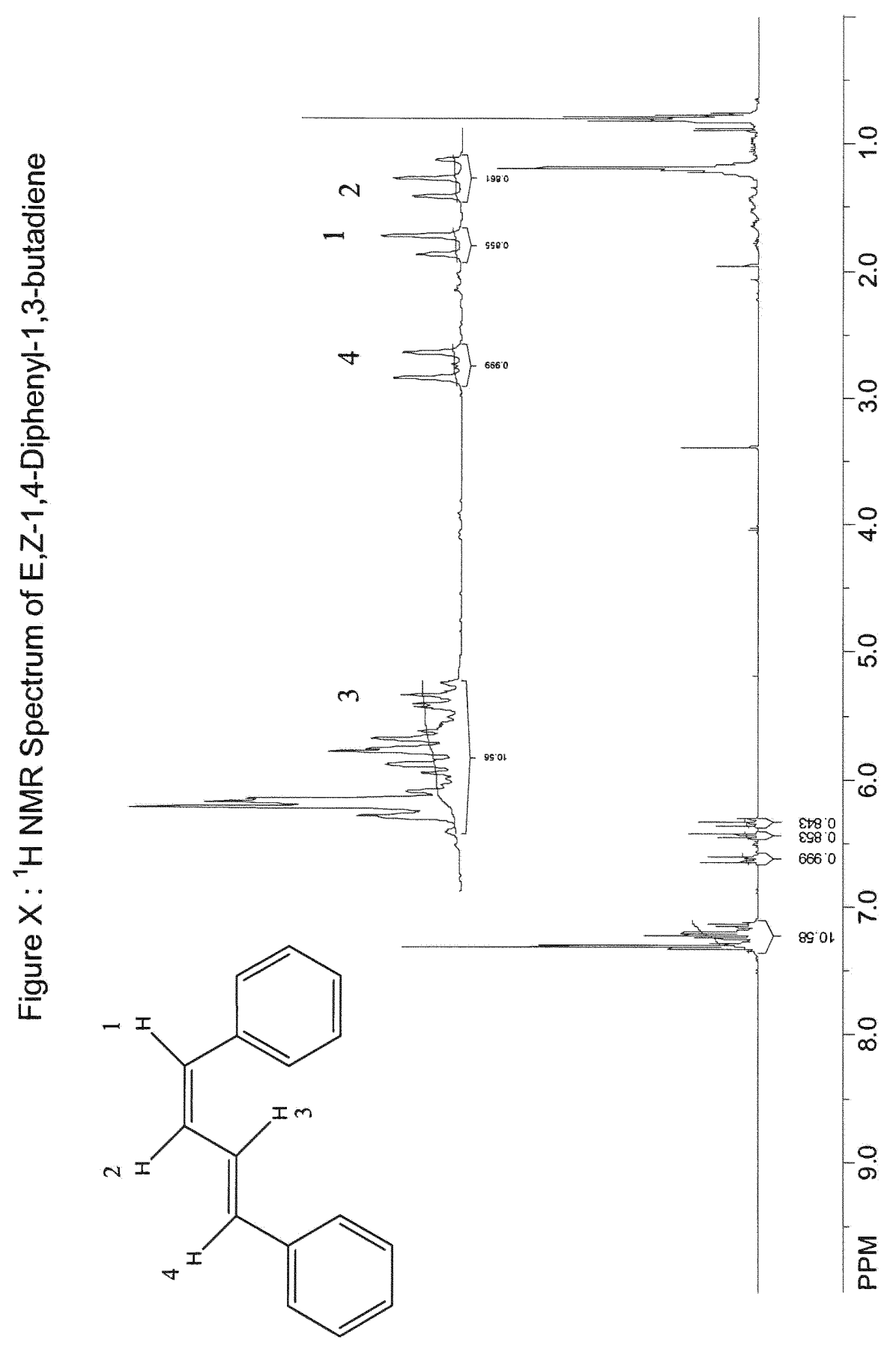

$\stackrel{\infty}{N}$ 

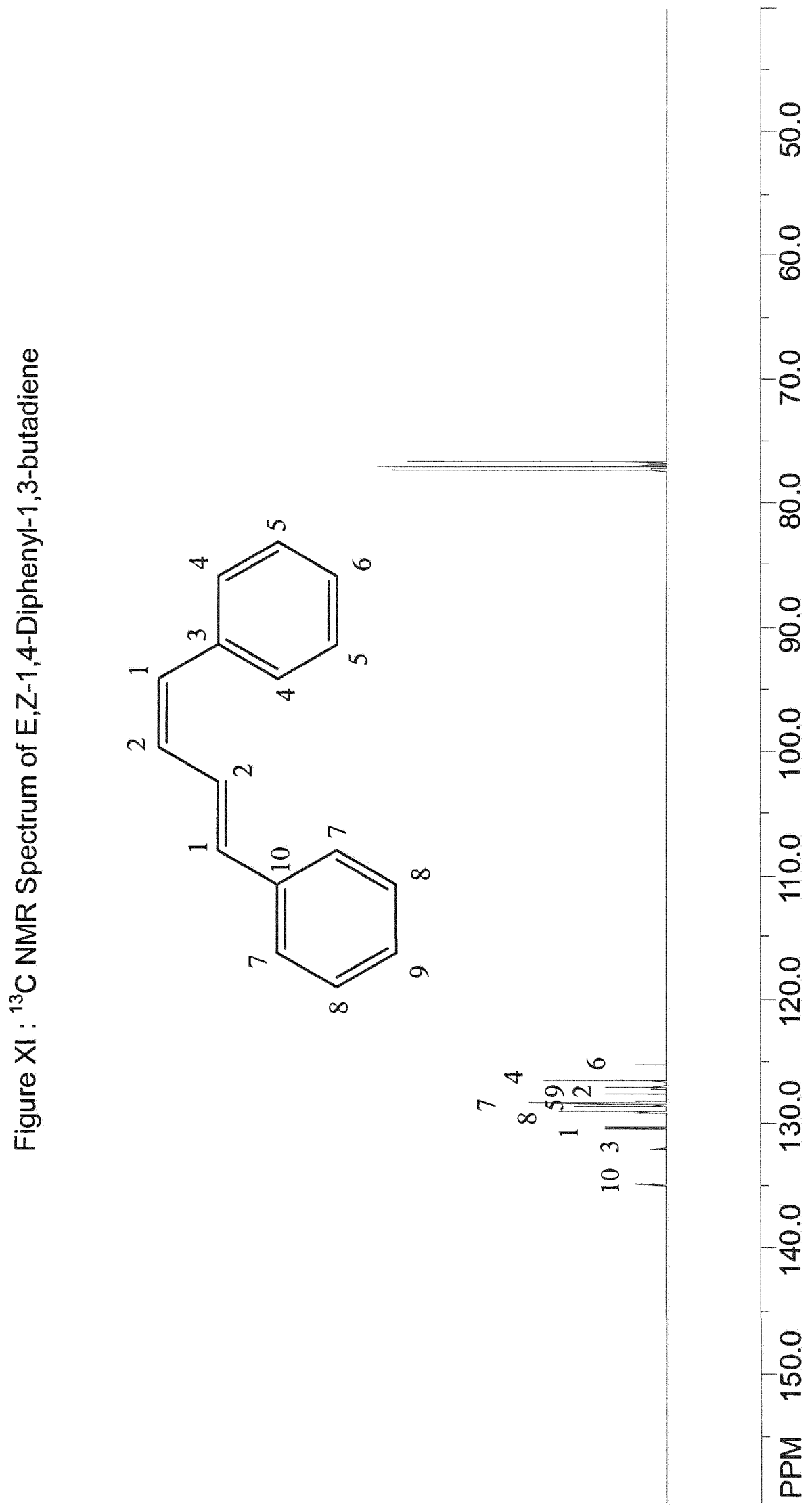
Figure XII : GC-MS spectrum of E,Z-1,4-Diphenyl-1,3-Butadiene

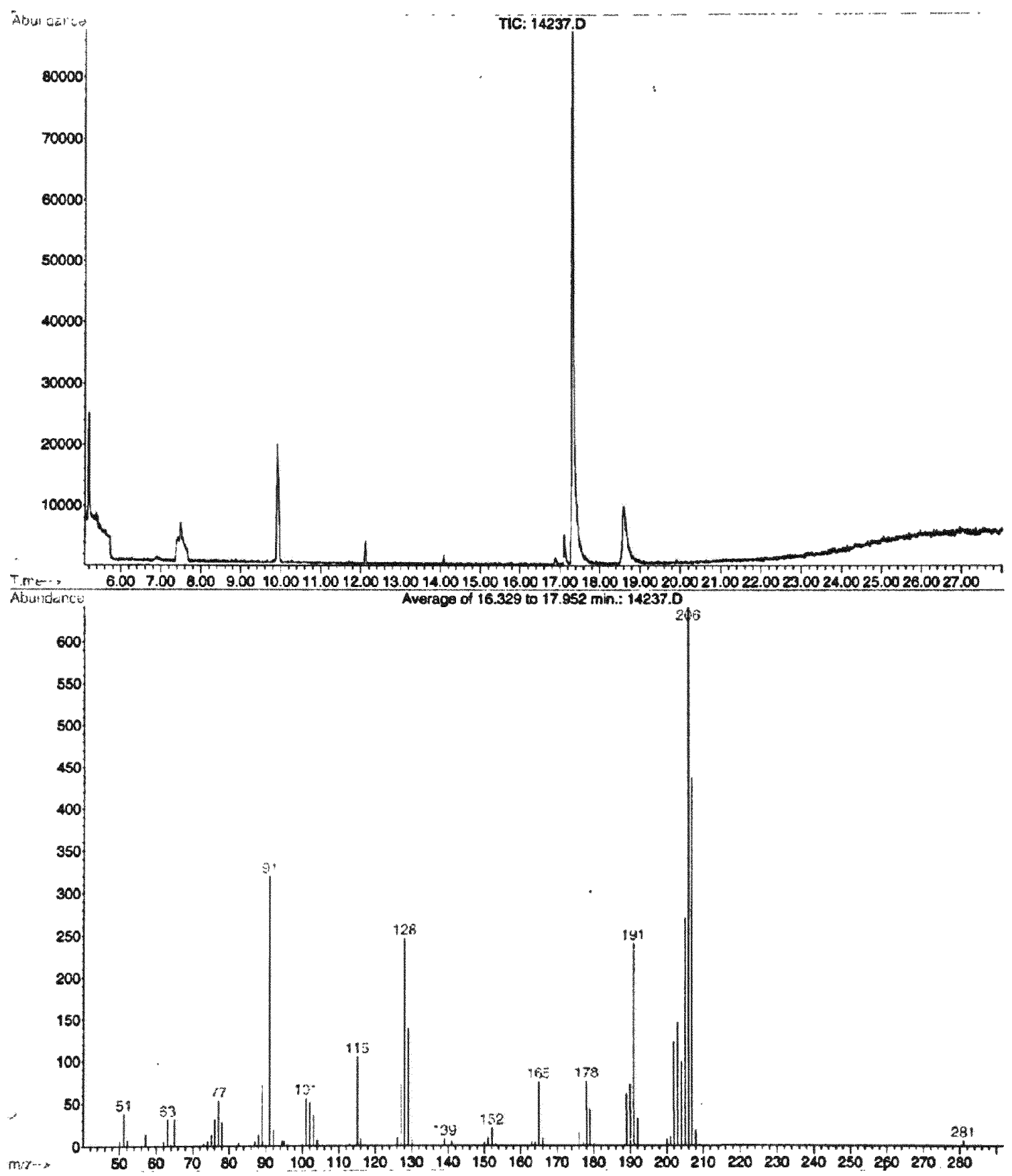




\subsection{Synthesis and Characterization of Z, Z-1,4-Diphenyl-1,3-butadiene}

Various attempts were made to prepare Z,Z-1,4-diphenyl-1,3- butadiene. To a solution of 1,4-butadiyne, Lindlars catalyst and pyridine were added and reaction mixture was stirred for 24 hrs in $\mathrm{H}_{2}$ atmosphere. Reaction was run for $12 \mathrm{hrs}, 8$ hrs, $4 \mathrm{hrs}$, and $2 \mathrm{hrs}$ and we had used $\mathrm{H}_{2}$ balloon and a Parr shaker. Major problem was low yields because of over hydrogenation. Finally, Z,Z-1,4-diphenyl1,3- butadiene was prepared from 1,4-diphenylbutadiyne by hydrogenation over Lindlar Pd for 30 mins. The catalyst must be filtered off immediately to avoid over hydrogenation. The yield was $80 \%$ of the pure product.

\section{Scheme:}
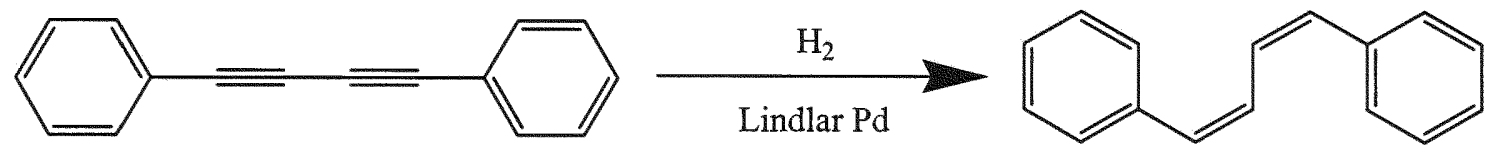

\section{Experimental:}

1,4-Diphenylbutadiyne ( $0.2 \mathrm{~g}, 0.99$ mmoles), Lindlar catalyst $(0.1 \mathrm{~g})$ were added to $150 \mathrm{mLs}$ of hexane in $500 \mathrm{ml}$ Parr bottle. The reaction mixture was stirred for $1 / 2$ hr. under $\mathrm{H}_{2}$ atmosphere. $\mathrm{H}_{2}$ gas (350 mLs) was flushed through the reaction mixture initially. After 30 mins of reaction at room temperature the reaction mixture was immediately vacuum filtered to remove the Lindlar's catalysts. 100 $\mathrm{mLs}$ distilled water was added and the mixture was transferred into a $250 \mathrm{mLs}$ 
separatory funnel. The solution was extracted with $50 \mathrm{mLs}$ of saturated $\mathrm{NaCl}$

solution. Then organic layer was dried over $\mathrm{MgSO}_{4}$ for 5-7 mins; filtered through

Buchner funnel (vacuum filtration), and the solvent was removed by high

pressure vacuum pump.

Z,Z-1,4-Diphenyl-1,3-butadiene was characterized by ${ }^{1} \mathrm{H}$ NMR and GC-MS.

${ }^{1} \mathrm{H} \mathrm{NMR}\left(400 \mathrm{MHz}, \mathrm{CDCl}_{3}\right.$ ) $\delta(\mathrm{ppm}): 6.65$ (d of d, $2 \mathrm{H}$ ), 6.5 (d of d, $2 \mathrm{H}$ ) 7.20-7.50 $(\mathrm{m}, 10 \mathrm{H})$;

${ }^{13} \mathrm{C}$ NMR (ppm) : 126.5 (s), 127.5 (s), 128 (s), 129 (s), 133 (s), 137.5 (s).

MS m/z 206(M) 


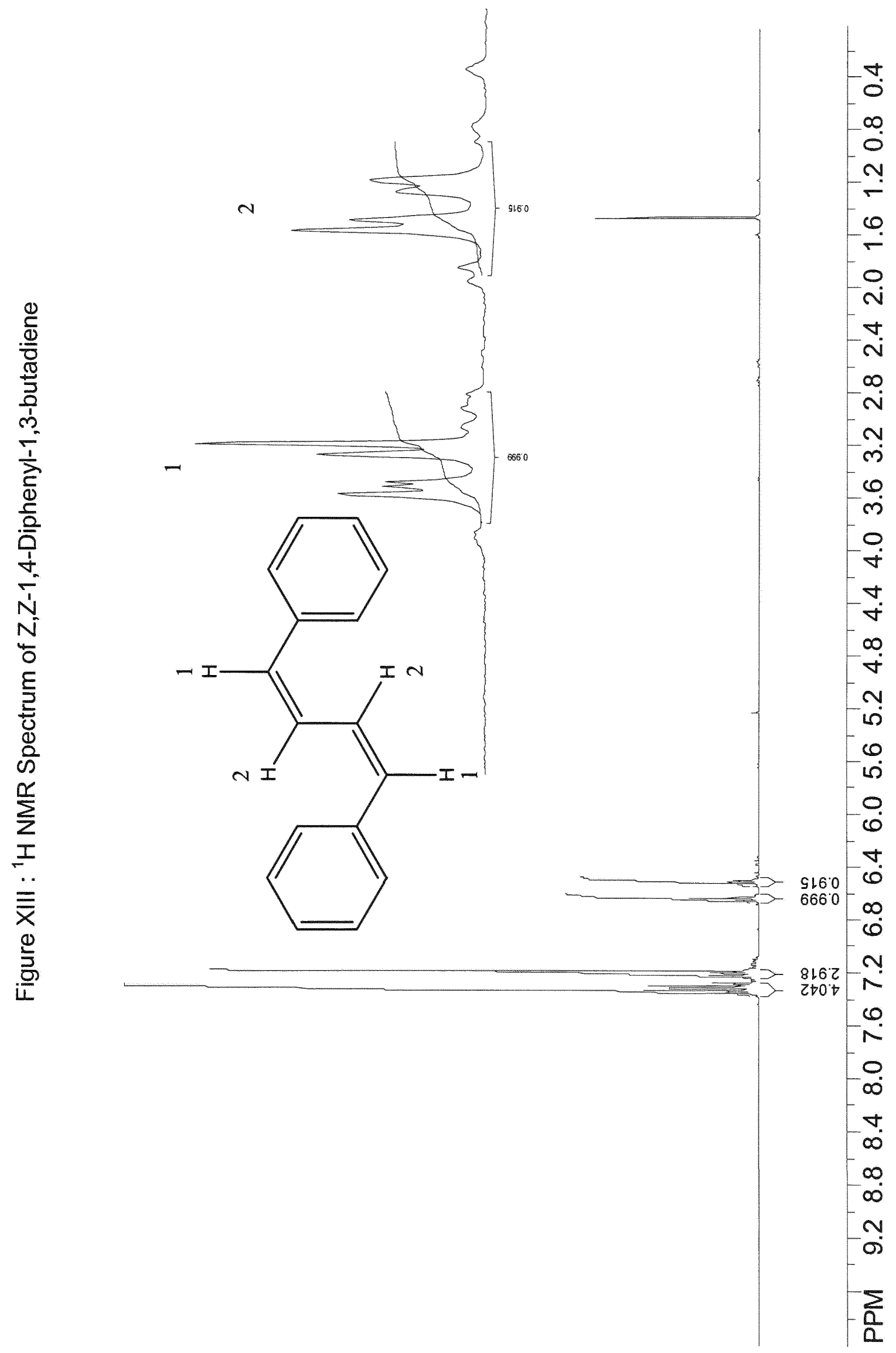



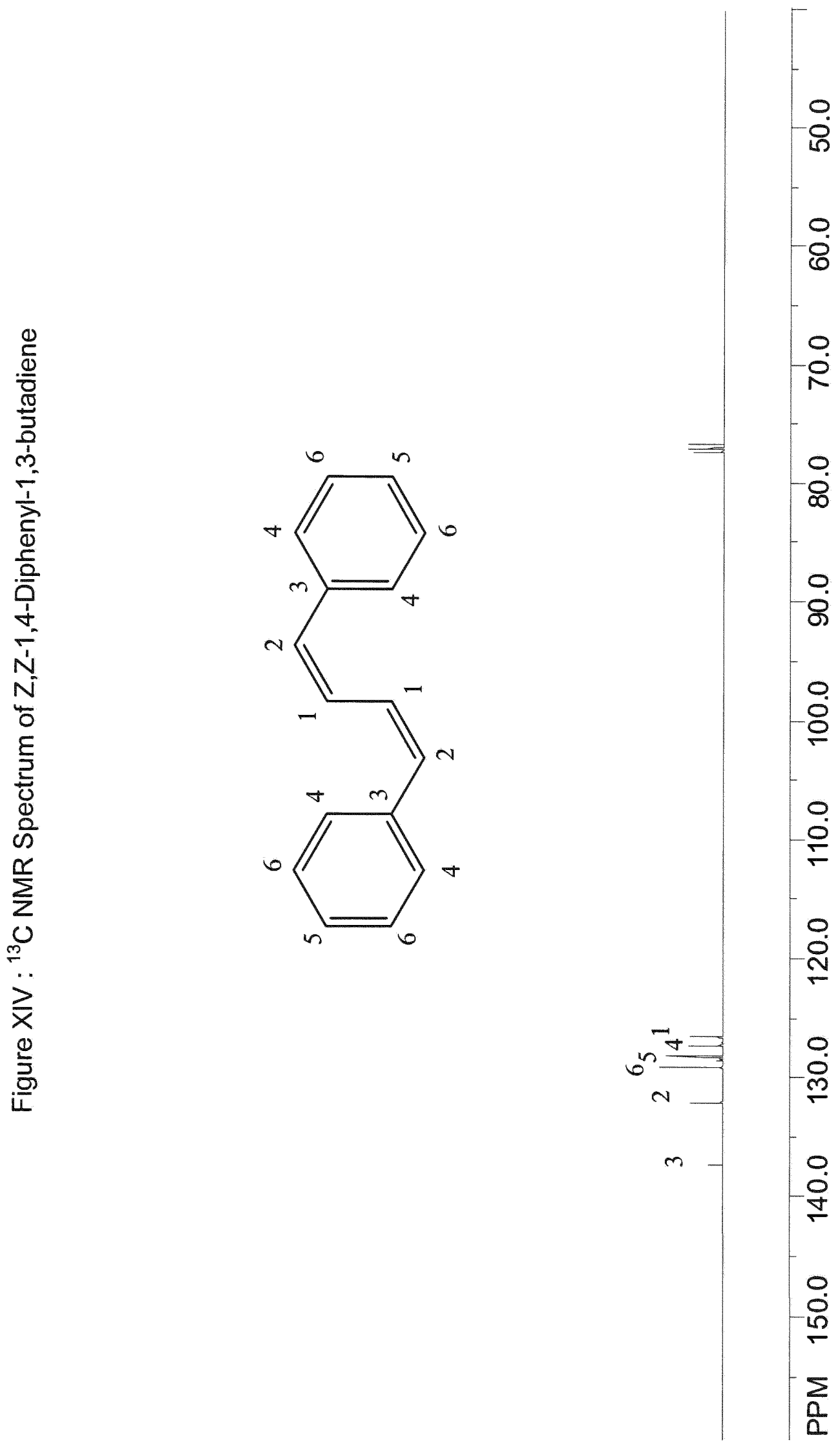


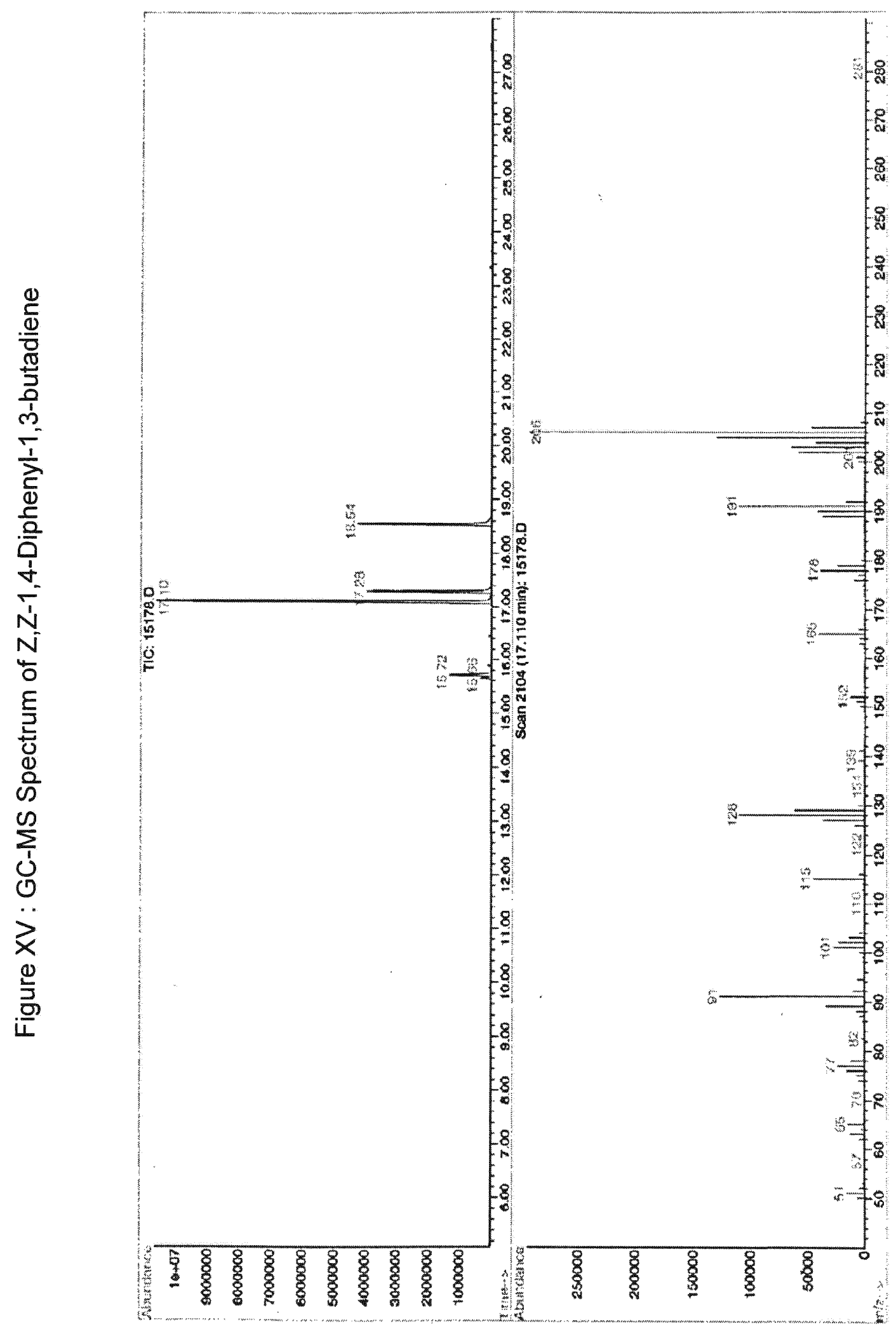


3.1 Singlet Oxygen reactions with 1,1-Disubstituted-ethylenes and

\section{1,4-Diphenyl-1,3-butadienes}

\subsubsection{The Reaction of 1,1-Diphenyl-ethylene with Singlet Oxygen}

1,1-Diphenylethylene was chosen as a probe to study the reaction mechanism of the electrophiles, ${ }^{1} \mathrm{O}_{2}$ and MTAD with olefins. Since phenyl groups have electron-donating abilities, phenyl substituted ethylenes are expected to be electron rich and be reactive toward electrophiles. Phenyl groups also stabilize positive charge through induction and the presence of a phenyl group are projected to stabilize a zwitterionic intermediate such that direct observation or trapping may be feasible, as shown below .

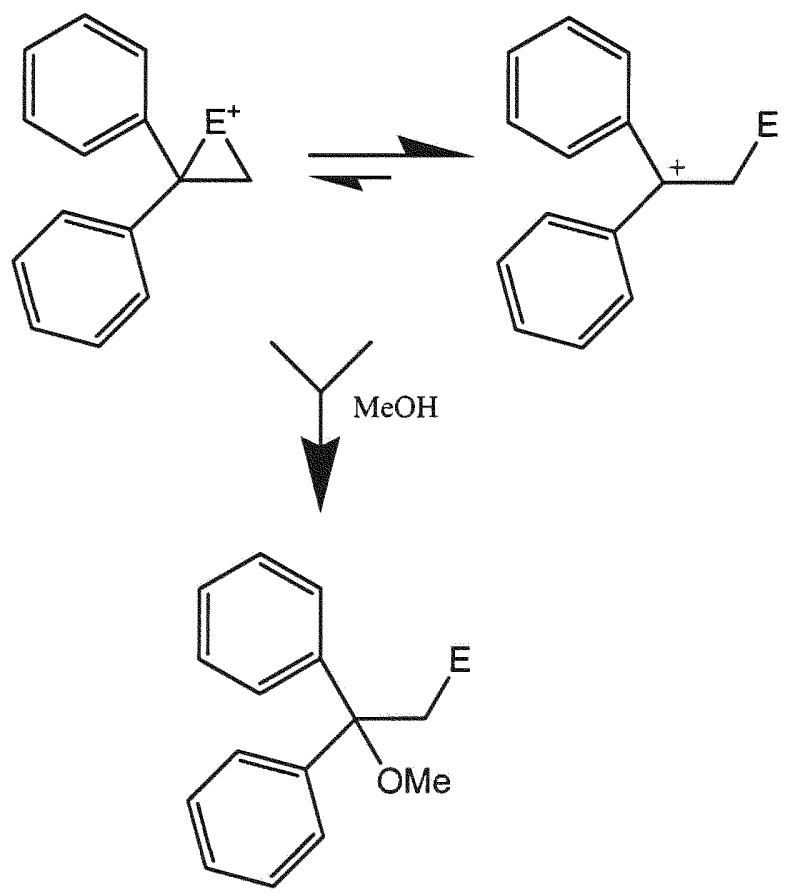




\section{General Photolysis Procedure:}

1,1-Diphenylethylene ( $0.3 \mathrm{~mL}, 0.0016$ mmoles), $0.1 \mathrm{~mL}$ of singlet oxygen photosensitizer solution ( $10^{-4} \mathrm{M}$ Rose Bengal, lamda max $550 \mathrm{~nm}$, in $\mathrm{CDCl}_{3}$ ) and $\sim 0.5 \mathrm{~mL}$ of $\mathrm{CDCl}_{3}$ were placed in a NMR tube. The NMR tube was placed in a windowed Dewar flask maintaining a slow, steady flow of oxygen through the solution and a temperature of $0^{\circ} \mathrm{C}$. A 150 watt Xenon lamp, Oriel model 68806 was used to irradiate the samples. A yellow Pyrex glass was used to eliminate short UV wavelengths (550 $\mathrm{nm}$ ) and to ensure no direct excitation of the olefin. GC-MS spectroscopy and ${ }^{1} \mathrm{H}-\mathrm{NMR}$ were used to monitor the reaction. No detectable changes were observed in the starting materials after $2 \mathrm{hrs}$ of irradiation.

\section{Results:}

We found that photooxidation of 1,1-diphenyl-ethylene in the presence of Rose Bengal, $\mathrm{O}_{2}$ and at $0^{\circ} \mathrm{C}$ yielded no appreciable reactions.

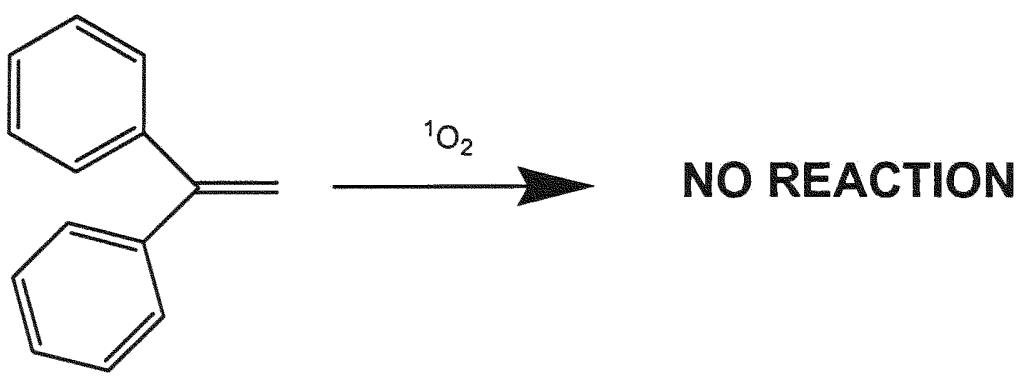


To confirm singlet oxygen formation during the photooxidation, tetramethylethylene (TME) $(10 \mu \mathrm{L})$ was added to the reaction mixture. TME is commonly used as a diagnostic reagent to determine if singlet oxygen is being formed under specific experimental conditions. After one hour of irradiation ${ }^{1} \mathrm{H}$ NMR showed the presence of the characteristic hydroperoxide confirming the generation of ${ }^{1} \mathrm{O}_{2}$ in solution under our reaction conditions.

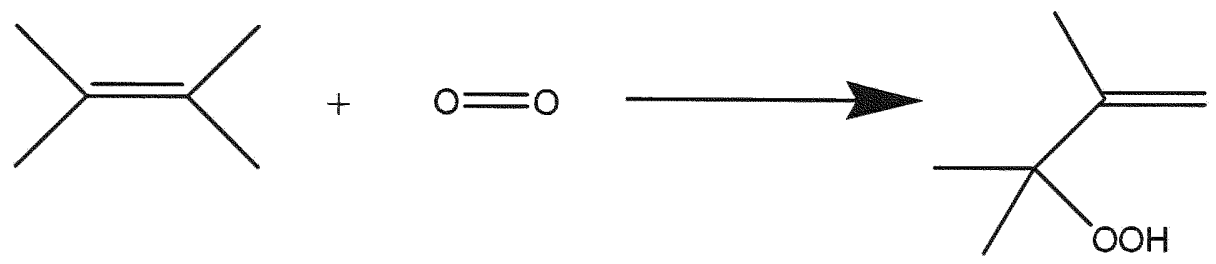

Our results demonstrate the reaction involving ${ }^{1} \mathrm{O}_{2}$ with 1,1-diphenylethylene is negligible under our experimental conditions. 

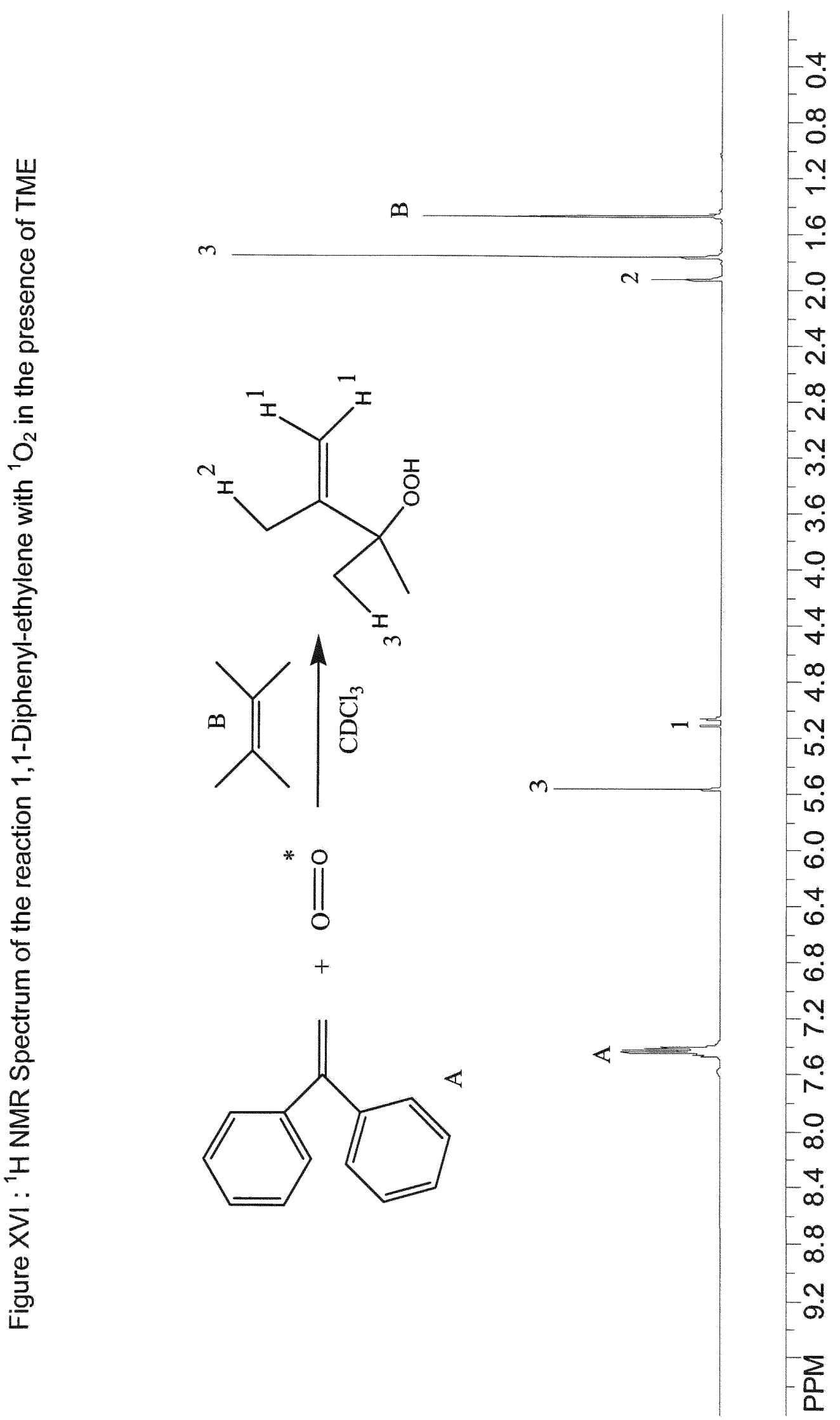


\subsubsection{The Reaction of Methyleneindan with Singlet Oxygen}

We chose to use methyleneindan to further probe the reactivity of ${ }^{1} \mathrm{O}_{2}$ towards phenyl substituted olefins. The photooxidation of methyleneindan may give ' $4+2$ ', '2+2' or 'ene' products as illustrated below.

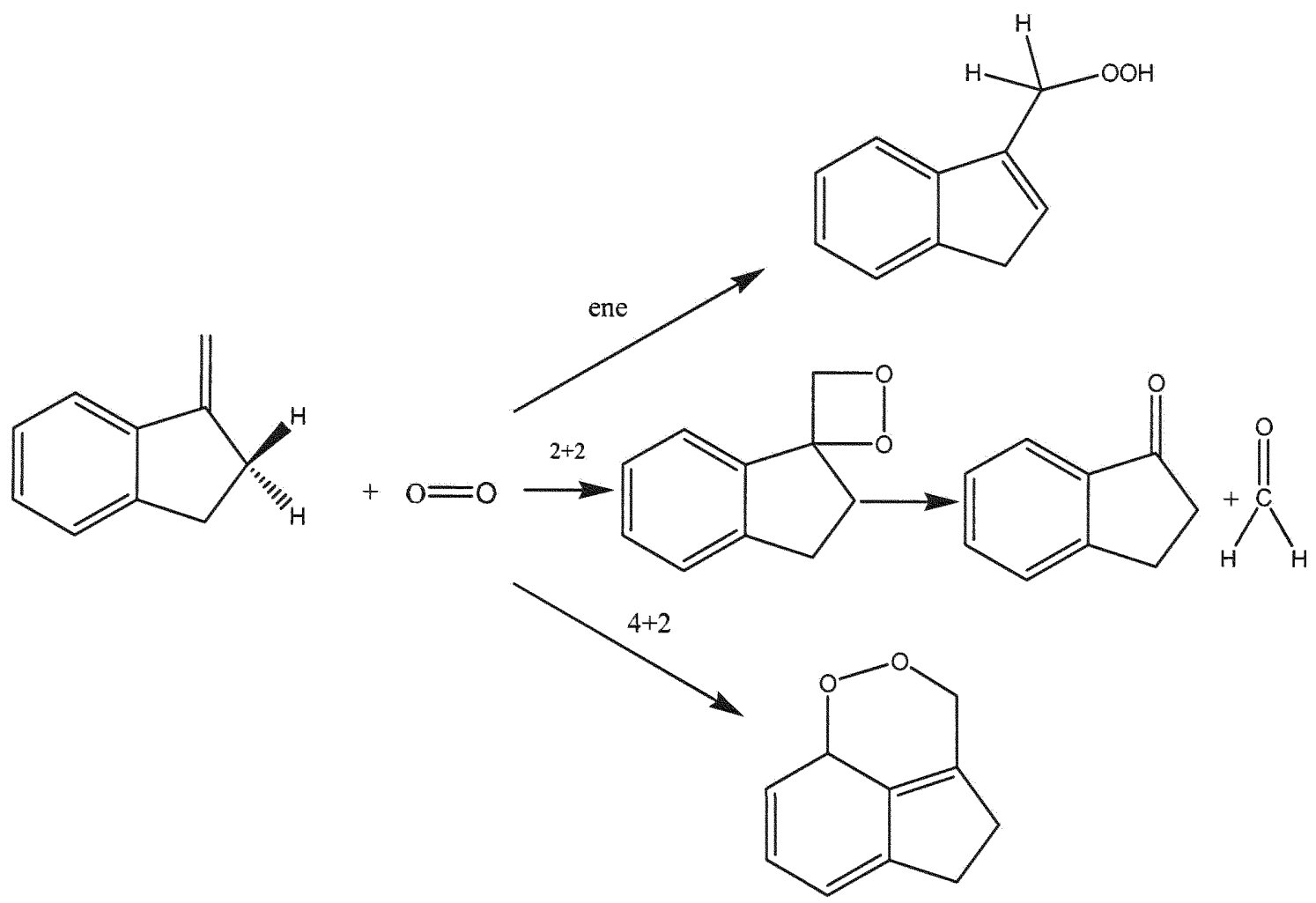

\section{Results:}

The ' $2+2$ ' reaction of 1,1-type alkenes is typically slow. The formation of ' $4+2$ ' requires the loss of aromaticity and may possess significant strain. Our results indicate that methyleneindan reacts with singlet oxygen to give the ene product among a complex mixture of products. While the orientation of at least one of the allylic hydrogens may be favorable for 'ene' reaction, the complex mixture of products did allow us to further characterize the product using ${ }^{13} \mathrm{C}$ and $2 \mathrm{D}$ NMR 
processes. Tentative assignment for the ene product are made for ${ }^{1} \mathrm{H}$ NMR on the following page. 


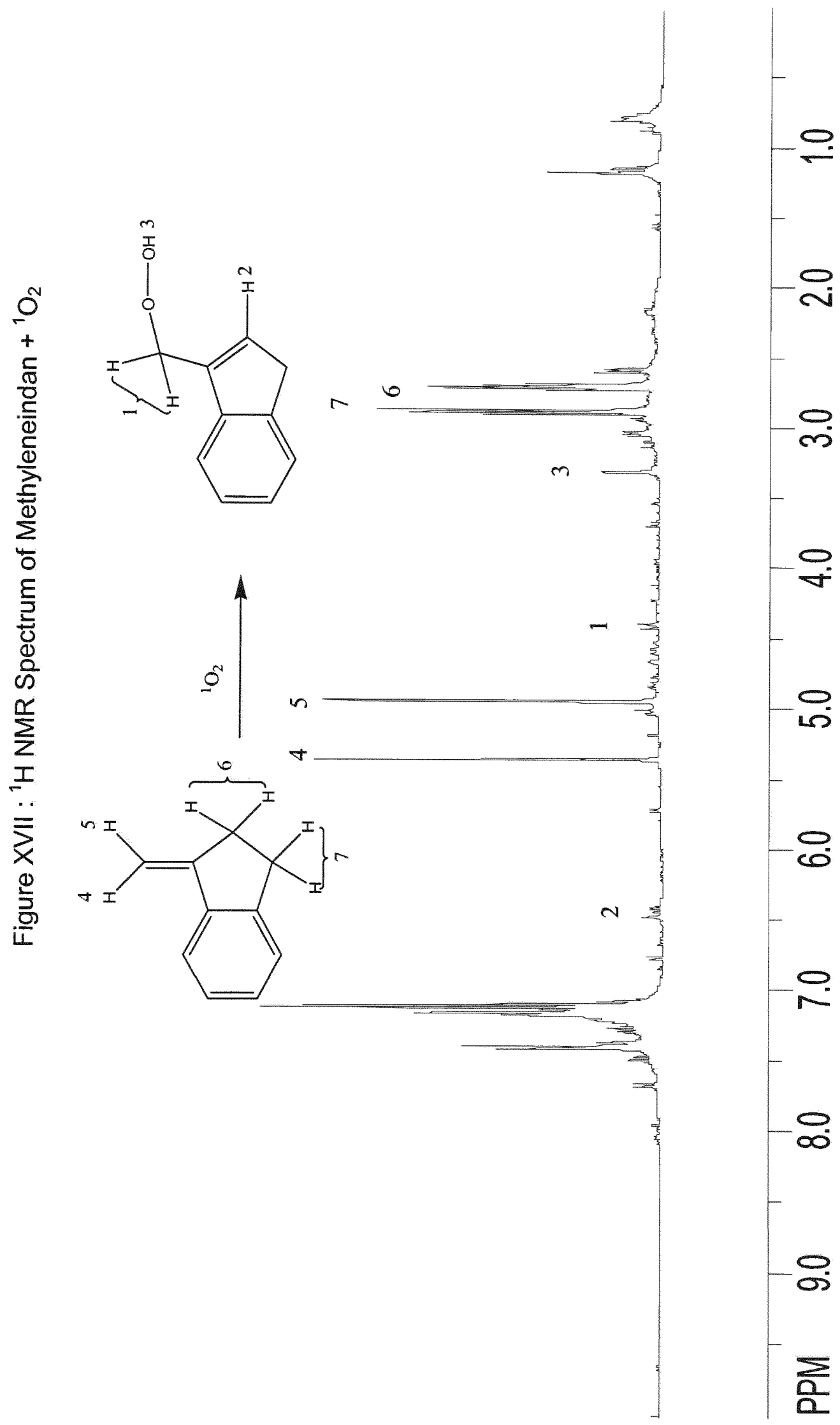




\subsubsection{The Reaction of Fluorenene with Singlet Oxygen}

We chose fluorenene to use to further probe the reactivity of ${ }^{1} \mathrm{O}_{2}$ towards disubstituted olefins. Unlike the previous 1,1-diphenylethylene, fluorenene has a ridged fixed conformation. The photooxidation of fluorenene may yield ' $4+2$ ' and/or, ' $2+2$ ' adducts as illustrated below.
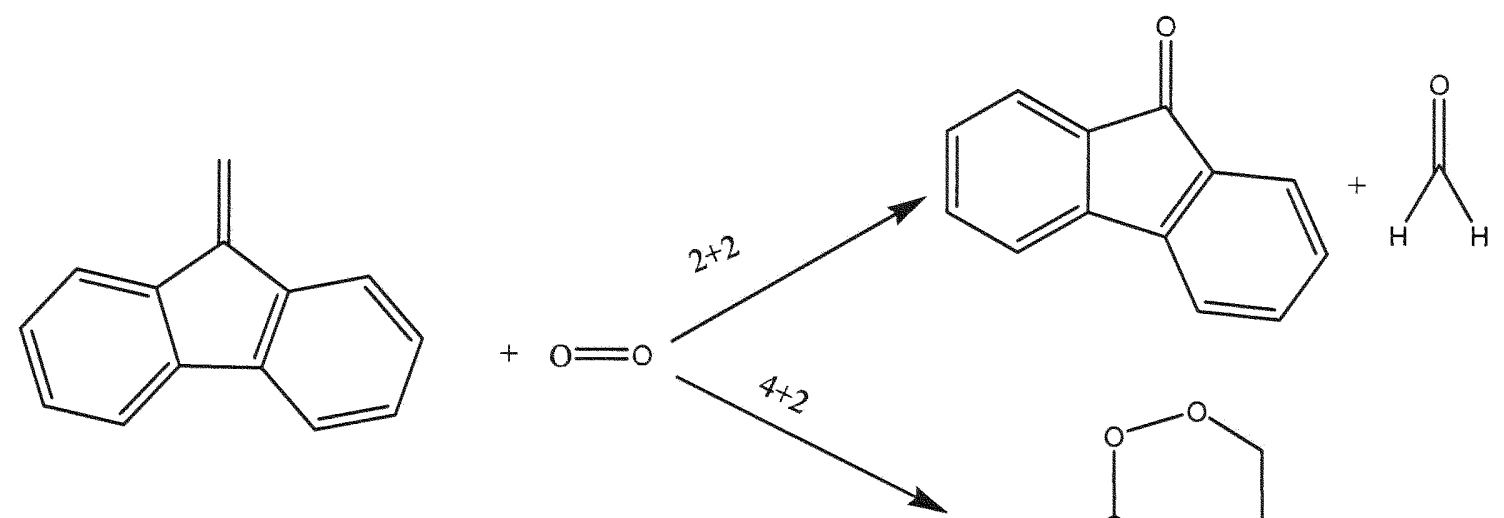

\section{Results:}

Our results indicate that photooxidation of fluorenene in the presence of Rose Bengal, $\mathrm{O}_{2}$ and at $0^{\circ} \mathrm{C}$ is very slow or negligible. The reaction was run for $4 \mathrm{hrs}$ using 150 watt Xenon lamp, Oriel model 68806.
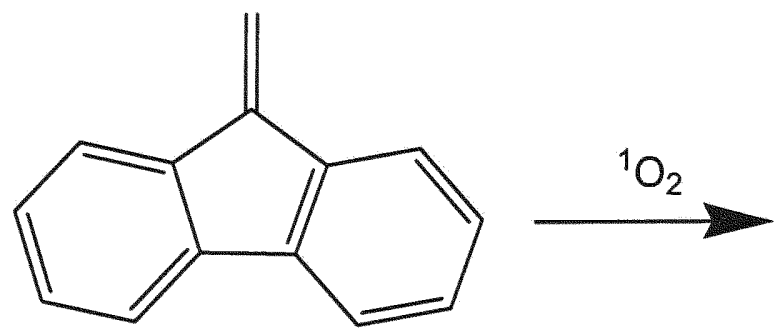


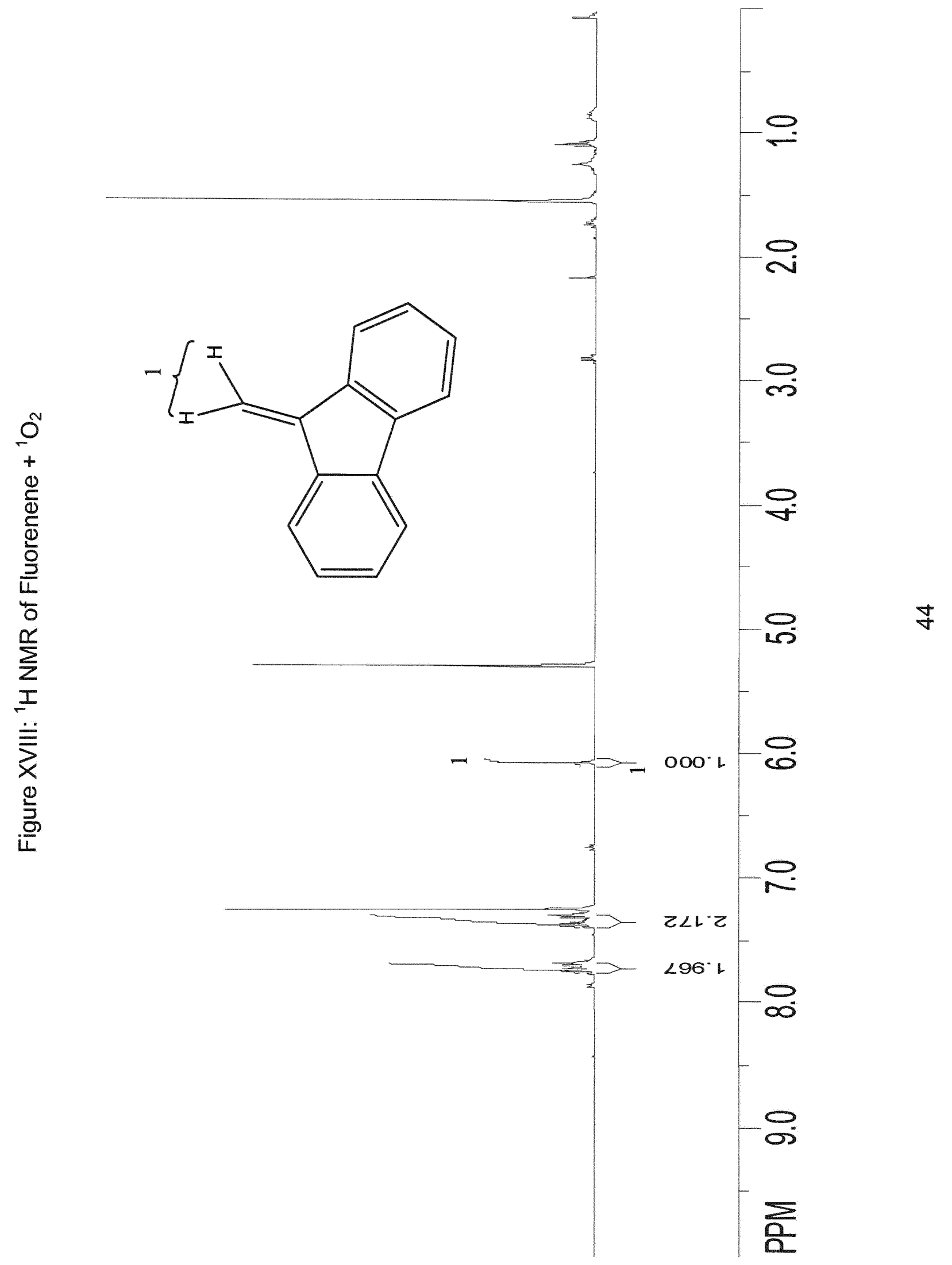




\subsubsection{The Reaction E,E 1,4-diphenyl-1,3-butadiene with Singlet Oxygen}

E,E-1,4-diphenyl-1,3-butadiene was used to probe the stereochemical consequences of the reactions of electrophiles with dienes. Isomeric 1,4diphenyl-1,3-butadienes may follow ' $4+2$ ' and ' $2+2$ ' reaction pathways but not ene type reactions. Concerted addition of singlet oxygen to E,E-1,4-diphenyl-1,3butadiene (according to Woodward-Hoffman rules) or through a closed intermediate, is expected to yield the product stereospecifically. If the reaction involves non-concerted reaction pathways involving an open intermediate, the stereochemistry would not be maintained in the products.

The expected products of E,E-1,4-diphenyl-1,3-butadiene with ${ }^{1} \mathrm{O}_{2}$ are shown below:
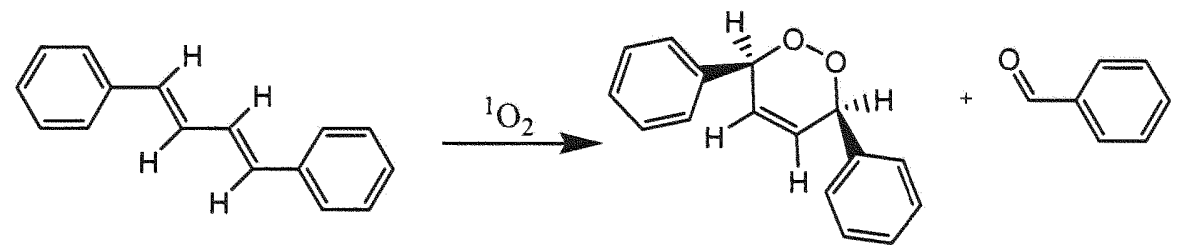<smiles>O=C/C=C/c1ccccc1</smiles>

Results: Our results demonstrate that E,E-1,4-diphenyl-1,3-butadiene reacts with ${ }^{1} \mathrm{O}_{2}$ to give $99 \%$ endoperoxide (4+2) product and $1 \% 2+2$ products. 


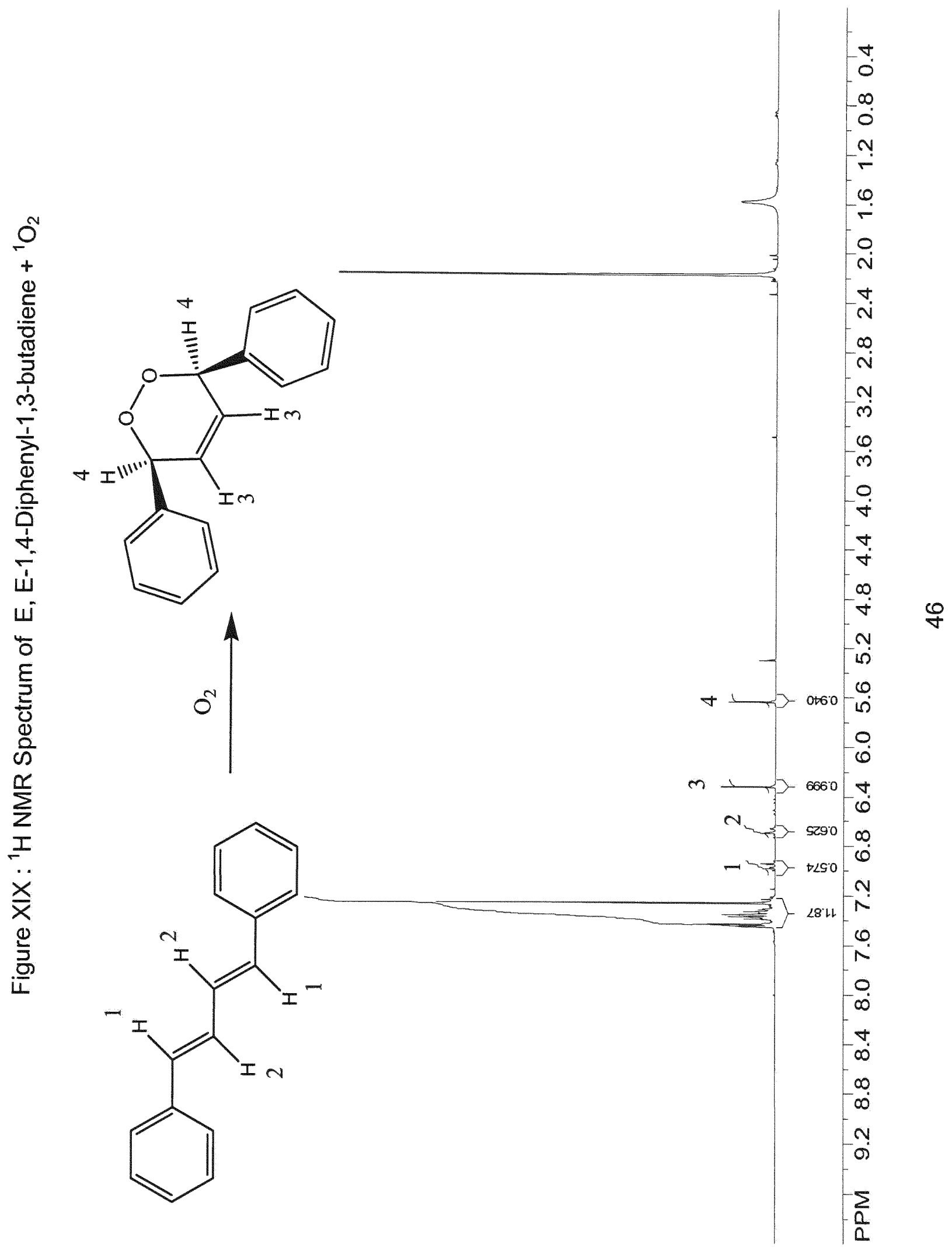




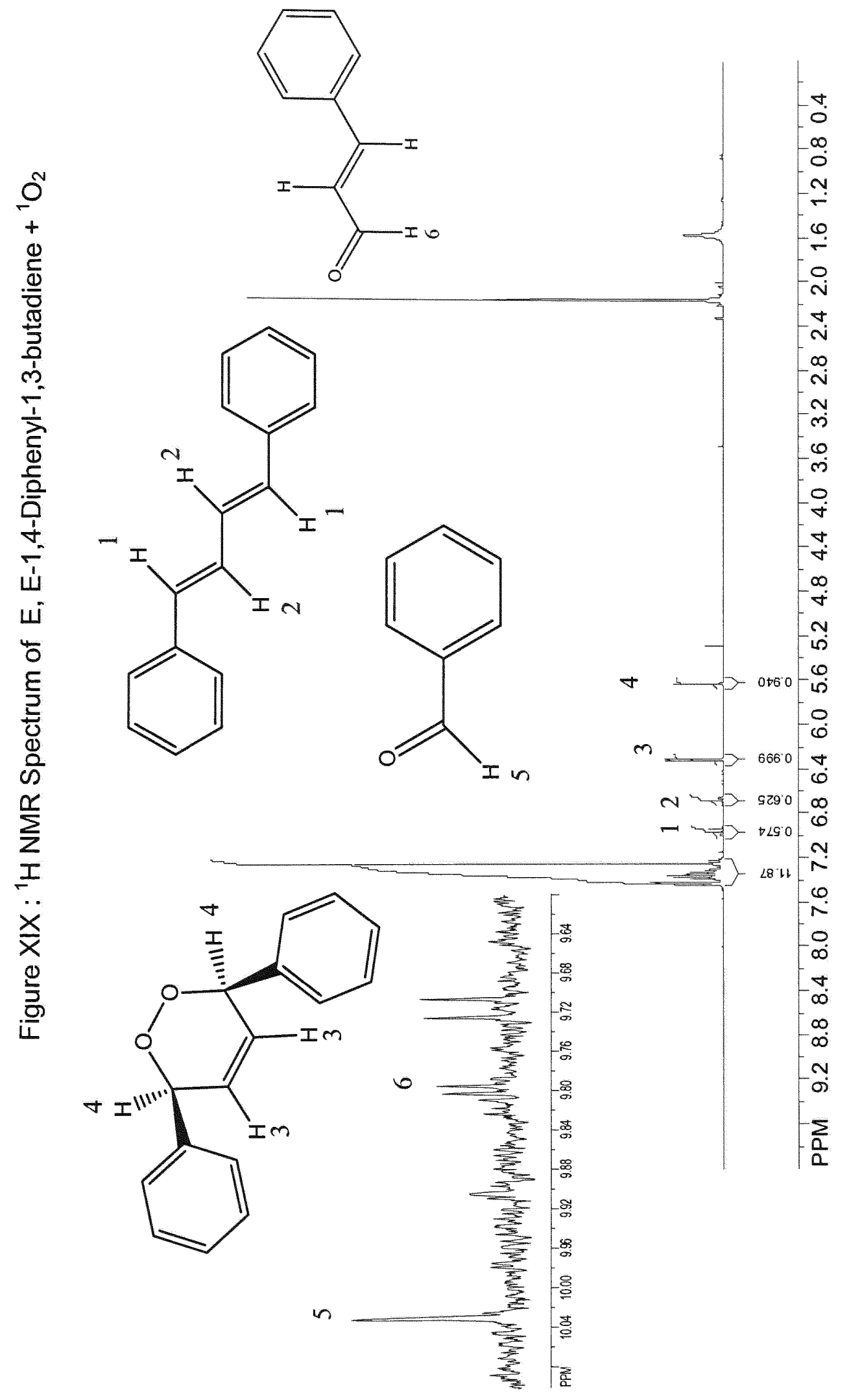




\subsubsection{The Reaction of E, Z-1,4-diphenyl-1,3-butadiene with Singlet Oxygen}

E,Z-1,4-diphenyl-1,3-butadiene $(0.2 \mathrm{~mL}, 0.0009 \mathrm{mmoles}), 0.1 \mathrm{~mL}$ of singlet oxygen photosensitizer solution ( $10^{-4} \mathrm{M}$ Rose Bengal, lamda max $550 \mathrm{~nm}$, in $\mathrm{CDCl}_{3}$ ) and $\sim 0.5 \mathrm{~mL}$ of $\mathrm{CDCl}_{3}$ were placed in a NMR tube. The NMR tube was placed in a windowed Dewar flask maintaining a slow, steady flow of oxygen through the solution and a temperature of $0^{\circ} \mathrm{C}$. A 150 watt Xenon lamp, Oriel model 68806 was used to irradiate the samples. E,Z-1,4-diphenyl-1,3-butadiene is isomerized to E,E-1,4-diphenyl-1,3-butadiene as soon as we started photolysis reaction. To stop the photoisomerization, a Pyrex filter glass was used to eliminate short UV wavelengths $(410 \mathrm{~nm})$ and to ensure no direct excitation of the olefin. The NMR tube with the solution of E,Z-1,4-diphenyl-1,3-butadiene and rose bengal, was placed in a windowed Dewar flask maintaining a slow, steady flow of oxygen through the solution and a temperature of $-78^{\circ} \mathrm{C}$. The 150 watt Xenon lamp, Oriel model 68806 was used to irradiate the samples. GC-MS spectroscopy and ${ }^{1} \mathrm{H}-\mathrm{NMR}$ were used to monitor the reaction. No detectable changes were observed in the starting materials after $2 \mathrm{hrs}$ of irradiation. To confirm singlet oxygen formation during the photooxidation, tetramethylene (TME) $(10 \mu \mathrm{L})$ was added to the reaction mixture. After one hour of irradiation ${ }^{1} \mathrm{H}-$ NMR showed the presence of the characteristic hydroperoxide confirming the generation of ${ }^{1} \mathrm{O}_{2}$ in solution under our standard reaction conditions. It explains that reactions of E,Z-1,4-diphenyl-1,3-butadiene with singlet oxygen is much slower than that of TME. 
Control reactions of E,Z-1,4-diphenyl-1,3-butadiene without singlet oxygen sensitizer were performed following/maintaining the same reaction conditions. No addition products eg. endoperoxide were observed without sensitizer. Control reactions of E,Z-1,4-diphenyl-1,3-butadiene without filter were also performed following/maintaining the same reaction conditions. E,Z-1,4-diphenyl1,3-butadiene isomerized to E,E-1,4-diphenyl-1,3-butadiene as soon as the photolysis starts and gives endoperoxide product. 


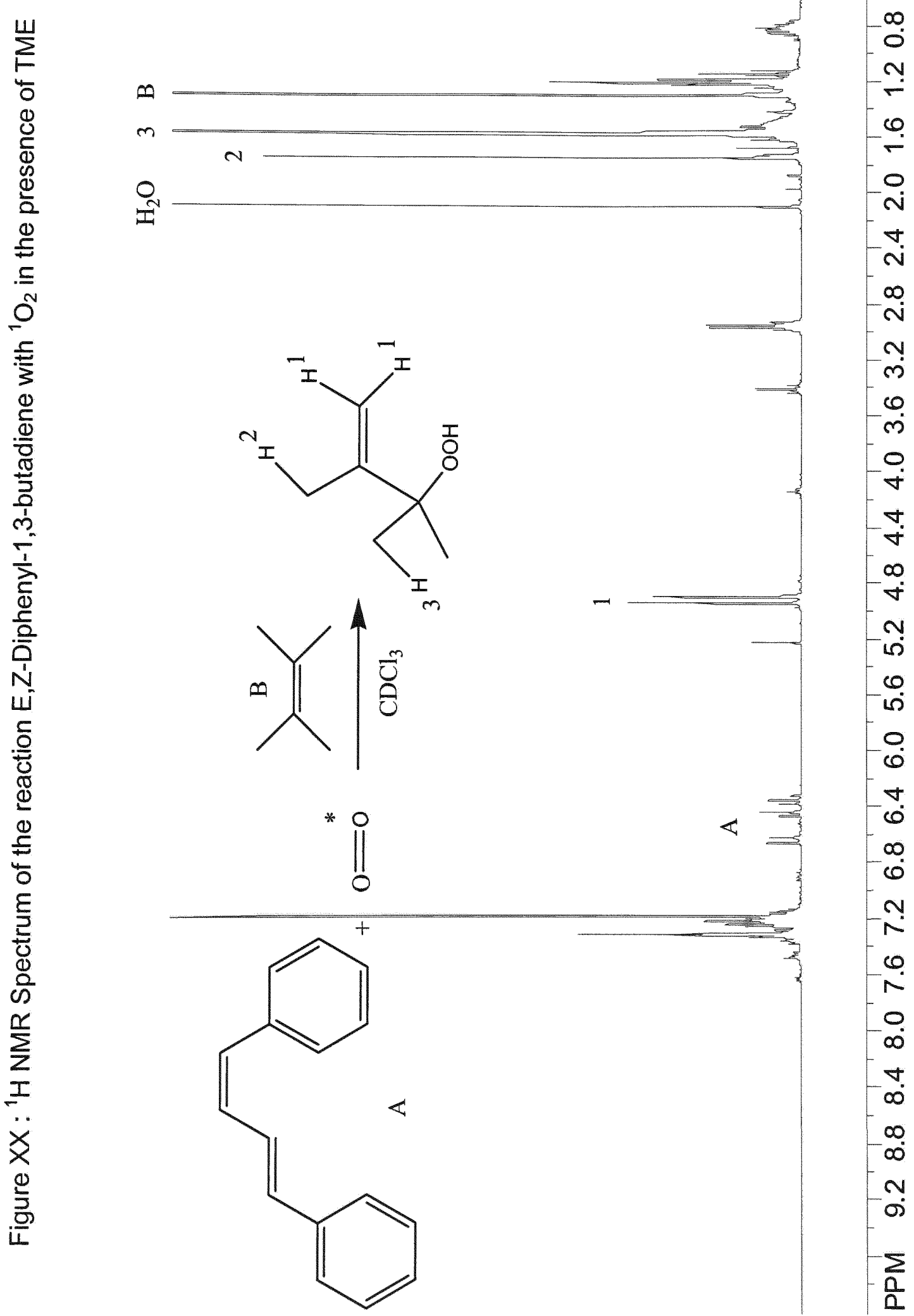




\subsubsection{The Reaction of Z,Z-1,4-diphenyl-1,3-butadiene with Singlet Oxygen}

Z,Z-1,4-diphenyl-1,3-butadiene (0.2 mL, $0.9 \mu$ moles), $0.1 \mathrm{~mL}$ of singlet oxygen photosensitizer solution ( $10^{-4} \mathrm{M}$ Rose Bengal, lamda max $550 \mathrm{~nm}$, in $\mathrm{CDCl}_{3}$ ) and $\sim 0.5 \mathrm{~mL}$ of $\mathrm{CDCl}_{3}$ were placed in a NMR tube. The NMR tube was placed in a windowed Dewar flask maintaining a slow, steady flow of oxygen through the solution and a temperature of $0^{\circ} \mathrm{C}$. A 150 watt Xenon lamp, Oriel model 68806 was used to irradiate the samples. Z,Z-1,4-diphenyl-1,3-butadiene is also isomerized to E,E-1,4-diphenyl-1,3-butadiene as soon as we started photolysis reaction. To stop the photoisomerization, a Pyrex filter glass was used to eliminate short UV wavelengths $(410 \mathrm{~nm})$ and to ensure no direct excitation of the olefin. The NMR tube with the solution of Z,Z-1,4-diphenyl-1,3-butadiene and rose bengal, was placed in a windowed Dewar flask maintaining a slow, steady flow of oxygen through the solution and a temperature of $-78^{\circ} \mathrm{C}$. The 150 watt Xenon lamp, Oriel model 68806 was used to irradiate the samples. GC-MS spectroscopy and ${ }^{1} \mathrm{H}$-NMR were used to monitor the reaction. No detectable changes were observed in the starting materials after 2 hrs of irradiation. To confirm singlet oxygen formation during the photooxidation, tetramethylene (TME) $(10 \mu \mathrm{L})$ was added to the reaction mixture. After one hour of irradiation ${ }^{1} \mathrm{H}$ NMR showed the presence of the characteristic hydroperoxide confirming the generation of ${ }^{1} \mathrm{O}_{2}$ in solution under our standard reaction conditions. It explains that reactions of $Z, Z-1,4$-diphenyl-1,3-butadiene with singlet oxygen is much slower than that of TME. 
Control reactions of Z,Z-1,4-diphenyl-1,3-butadiene without singlet oxygen sensitizer were performed following/maintaining the same reaction conditions. No products eg. endoperoxide were observed without sensitizer.

Control reactions of Z,Z-1,4-diphenyl-1,3-butadiene without filter were also performed following/maintaining the same reaction conditions. Z,Z-1,4-diphenyl1,3-butadiene gets isomerized to E,E-1,4-diphenyl-1,3-butadiene and gives endoperoxide product but E,Z-1,4-diphenyl-1,3-butadiene was not observed during photolysis. 


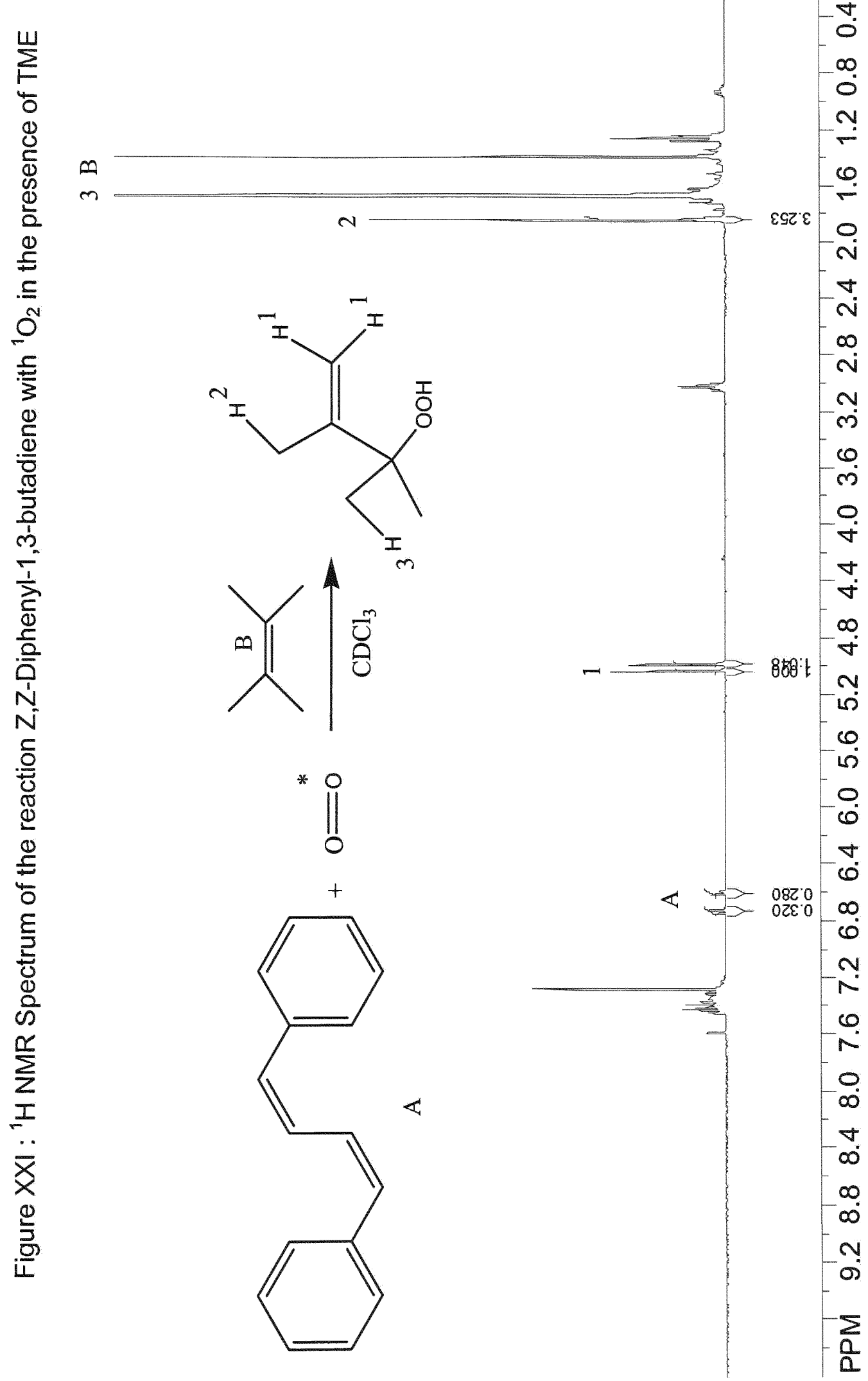


Summary of the reactions of singlet oxygen reactions with reaction probes:
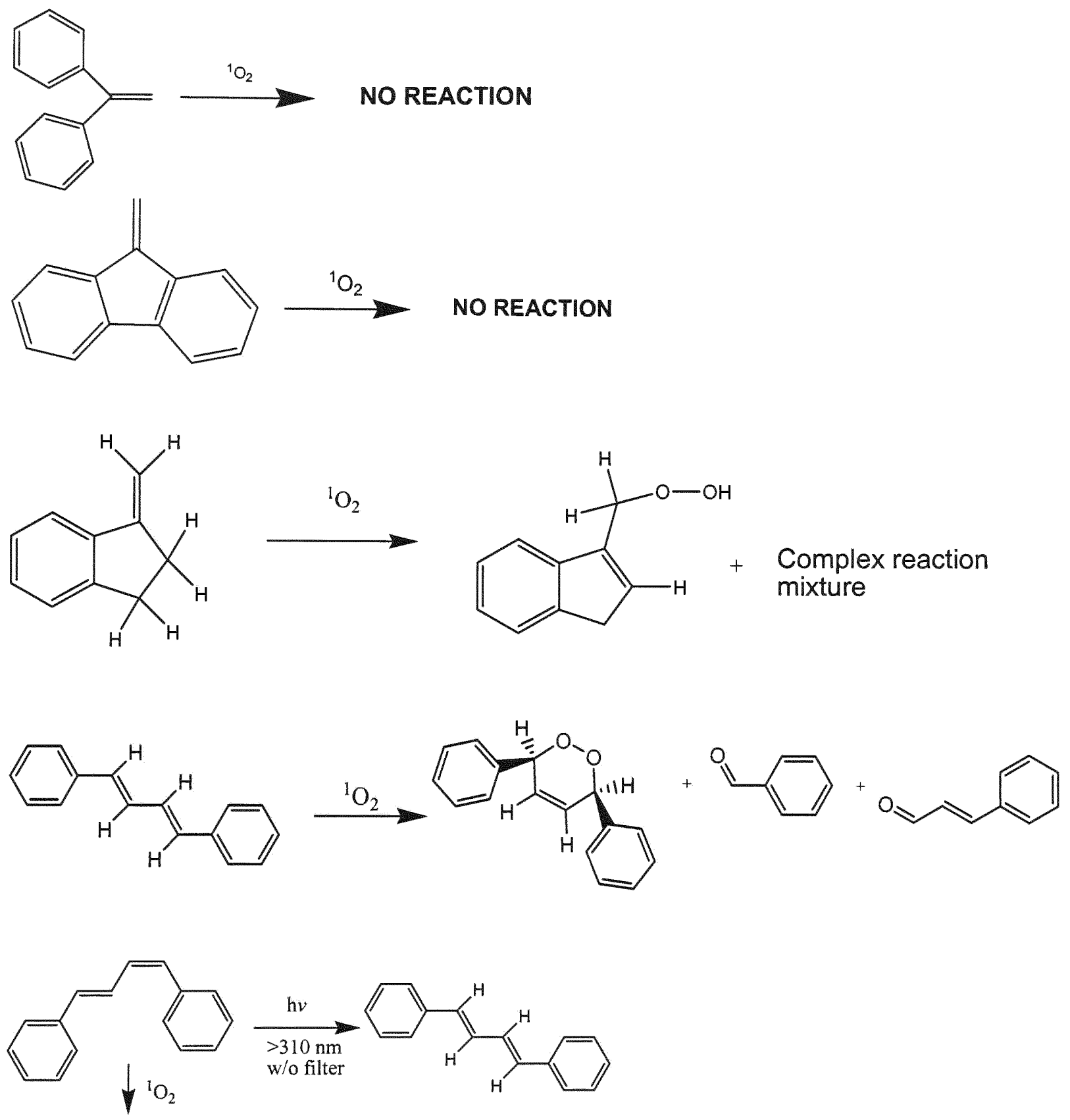

NO REACTION

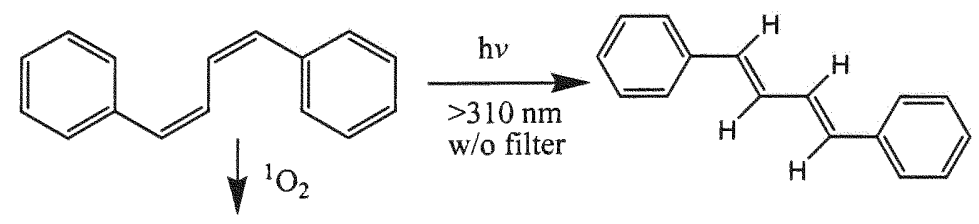

NO REACTION 
3.2 Reactions of 4-Methyl-1,2,4-triazoline-3,5-dione (MTAD) with 1,1Disubstituted-ethylenes and 1,4-Diphenyl-1,3-butadiene

3.2.1 Reaction of 4-Methyl-1,2,4-triazoline-3,5-dione (MTAD) with 1,1Diphenyl-ethylenes

4-Methyl-1,2,4-triazoline-3,5-dione (MTAD), is known to be a stronger electrophile than singlet oxygen, and generally reacts readily with olefins, including disubstituted olefins. The expected product of 1,1-diphenylethylene and MTAD is $2+2$ product, formation of the $4+2$ adduct requires loss of aromaticity.

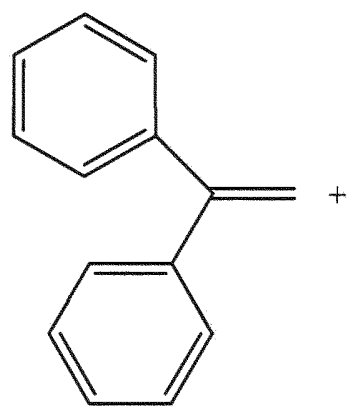<smiles>CN1C(=O)N=NC1=O</smiles>

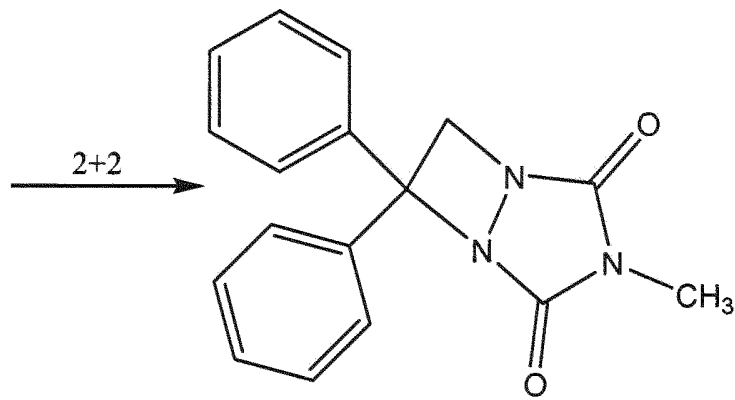<smiles>[C+]=C(c1ccccc1)c1ccccc1</smiles><smiles>CN1C(=O)N=NC1=O</smiles><smiles>C[14CH2][14CH2][14CH2][14CH2]c1ccccc1</smiles> 


\section{Experimental:}

1,1-diphenylethylene $(0.05 \mathrm{~mL}, 0.27 \mu$ moles) were transferred to a NMR tube and $0.5 \mathrm{ml}$ of $\mathrm{CDCl}_{3}$ were added. MTAD $(0.061 \mathrm{mg}, 0.54 \mu$ moles $)$ were weighed out and transferred to a small test tube, and dissolved in $1 \mathrm{ml}$ of $\mathrm{CDCl}_{3}$. Each tube was placed in an ice-water bath for five minutes and then the MTAD/CDCl 3 was added dropwise to the 1,1-diphenylethylene/CDCl 3 solution using a Pasteur pipet. As the pink solution of $\mathrm{MTAD} / \mathrm{CDCl}_{3}$ was added to the olefin, the pink color disappeared; indicating that a reaction was taking place. When all of the solution was transferred, the solution remained dark pink for $\sim 3$ minutes, and then the color faded and ${ }^{1} \mathrm{H},{ }^{13} \mathrm{C}$ and COSY NMR spectrum were run.

\section{Results :}

Our results have shown an interesting observation that 1,1-Diphenylethylene reacts with MTAD as 1:2 molar ratio based on MS results. Our NMR results did not show any mono adduct corresponding to a $1: 1$ molar ratio. After addition of a second equivalent of MTAD, NMR interpretation was leading to assignment of $4+2 /$ ene and $4+2 / 4+2$ adducts. The interconnections among the hydrogens were confirmed by COSY NMR. Both the $4+2 /$ ene and $4+2 / 4+2$ adducts have the mass of 406 and LC-MS spectrum supported it $(406+1)$. 
Probable mechanistic pathways of the reaction of 1,1-Diphenylethylene with MTAD is shown below:

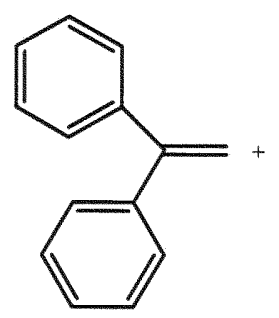<smiles>CN1C(=O)N=NC1=O</smiles><smiles>C/C=C/C</smiles>

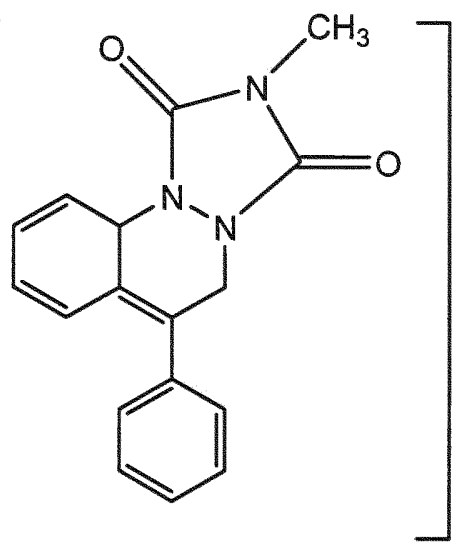
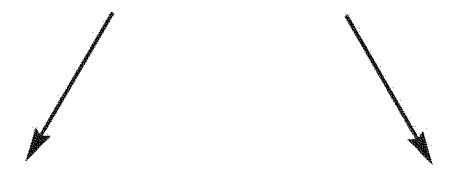<smiles></smiles>

$4+2 /$ ene adduct

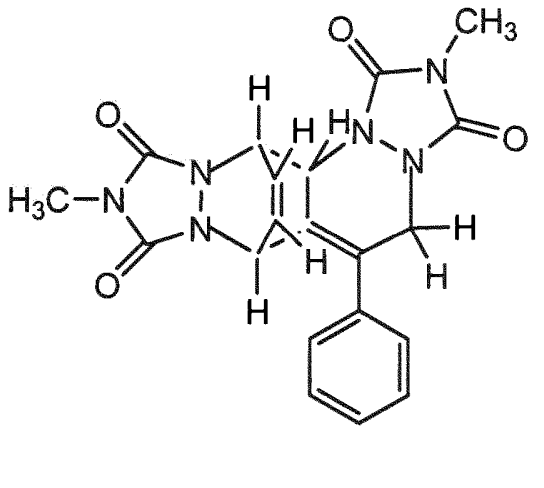

$4+2 / 4+2$ adduct 


\section{MeOH trapping attempt:}

1,1-diphenylethylene $(0.05 \mathrm{ml}, 0.27 \mu$ moles $)$ were transferred to a small test tube and $0.5 \mathrm{ml}$ of $\mathrm{CDCl}_{3}$ were added. One drop of $\mathrm{MeOH}$ was added to the 1,1diphenylethylene/ $\mathrm{CDCl}_{3}$ solution. MTAD $(0.061 \mathrm{mg}, 0.54 \mu$ moles $)$ was weighed out and transferred to a small test tube to which $1 \mathrm{ml}$ of $\mathrm{CDCl}_{3}$ was added. . Each test tube was placed in an ice-water bath for five minutes and then the $\mathrm{MTAD} / \mathrm{CDCl}_{3}$ was added dropwise to the 1,1-diphenylethylene/ $\mathrm{CDCl}_{3} / \mathrm{MeOH}$ solution using a Pasteur pipet. As the pink solution of $\mathrm{MTAD} / \mathrm{CDCl} \mathrm{C}_{3}$ was added to the olefin, the pink color disappeared; indicating that a reaction was taking place. When all of the solution was transferred, the solution remained dark pink for $\sim 3$ minutes, and then the color faded. $A{ }^{1} H$ NMR spectrum was run. No new peaks were observed; no intermediates were trapped. This procedure was repeated at $-78^{\circ} \mathrm{C}$ using a dry ice/acetone bath, and with $\mathrm{CD}_{2} \mathrm{Cl}_{2}$ as the solvent. 


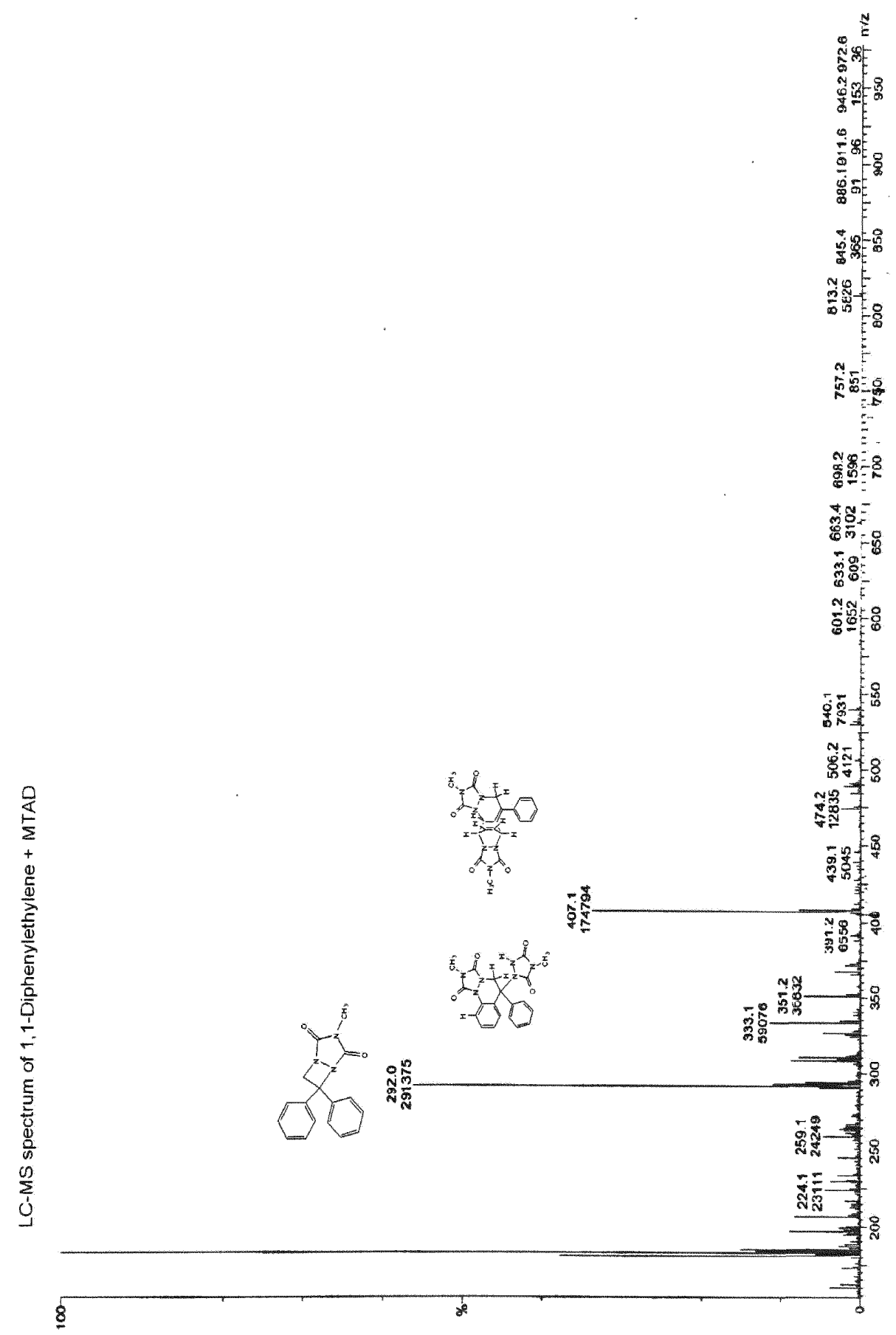

용 


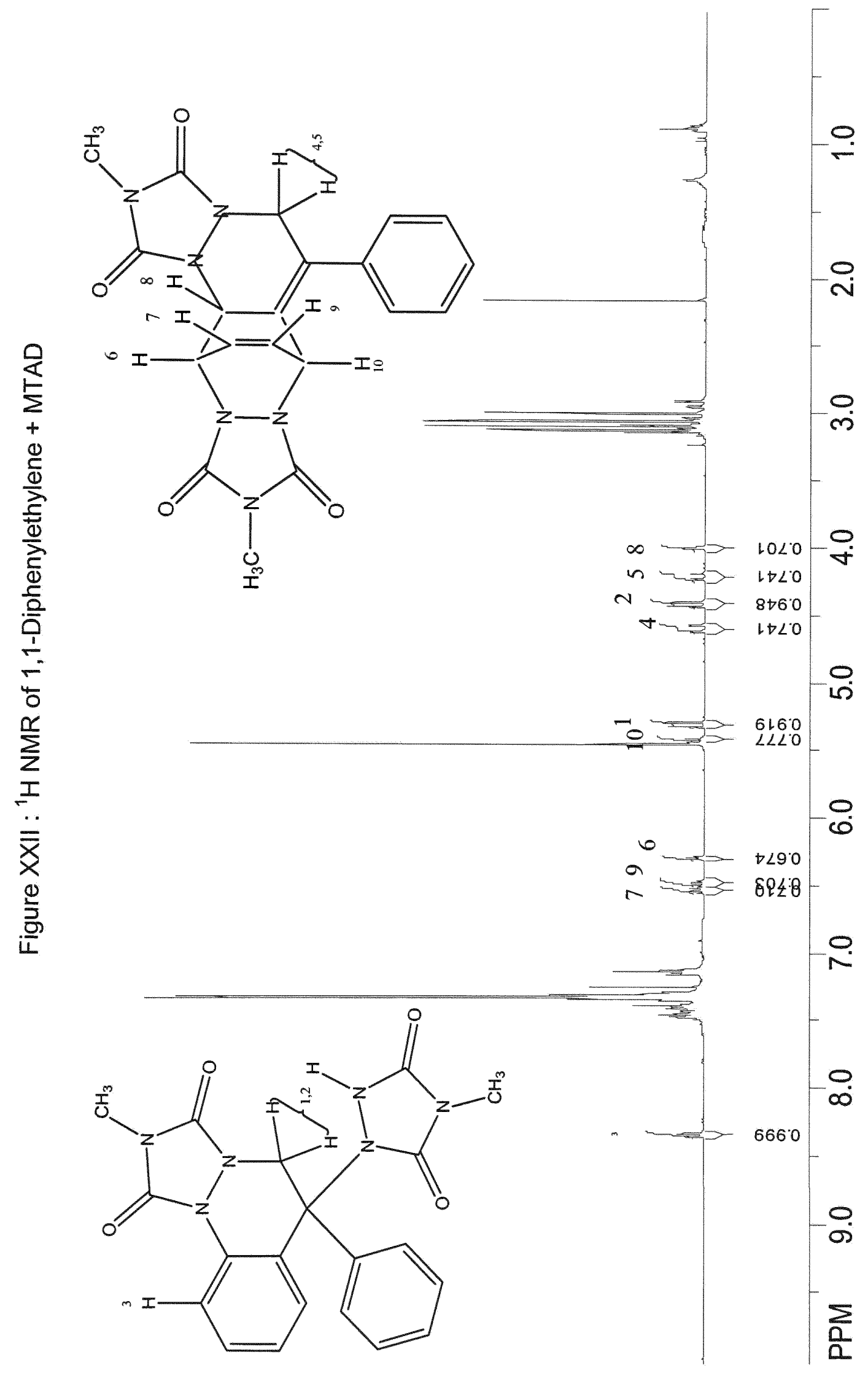




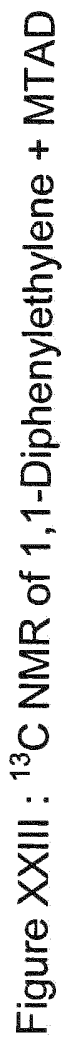

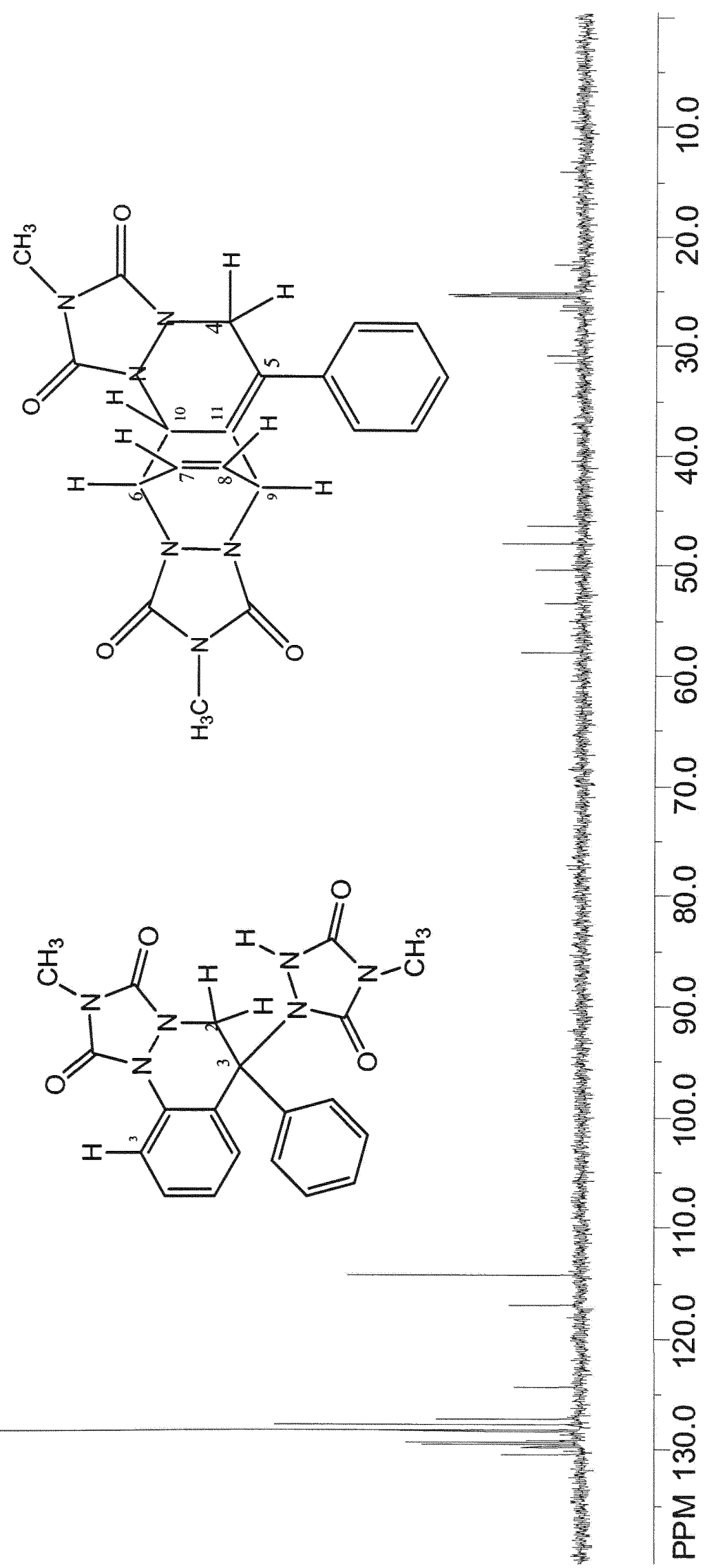



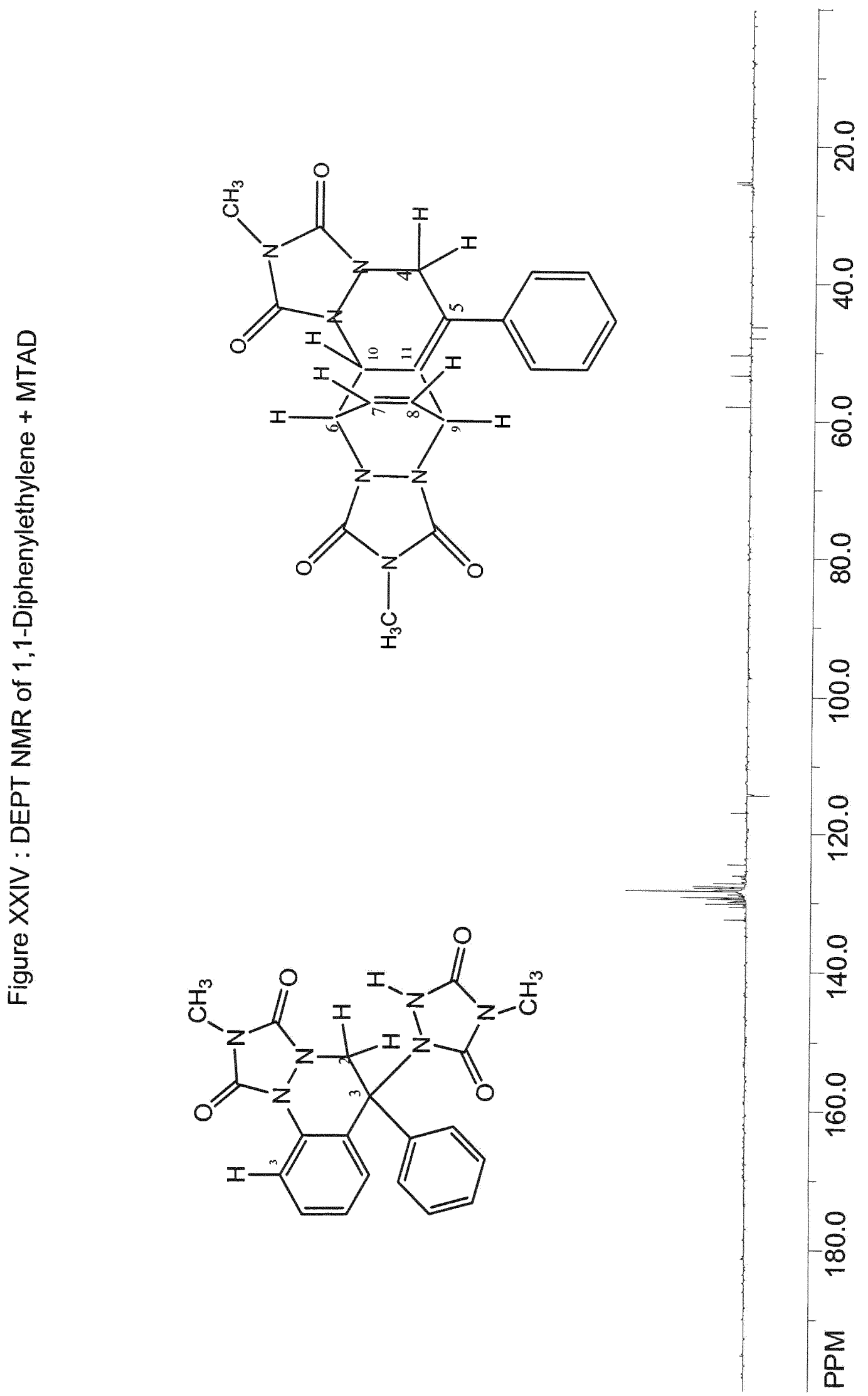


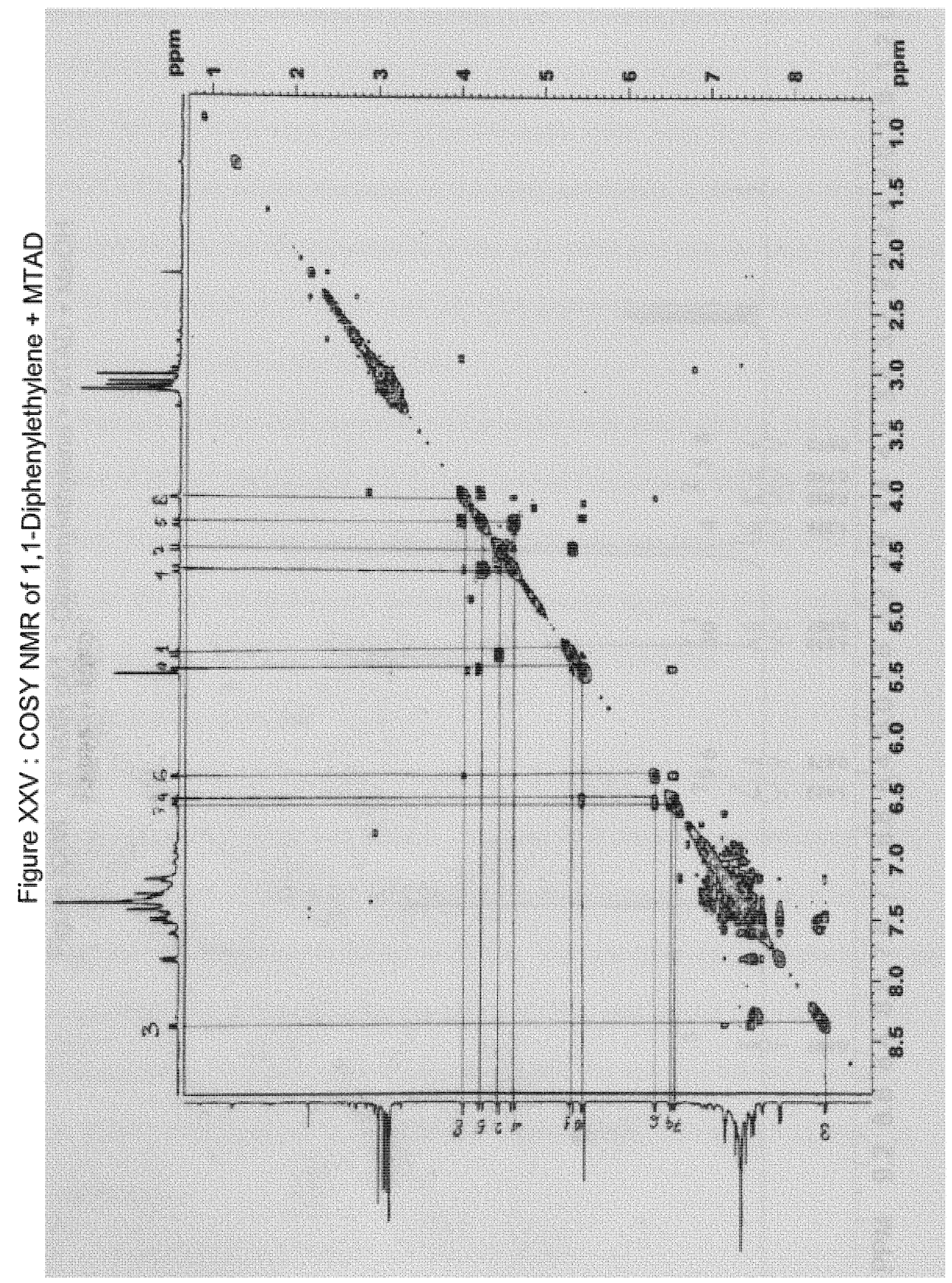



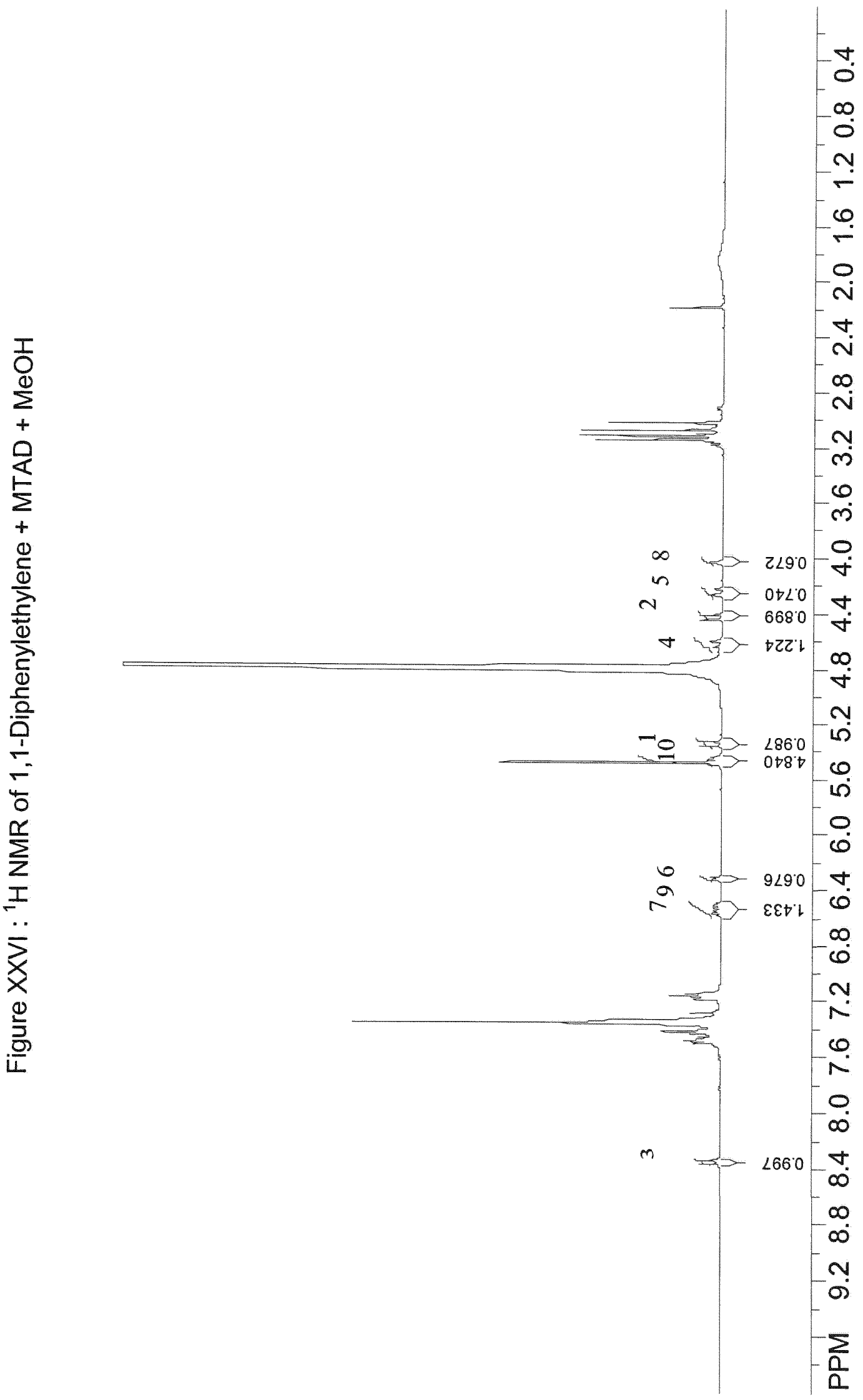


\subsubsection{Reaction of 4-Methyl-1,2,4-triazoline-3,5-dione (MTAD) with}

\section{Methyleneindan:}

Experimental: Methyleneindan $(0.1356 \mathrm{~g}, 1.043 \mathrm{mmoles})$ were dissolved in 0.5 $\mathrm{ml}$ of $\mathrm{CDCl}_{3}$ and MTAD (0.1159 g, 1.026 mmoles) was dissolved in $0.5 \mathrm{ml}$ of $\mathrm{CDCl}_{3}$. The solutions were placed in an ice-water bath. After five minutes, the $\mathrm{MTAD} / \mathrm{CDCl}_{3}$ was added dropwise to the methyeneindan. Evidence of reaction was observed by the disappearance of the pink color and appearance of a yellow color in the solution. ${ }^{1}{ }^{1} H$ NMR was run. The peaks observed corresponded to the ene reaction, and unreacted olefin.

The reaction mixture was placed in an ice-water bath and $0.0612 \mathrm{~g}, 0.5416$ mmoles of MTAD dissolved in $\mathrm{CDCl}_{3}$ was added dropwise to the reaction solution. The solution remained pink. $A^{1} H$ NMR was run once more. The NMR spectrum did not show any new peaks. The reaction remained pink, indicating that the reaction is in a one to one molar ratio of the reactants.

\section{$\mathrm{MeOH}$ trapping attempt:}

Methyleneindan $(0.1560 \mathrm{~g}, 1.2 \mathrm{mmoles})$ was dissolved in $0.5 \mathrm{ml} \mathrm{of} \mathrm{CDCl}_{3}$. One drop of methanol Optima was added. The flask was placed in an ice-water bath. $0.1370 \mathrm{~g}, 1.212$ of MTAD were weighed out and transferred to a small test tube. The MTAD was dissolved in $0.5 \mathrm{ml}$ of $\mathrm{CDCl}_{3}$. The test tube was also placed in an ice-water bath. After five minutes the $\mathrm{MTAD} / \mathrm{CDCl}_{3}$ was added drop wise to the methyleneindan. The pink color disappeared and the solution turned a yellow color. The NMR spectrum did not show any new peaks, indicating that trapping did not occur. 


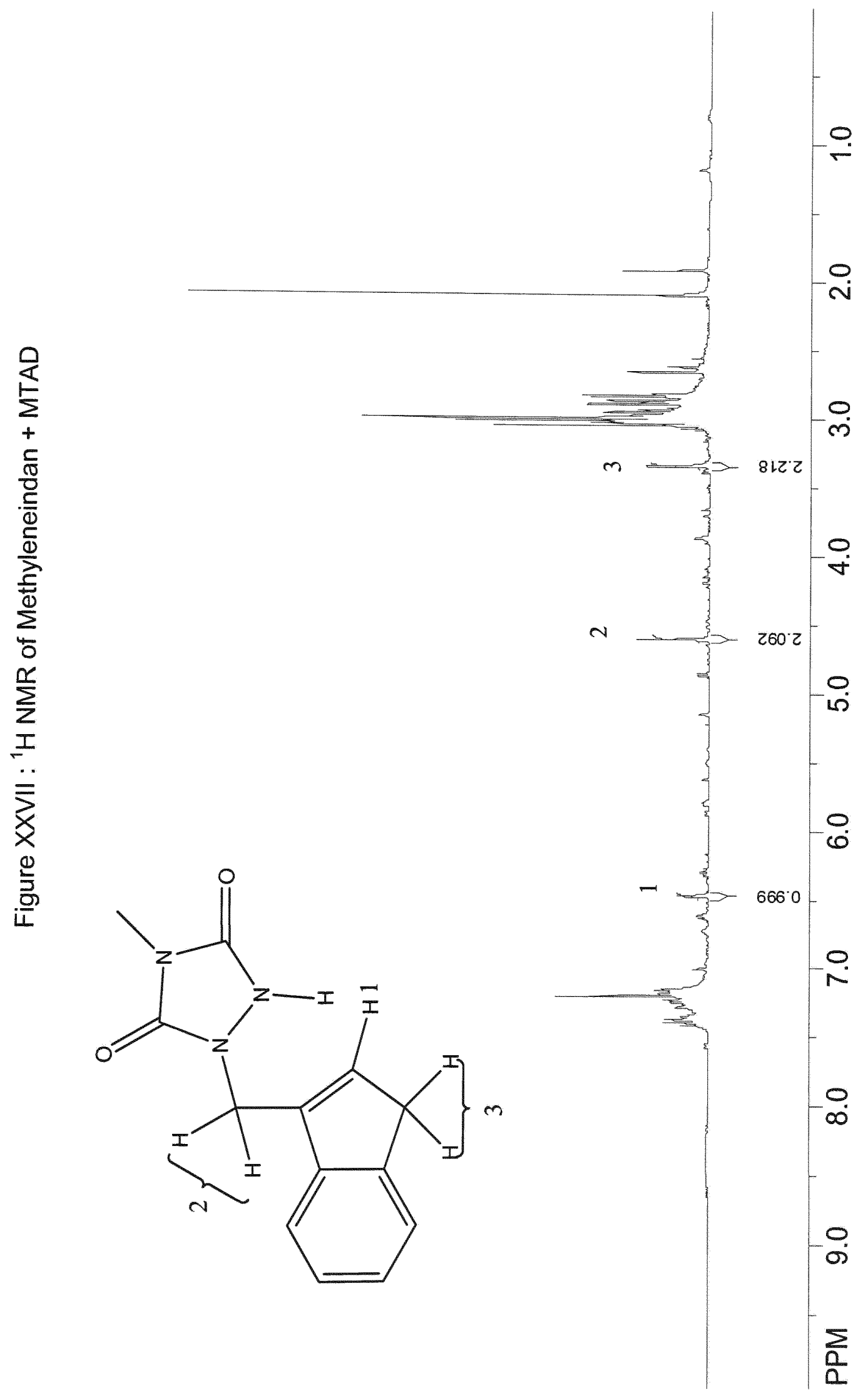




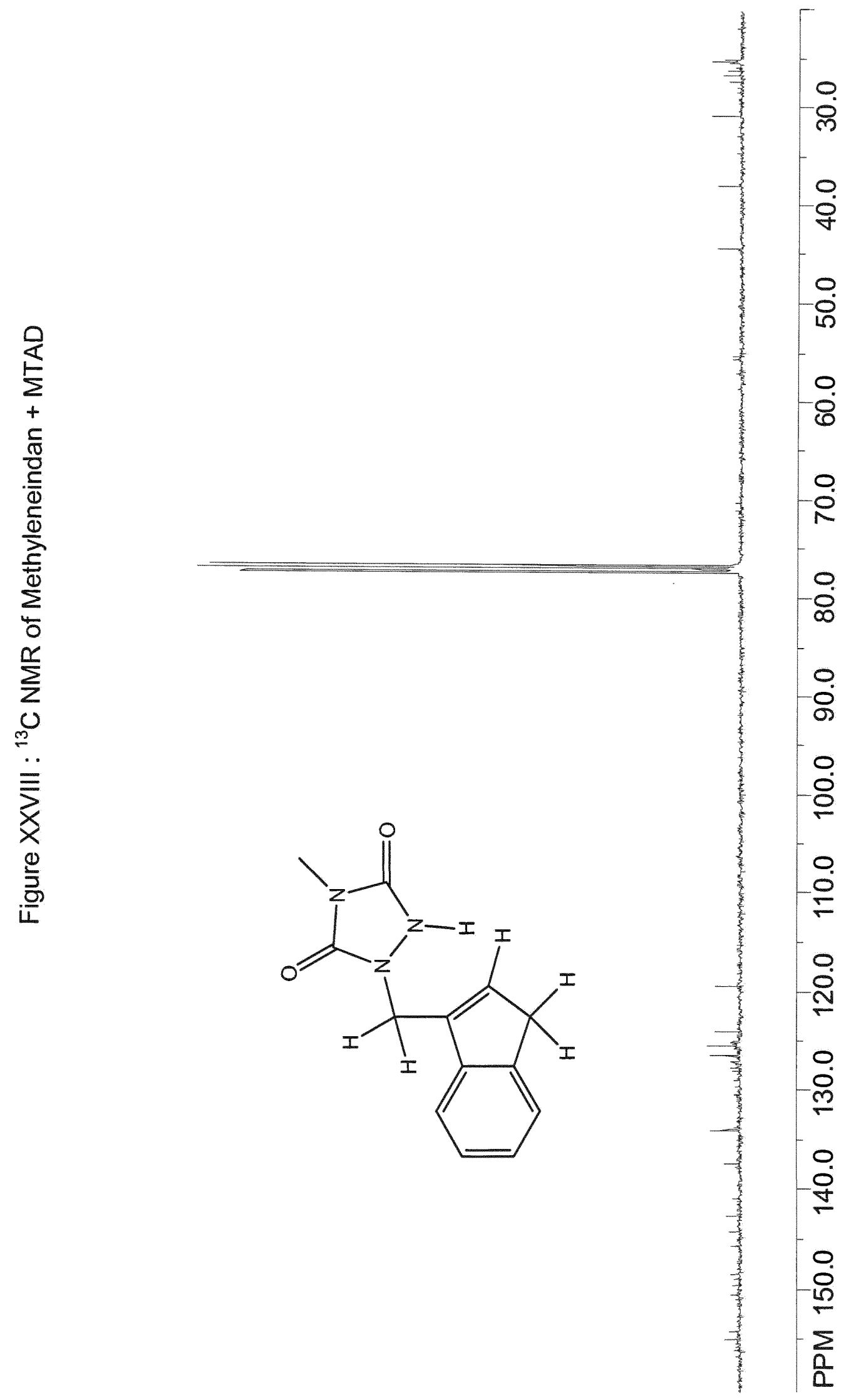



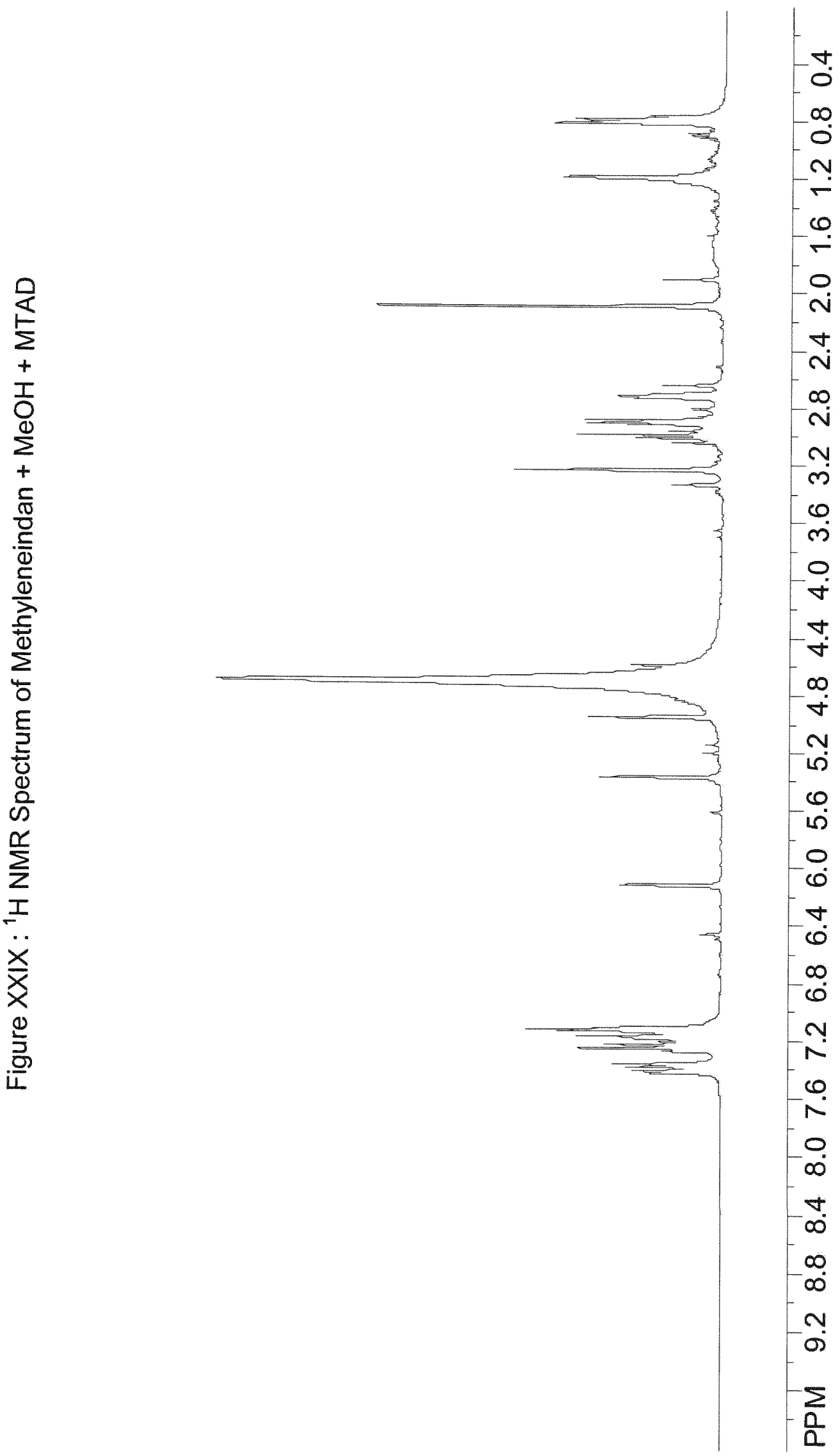


\subsubsection{Reaction of 4-Methyl-1,2,4-triazoline-3,5-dione (MTAD) with}

Fluorenene

\section{Experimental:}

Fluorenene $(0.1356 \mathrm{~g}, 0.7533 \mathrm{mmoles})$ was dissolved in $0.5 \mathrm{ml}$ of $\mathrm{CDCl}_{3}$ and MTAD (0.1159 g, 1.0257 mmoles) was dissolved in $0.5 \mathrm{ml}$ of $\mathrm{CDCl}_{3}$. The solutions were placed in an ice-water bath. After five minutes, the $\mathrm{MTAD} / \mathrm{CDCl}_{3}$ was added dropwise to the fluorenene. Evidence of reaction was observed by the disappearance of the pink color and appearance of a yellow color in the solution. A ${ }^{1} \mathrm{H}$ NMR was run. The peaks observed corresponded to a complex mixture. The reaction mixture was placed in an ice-water bath and $0.0612 \mathrm{~g}, 0.5415$ mmoles of MTAD dissolved in $\mathrm{CDCl}_{3}$ was added dropwise to the reaction solution. The solution remained pink. ${ }^{1}{ }^{1} \mathrm{H}$ NMR was run once more. The NMR spectrum did not show any new peaks. The reaction remained pink.

\section{$\mathrm{MeOH}$ trapping attempt:}

Fluorenene $\left(0.1560 \mathrm{~g}, 0.8666\right.$ mmoles) was dissolved in $0.5 \mathrm{~mL}$ of $\mathrm{CDCl}_{3}$. One drop of methanol Optima was added. The flask was placed in an ice-water bath. $0.1350 \mathrm{~g}$ of MTAD were weighed out and transferred to a small test tube. The MTAD was dissolved in $0.5 \mathrm{~mL}$ of $\mathrm{CDCl}_{3}$. The test tube was also placed in an icewater bath. After five minutes the $\mathrm{MTAD} / \mathrm{CDCl}_{3}$ was added drop wise to the fluorenene. The pink color disappeared. The NMR spectrum did not show any new peaks, indicating that trapping did not occur. 

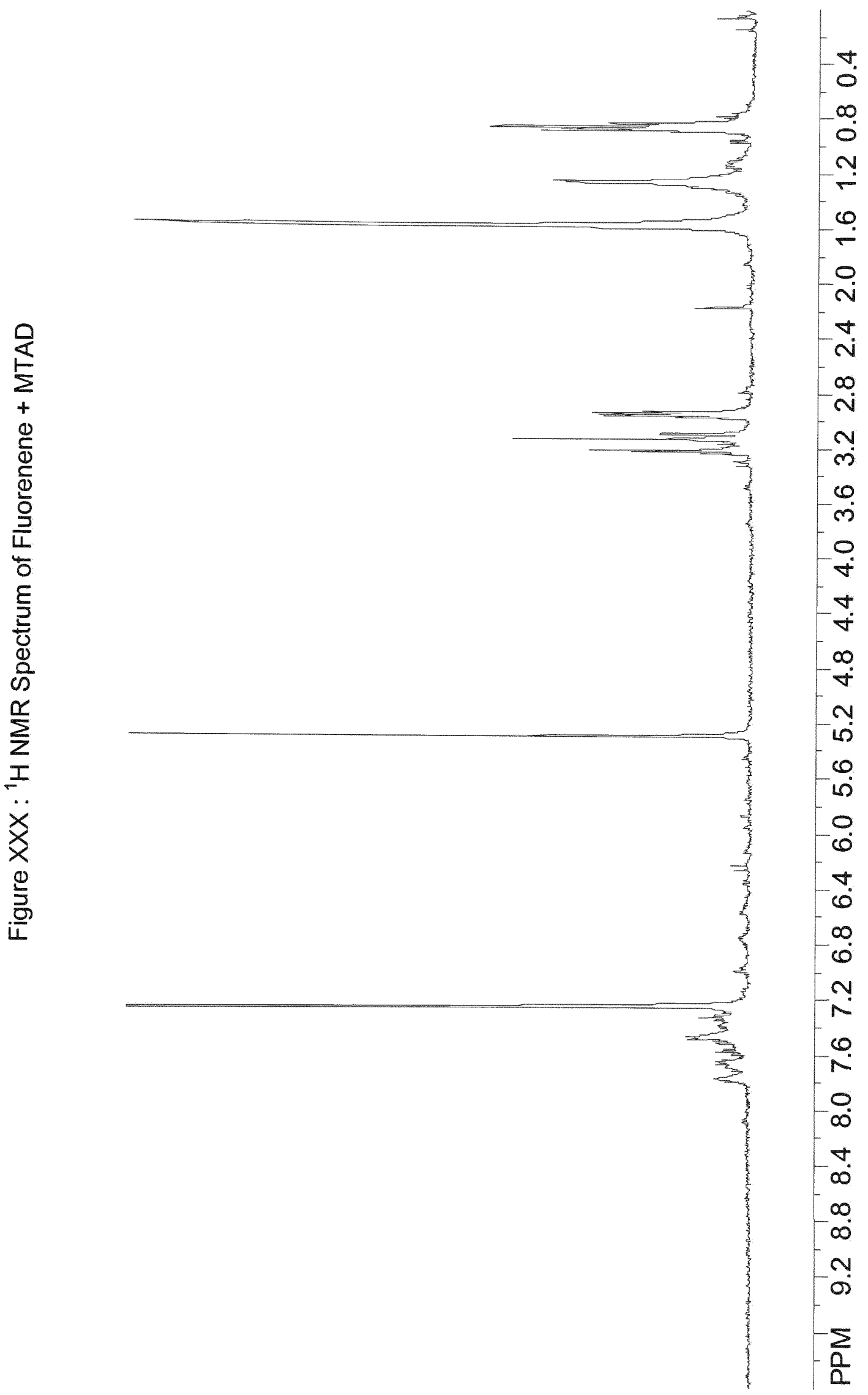


\subsubsection{Reaction of 4-Methyl-1,2,4-triazoline-3,5-dione (MTAD) with E,E-1,4- Diphenyl-1,3-butadiene}

The expected products of E,E-1,4-Diphenyl-1,3-butadiene and MTAD may be $2+2,4+2$ products but not ene type. Concerted addition of MTAD to E,E-1,4diphenyl-1,3-butadiene (according to Woodward-Hoffman rules) or through a closed intermediate, a product is expected to form stereospecifically. If the reaction involves non-concerted reaction pathways involving an open intermediate, the stereochemistry would not be maintained in the products.

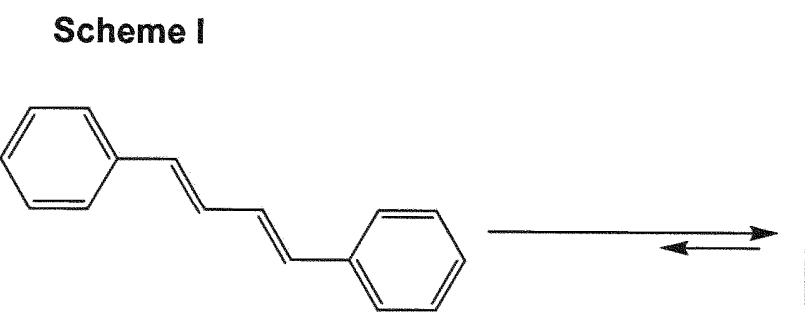

E,E 1,4-diphenyl 1,3-butadiene

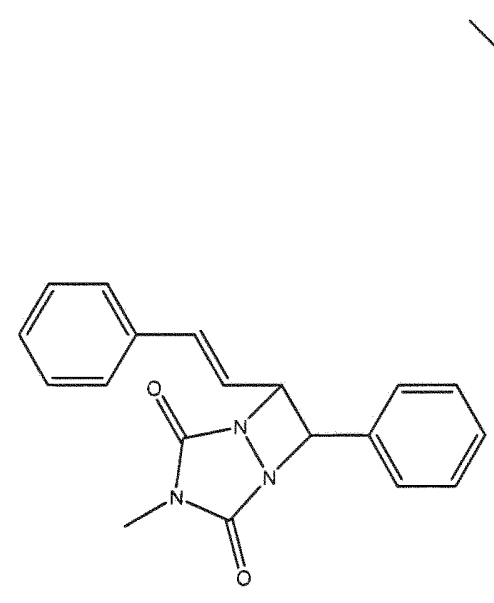

$2+2$ adduct

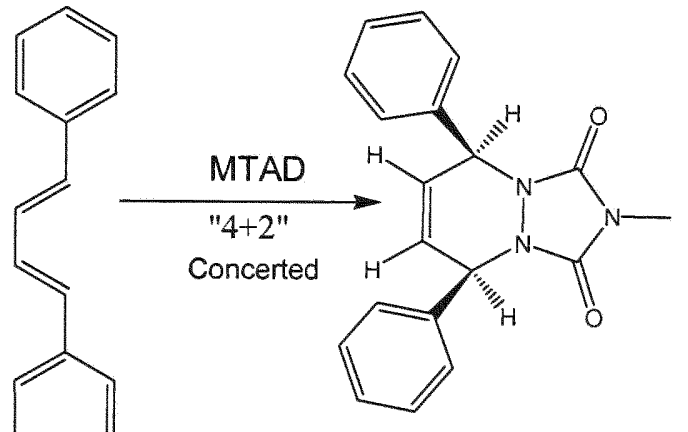

Cis $4+2$ adduct

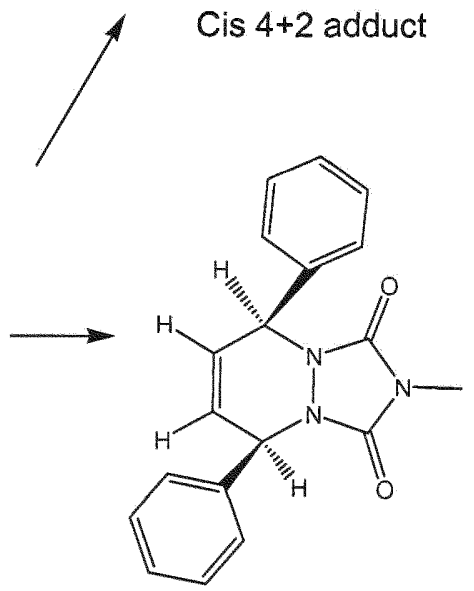

trans $4+2$ adduct 


\section{Experimental:}

E,E-1,4-Diphenyl-1,3-butadiene ( $0.5 \mathrm{mg}, 0.002427$ mmoles) were transferred to a NMR tube and $0.5 \mathrm{ml}$ of $\mathrm{CDCl}_{3}$ were added. MTAD $(0.5 \mathrm{mg}, 0.00425$ mmoles $)$ was weighed out and transferred to a small test tube to which $1 \mathrm{ml} \mathrm{of} \mathrm{CDCl}_{3}$ was added. Each tube was placed in an ice-water bath for five minutes and then the $\mathrm{MTAD} / \mathrm{CDCl}_{3}$ was added dropwise to the E,E-1,4-Diphenyl-1,3-butadiene $/ \mathrm{CDCl}_{3}$ solution using a Pasteur pipet. As the pink solution of $\mathrm{MTAD} / \mathrm{CDCl}_{3}$ was added to the olefin, the pink color disappeared; indicating that a reaction was taking place. When all of the solution was transferred, the solution remained dark pink for $\sim 5$ minutes, and then the color faded. Then ${ }^{1} H$ NMR spectrum was run.

Results: NMR and MS results have shown that E,E-1,4-Diphenyl-1,3-Butadiene yielded 100\% Diels-Alder (4+2) adduct with MTAD.

\section{$\mathrm{MeOH}$ trapping attempt:}

E,E-1,4-Diphenyl-1,3-butadiene ( $0.5 \mathrm{mg}, 0.002427$ mmoles) were transferred to a NMR tube and $0.5 \mathrm{ml}$ of $\mathrm{CDCl}_{3}$ were added. One drop of $\mathrm{MeOH}$ were added to the E,E-1,4-Diphenyl-1,3-butadiene / $\mathrm{CDCl}_{3}$ solution. MTAD (0.5 mg, 0.00425 mmoles) was weighed out and transferred to a small test tube to which $1 \mathrm{ml}$ of $\mathrm{CDCl}_{3}$ was added. Each tube was placed in an ice-water bath for five minutes and then the MTAD/CDCl 3 was added dropwise to the E,E-1,4-Diphenyl-1,3butadiene $/ \mathrm{CDCl}_{3} / \mathrm{MeOH}$ solution using a Pasteur pipet. As the pink solution of MTAD/CDCl 3 was added to the olefin, the pink color disappeared; indicating that 
a reaction was taking place. When all of the solution was transferred, the solution remained dark pink for $\sim 5$ minutes, and then the color faded. Then ${ }^{1} H$ NMR spectrum was run. No new peaks were observed; no intermediates were trapped. This procedure was repeated at $-78^{\circ} \mathrm{C}$ using a dry ice/acetone bath, and with $\mathrm{CD}_{2} \mathrm{Cl}_{2}$ as the solvent.

Even then we have not observed any new peaks. Therefore, intermediates may not form in this case. Concerted addition of MTAD to E,E-1,4-diphenyl-1,3butadiene (according to Woodward-Hoffman rules) can be reported here. If the reaction involves non-concerted reaction pathways involving an open intermediate, the stereochemistry would not be maintained in the products. 


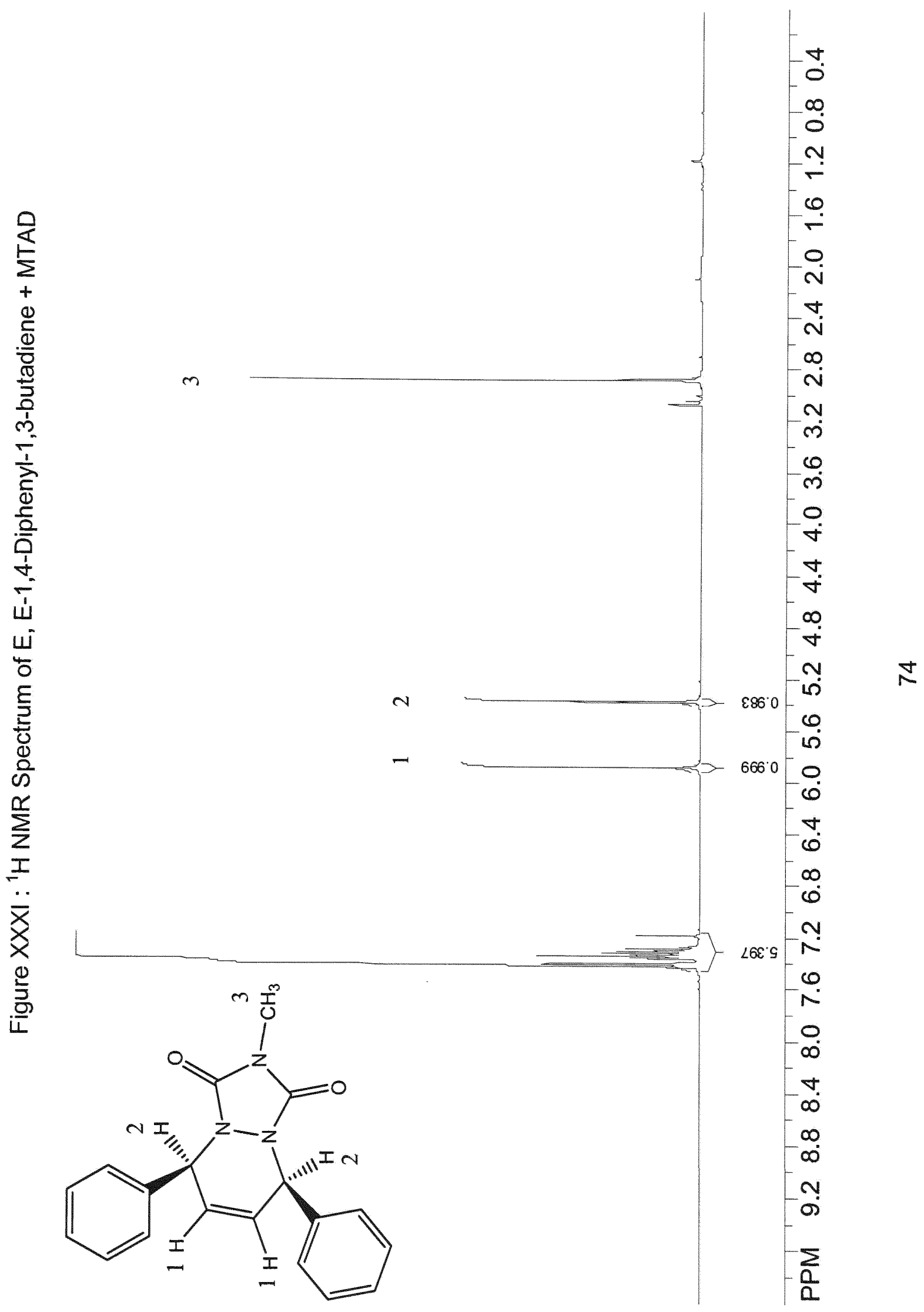




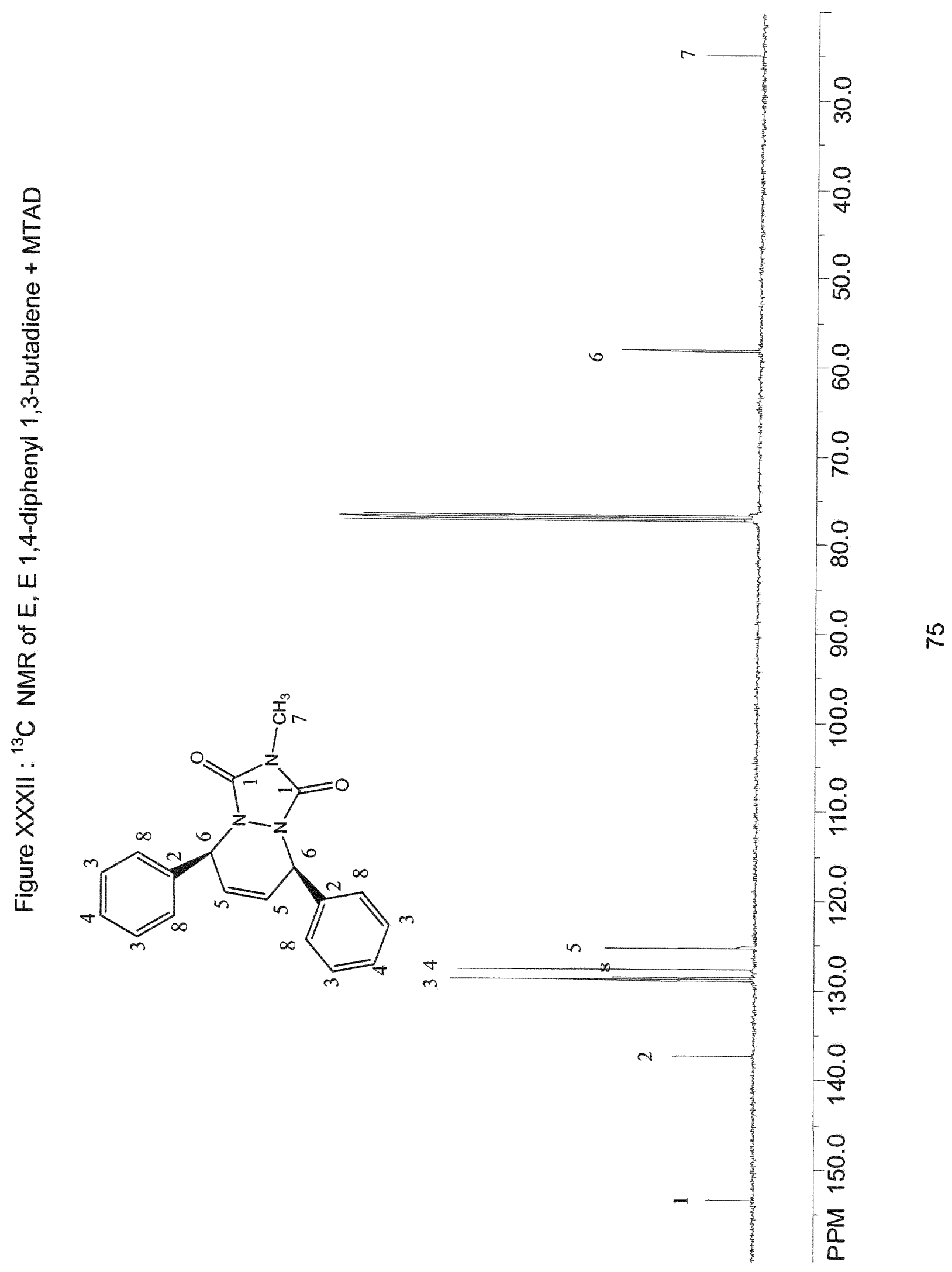




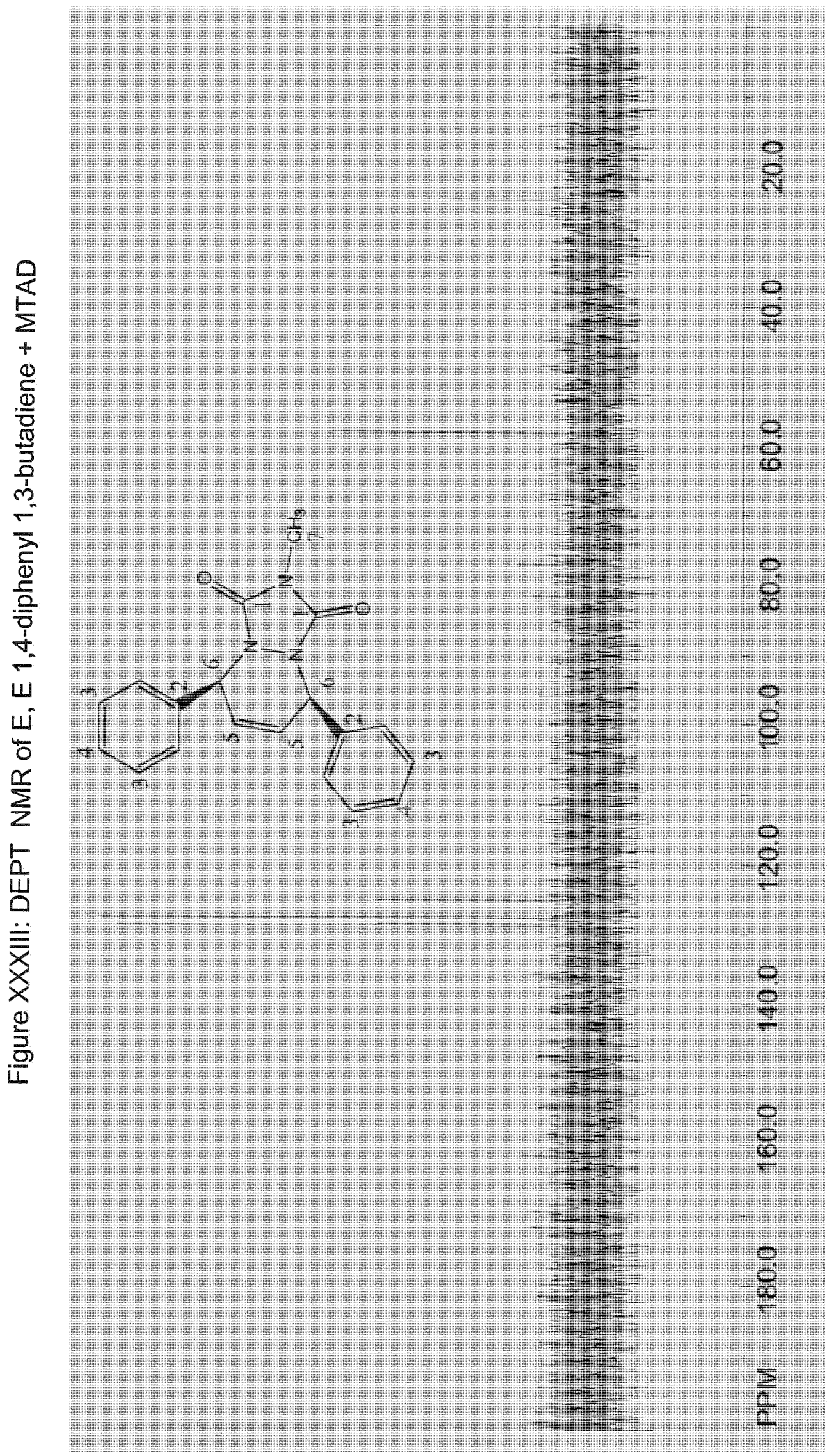




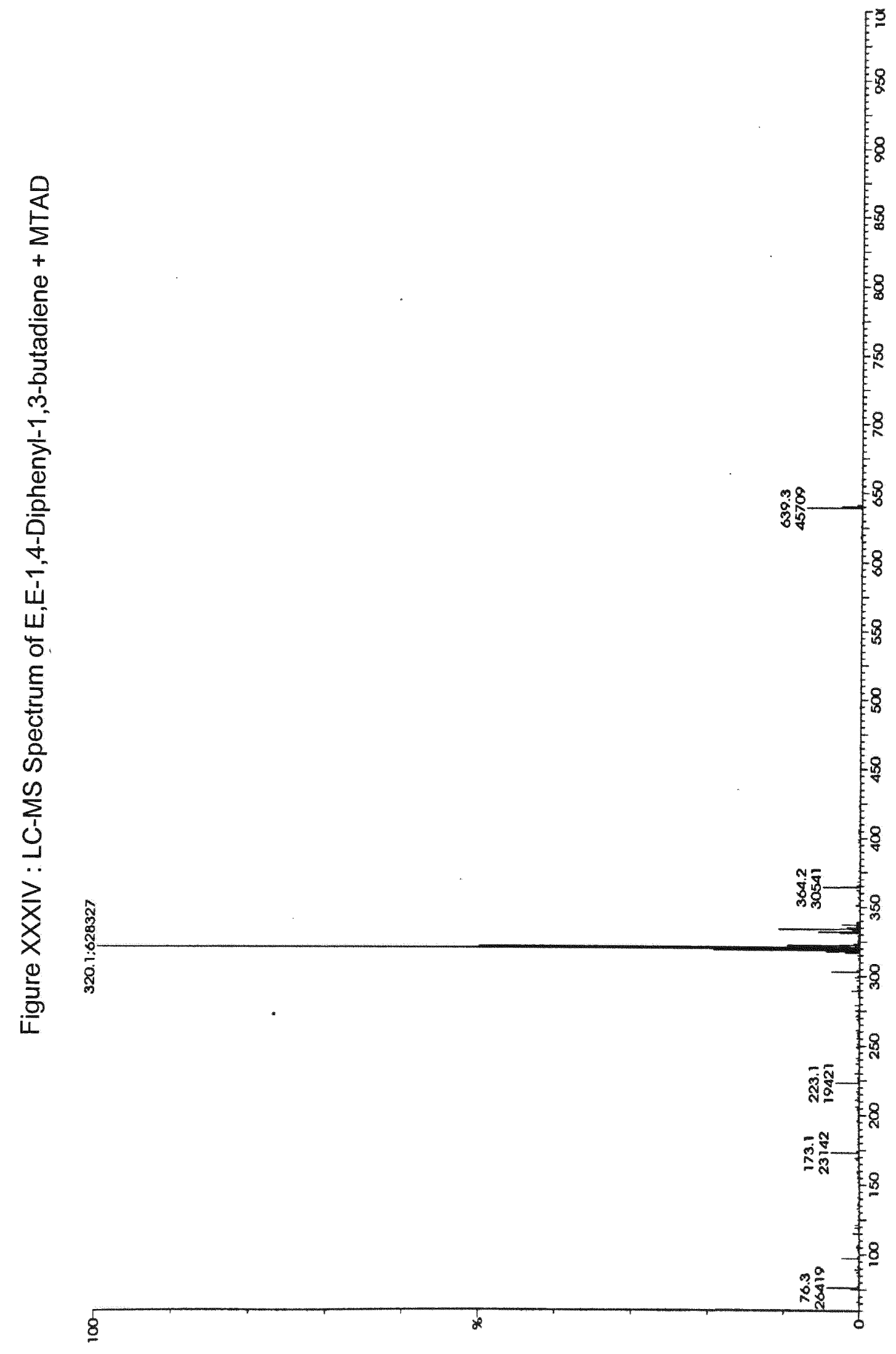



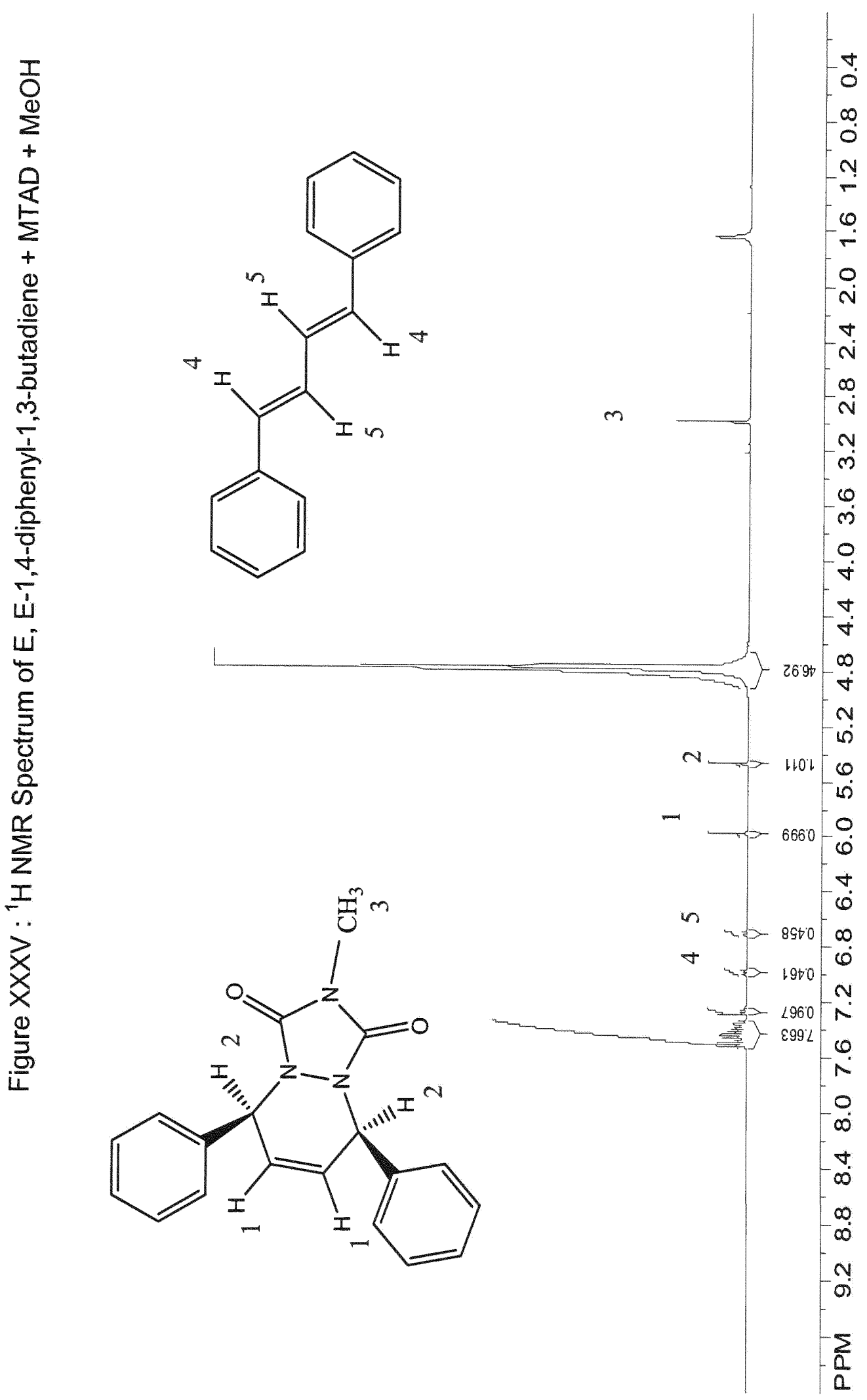


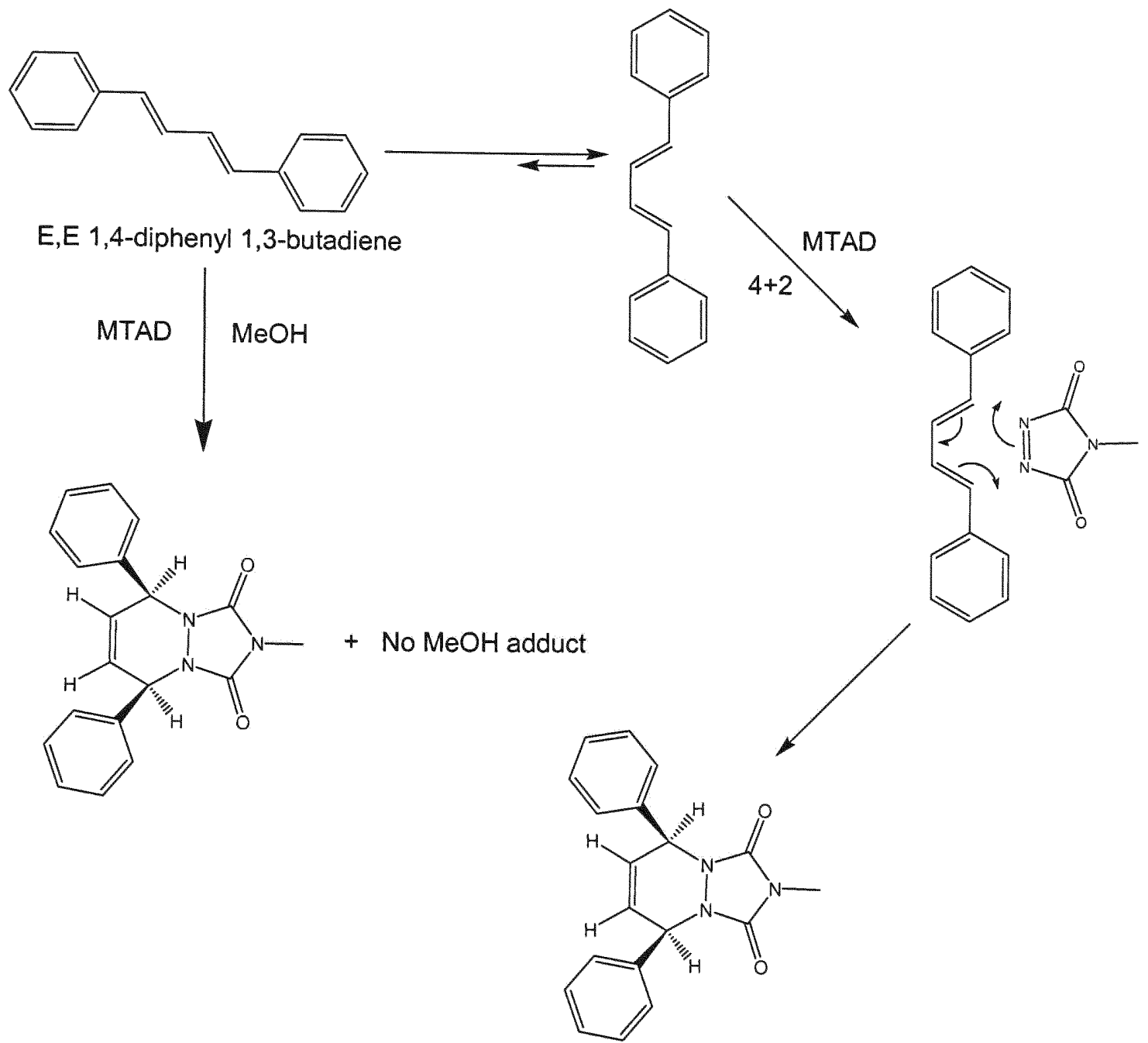

Cis $4+2$ adduct 


\subsubsection{Reaction of 4-Methyl-1,2,4-triazoline-3,5-dione (MTAD) with E,Z-1,4- Diphenyl-1,3-butadiene}

Experimental: E,Z-1,4-Diphenyl-1,3-butadiene (0.5 mg, 0.002427 mmoles) was transferred to a NMR tube and $0.5 \mathrm{ml}$ of $\mathrm{CDCl}_{3}$ was added. $0.5 \mathrm{mg}, 0.0442$ mmoles MTAD was transferred to a small test tube to which $1 \mathrm{ml}$ of $\mathrm{CDCl}_{3}$ was added. Each test tube was placed in an ice-water bath for five minutes and then the MTAD/CDCl 3 was added dropwise to the E,Z-1,4-Diphenyl-1,3-butadiene $/ \mathrm{CDCl}_{3}$ solution using a Pasteur pipet. As the pink solution of $\mathrm{MTAD} / \mathrm{CDCl}_{3}$ was added to the olefin, the pink color disappeared slowly; indicating that a reaction was taking place. When all of the solution was transferred, the solution remained dark pink for $\sim 5$ minutes, and then the color faded. Then ${ }^{1} H$ NMR spectrum was run.

Results: We have observed $80 \%$ trans and $20 \%$ cis Diels-Alder (4+2) adducts. Wee did not observe any " $2+2$ " adduct or isomerization.

\section{MeOH trapping attempt:}

E,Z-1,4-Diphenyl-1,3-butadiene ( $0.5 \mathrm{mg}, 0.002427 \mathrm{mmoles})$ was transferred to a NMR tube and $0.5 \mathrm{ml}$ of $\mathrm{CDCl}_{3}$ was added. One drop of $\mathrm{MeOH}$ was added to the $\mathrm{E}, \mathrm{Z}-1,4-$ Diphenyl-1,3-Butadiene/ $\mathrm{CDCl}_{3}$ solution. $0.5 \mathrm{mg}, 0.0442 \mathrm{mmoles}$ MTAD was transferred to a small test tube to which $1 \mathrm{ml}$ of $\mathrm{CDCl}_{3}$ was added. Each test tube was placed in an ice-water bath for five minutes and then the MTAD/CDCl 3 was added dropwise to the E,Z-1,4-Diphenyl-1,3-Butadiene $/ \mathrm{CDCl}_{3} / \mathrm{MeOH}$ 
solution using a Pasteur pipet. As the pink solution of $\mathrm{MTAD} / \mathrm{CDCl}_{3}$ was added to the olefin, the pink color disappeared; indicating that a reaction was taking place. When all of the solution was transferred, the solution remained dark pink for $\sim 5$ minutes, and then the color faded. Then ${ }^{1} \mathrm{H}$ NMR spectrum was run. No new peaks were observed; no intermediates were trapped. This procedure was repeated at $-78^{\circ} \mathrm{C}$ using a dry ice/acetone bath, and with $\mathrm{CD}_{2} \mathrm{Cl}_{2}$ as the solvent. Even then we have not observed any new peaks. No E,E-1,4-Diphenyl-1,3butadiene was observed during the reaction. We tried to trap radicals by using $\mathrm{O}_{2}$ but no peaks corresponding to radical intermediate were observed. 


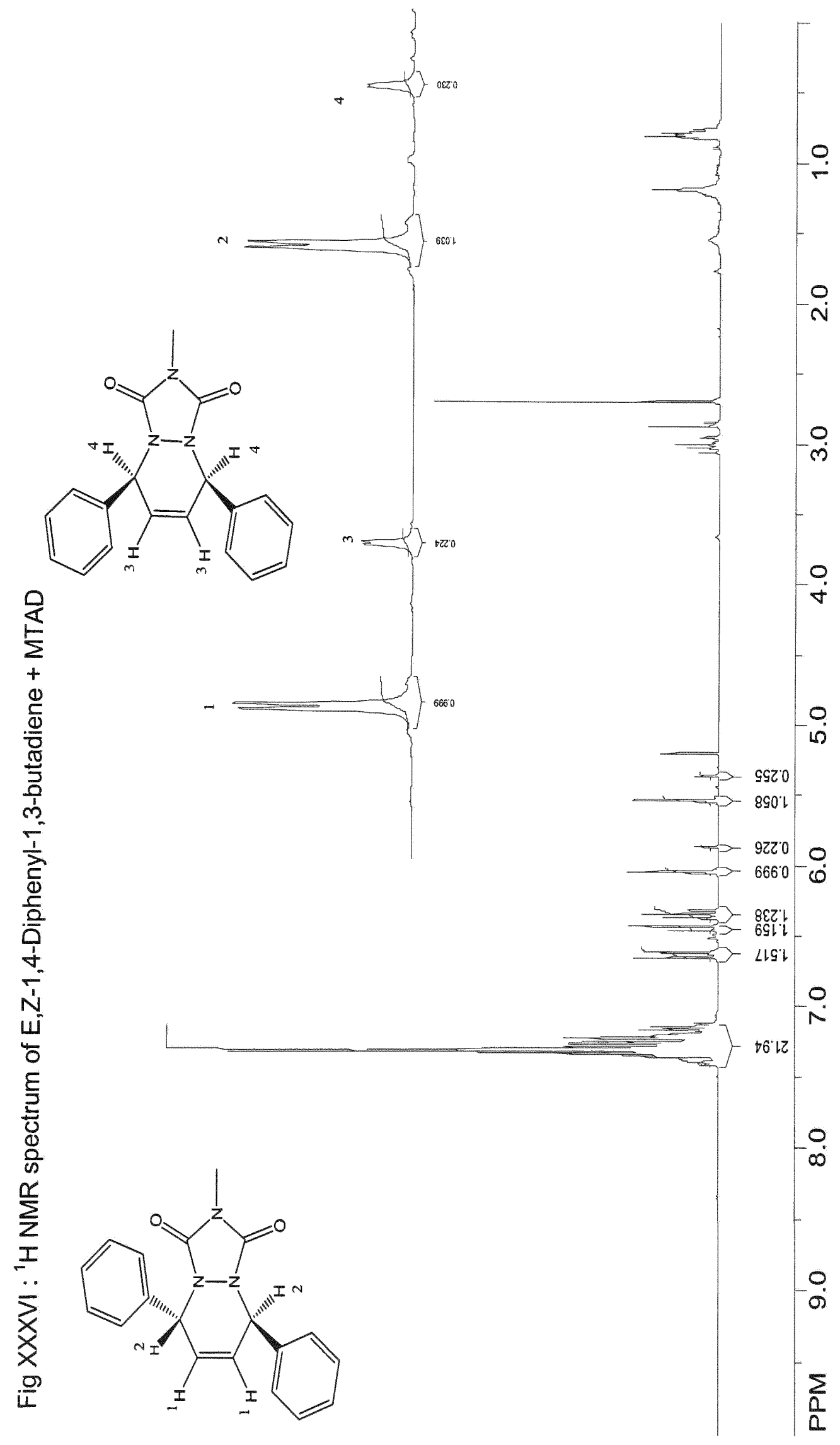



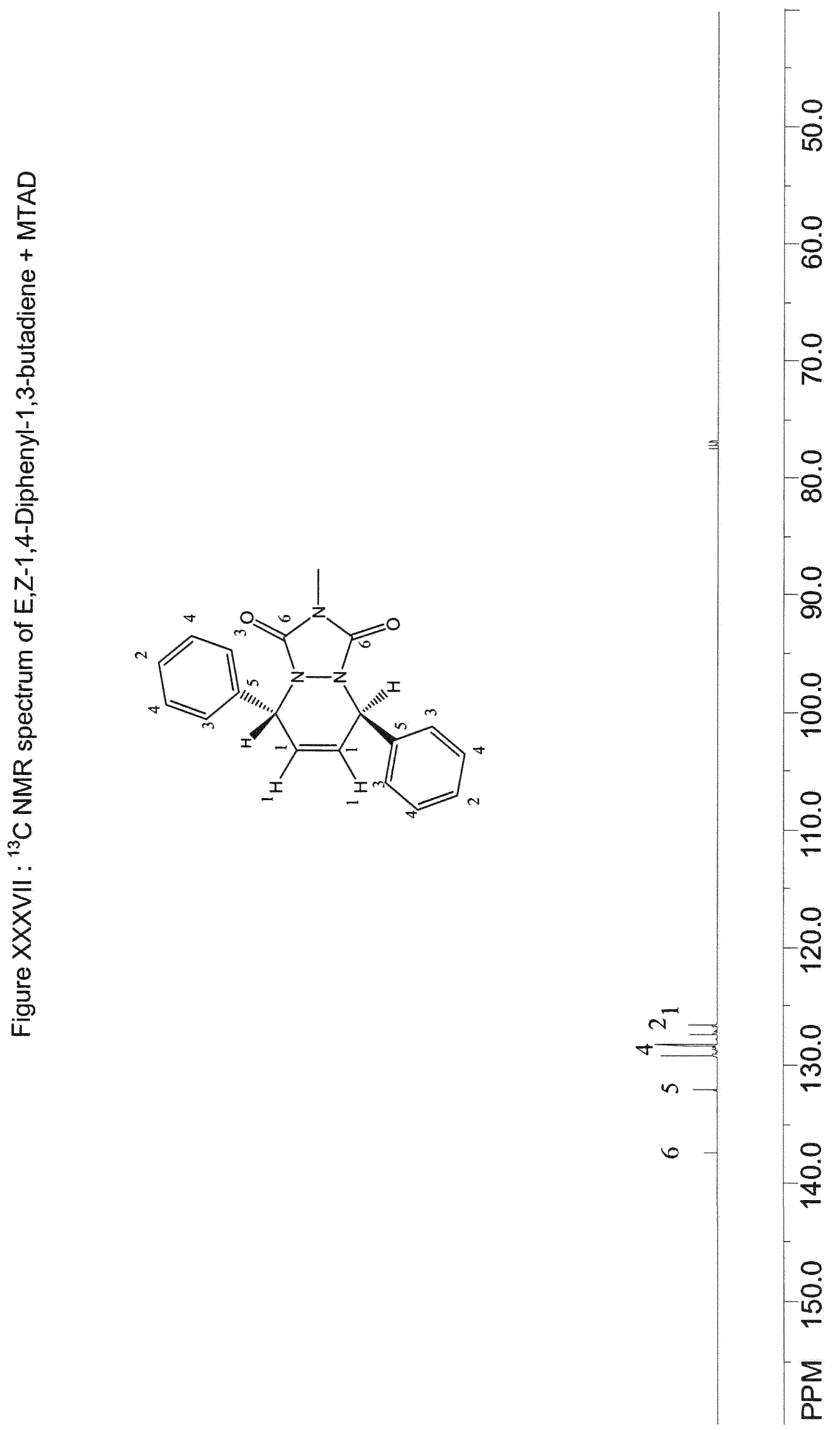
Mechanism of the MTAD reaction with E,Z-1,4-diphenyl-1,3-butadiene:

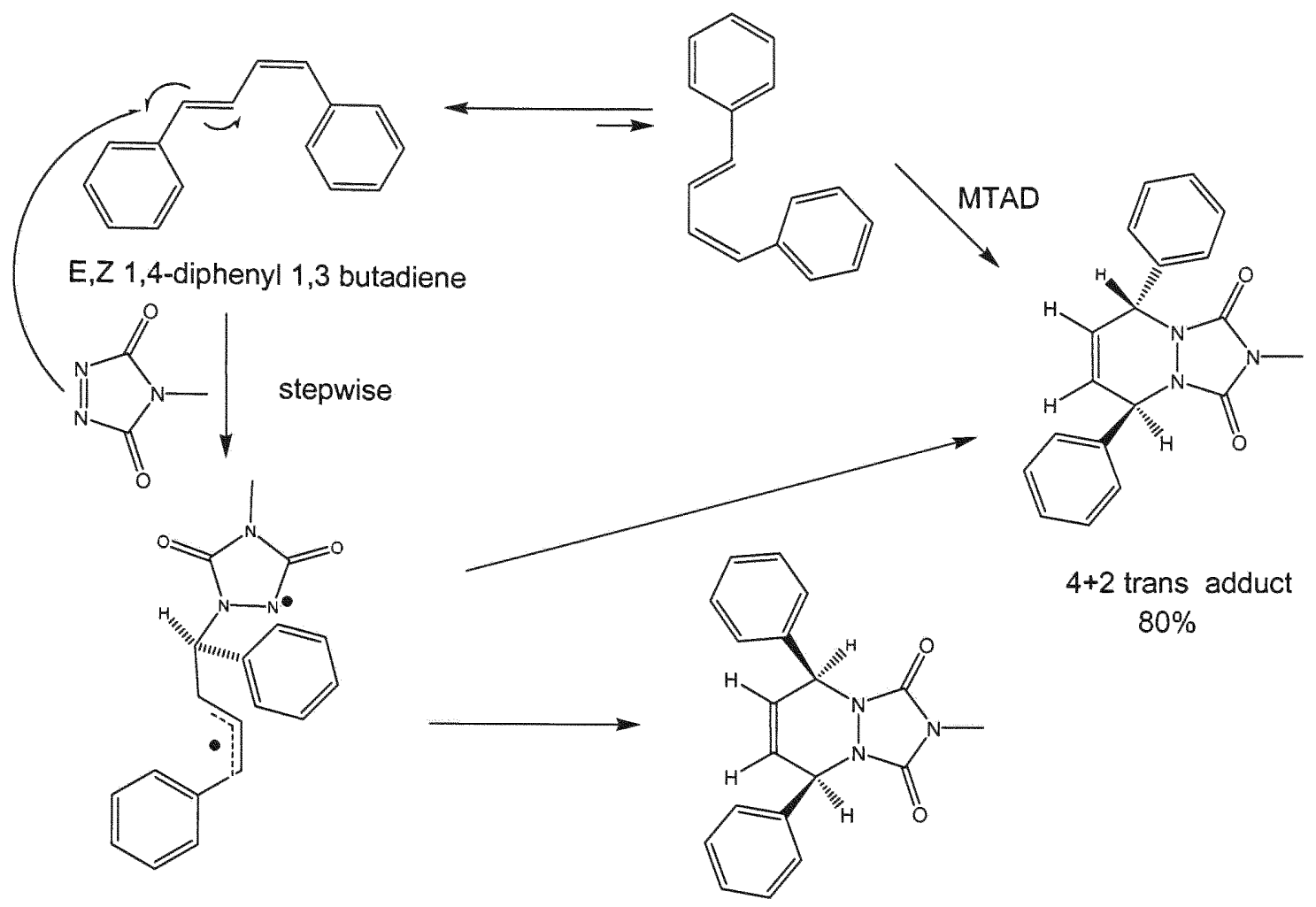

$4+2$ cis adduct

$20 \%$ 
Fig XXXVIII : ${ }^{1} \mathrm{H}$ NMR spectrum of E,Z-Diphenyl 1,3-Butadiene + MTAD + MeOH

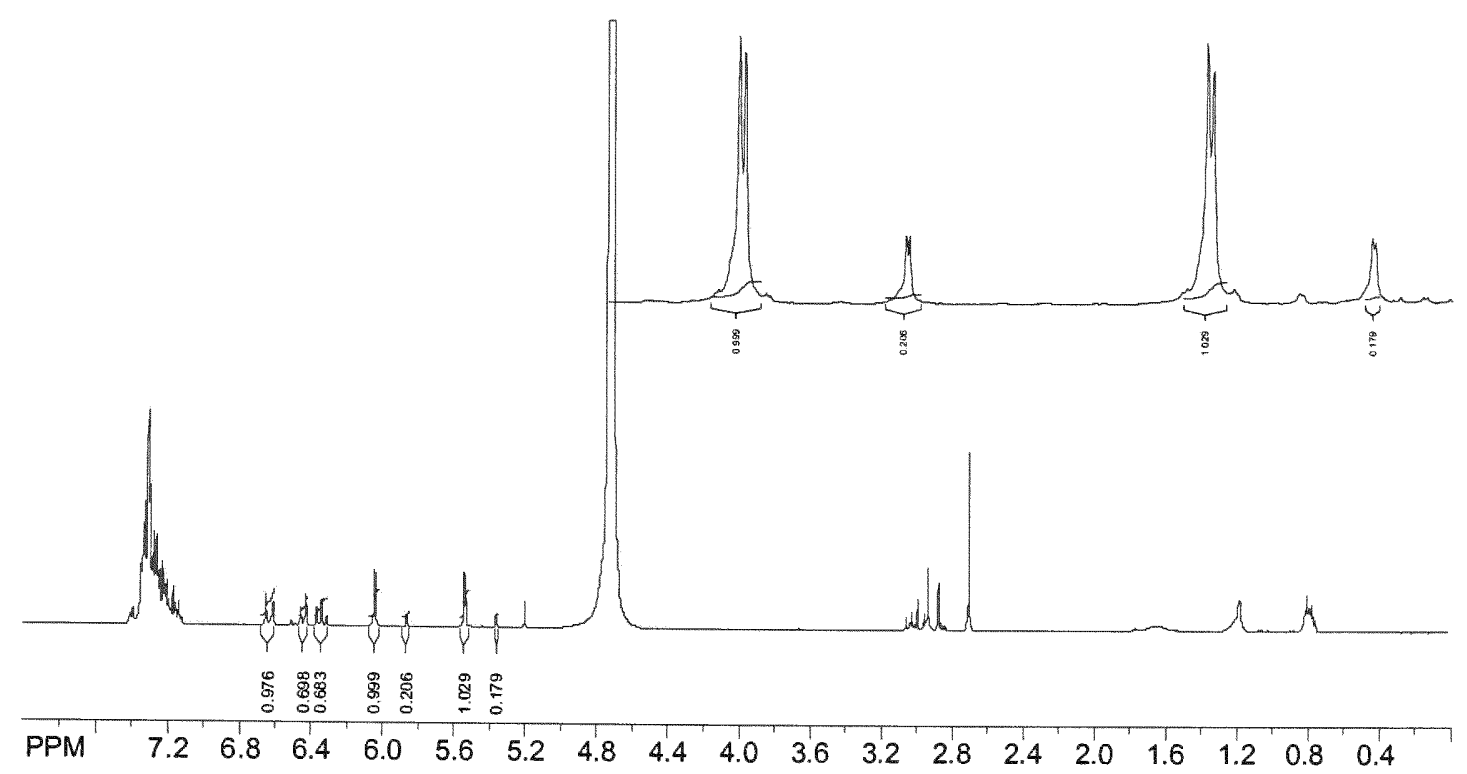




\subsubsection{Reaction of 4-Methyl-1,2,4-triazoline-3,5-dione (MTAD) with Z,Z-1,4- Diphenyl-1,3-butadiene}

Experimental: Z,Z-1,4-Diphenyl-1,3-Butadiene (0.5 mg, 0.002427 mmoles) was transferred to a NMR tube and $0.5 \mathrm{ml}$ of $\mathrm{CDCl} 3$ was added. $0.5 \mathrm{mg}, 0.0442$ mmoles MTAD was transferred to a small test tube to which $1 \mathrm{ml} \mathrm{of} \mathrm{CDCl}_{3}$ was added. Each test tube was placed in an ice-water bath for five minutes and then the $\mathrm{MTAD} / \mathrm{CDCl}_{3}$ was added dropwise to the $\mathrm{Z,Z-1,4-Diphenyl-1,3-Butadiene}$ $/ \mathrm{CDCl}_{3}$ solution using a Pasteur pipet. As the pink solution of $\mathrm{MTAD} / \mathrm{CDCl}_{3}$ was added to the olefin, the pink color disappeared very slowly; indicating that a reaction was taking place. When all of the solution was transferred, the solution remained dark pink. Then ${ }^{1} \mathrm{H}$ NMR spectrum was run.

Results: Our results have shown that reaction of Z,Z-1,4-Diphenyl-1,3-butadiene with 4-Methyl-1,2,4-triazoline-3,5-dione (MTAD) gives $50 \%$ cis and $50 \%$ trans Diels-Alder (4+2) adducts. We did not observe any "2+2" or isomerization.

\section{MeOH trapping attempt:}

Z, Z-1,4-Diphenyl-1,3-Butadiene (0.5 mg, 0.002427 mmoles) were transferred to a NMR tube and $0.5 \mathrm{ml}$ of $\mathrm{CDCl}_{3}$ were added. One drop of $\mathrm{MeOH}$ were added to the Z, Z-1,4-Diphenyl-1,3-butadiene $/ \mathrm{CDCl}_{3}$ solution. $0.5 \mathrm{mg}, 0.00424$ MTAD was transferred to a small test tube to which $1 \mathrm{ml}$ of $\mathrm{CDCl}_{3}$ was added. Each test tube was placed in an ice-water bath for five minutes and then the MTAD/CDCl 
was added dropwise to the Z, Z-1,4-Diphenyl-1,3-butadiene $/ \mathrm{CDCl}_{3} / \mathrm{MeOH}$ solution using a Pasteur pipet. As the pink solution of MTAD/CDCl 3 was added to the olefin, the pink color disappeared; indicating that a reaction was taking place. When all of the solution was transferred, the solution remained dark pink for $\sim 5$ minutes, and then the color faded. Then ${ }^{1} \mathrm{H}$ NMR spectrum was run. No new peaks were observed; no intermediates were trapped. This procedure was repeated at $-78{ }^{\circ} \mathrm{C}$ using a dry ice/acetone bath, and with $\mathrm{CD}_{2} \mathrm{Cl}_{2}$ as the solvent. Even then we have not observed any new peaks. 


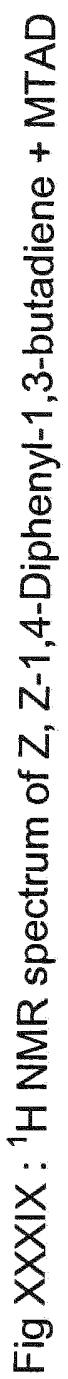

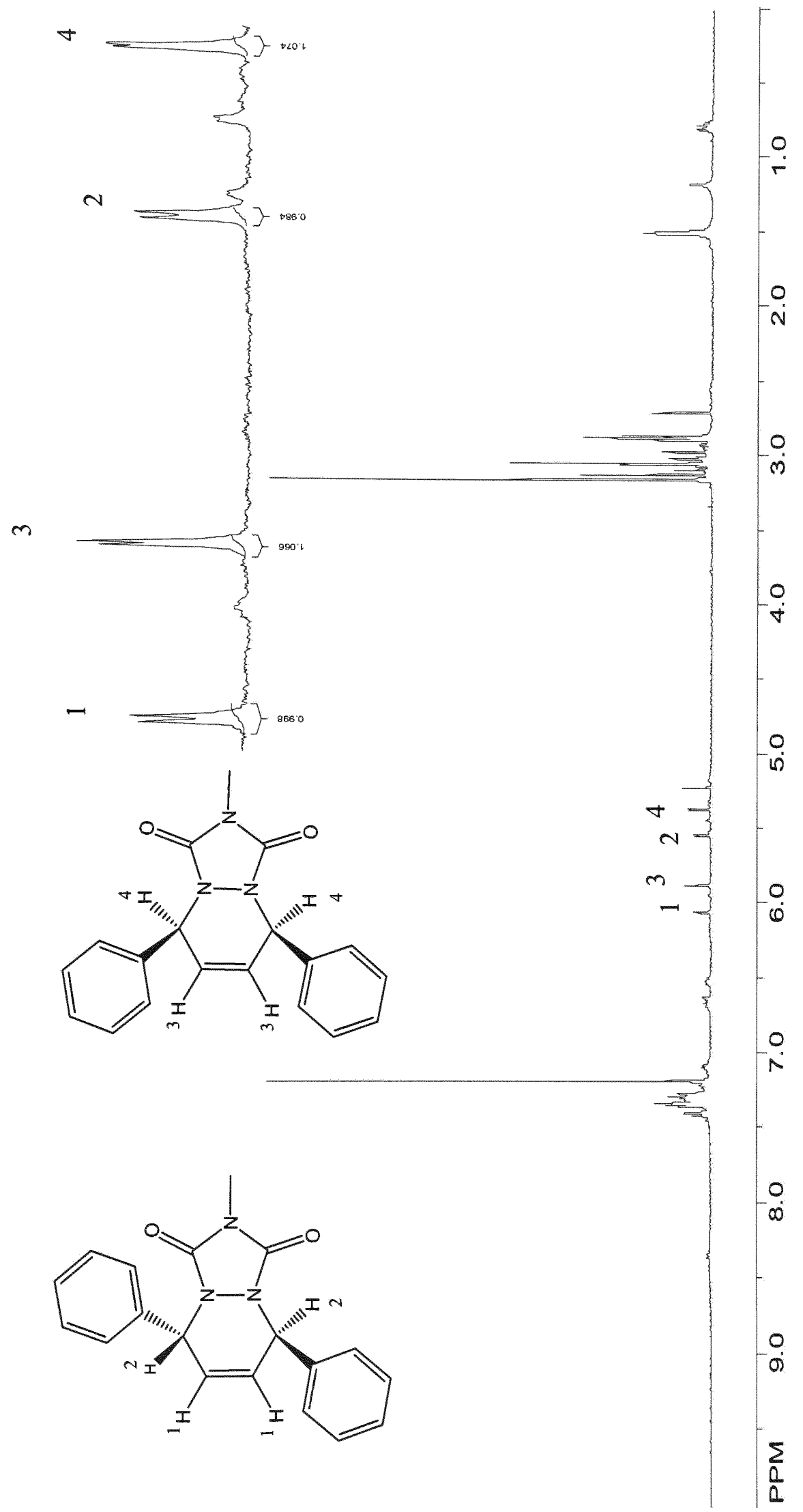



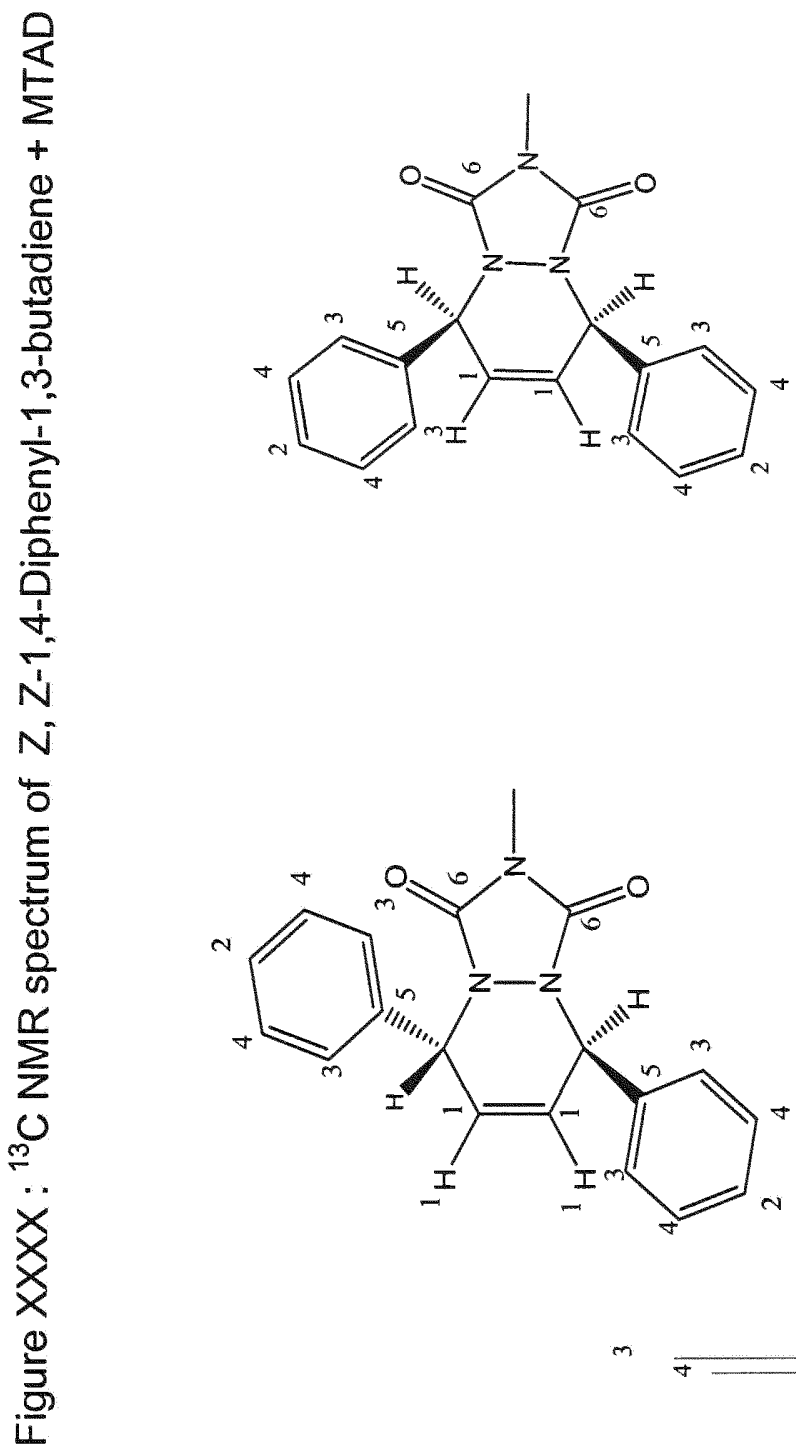

$\infty$

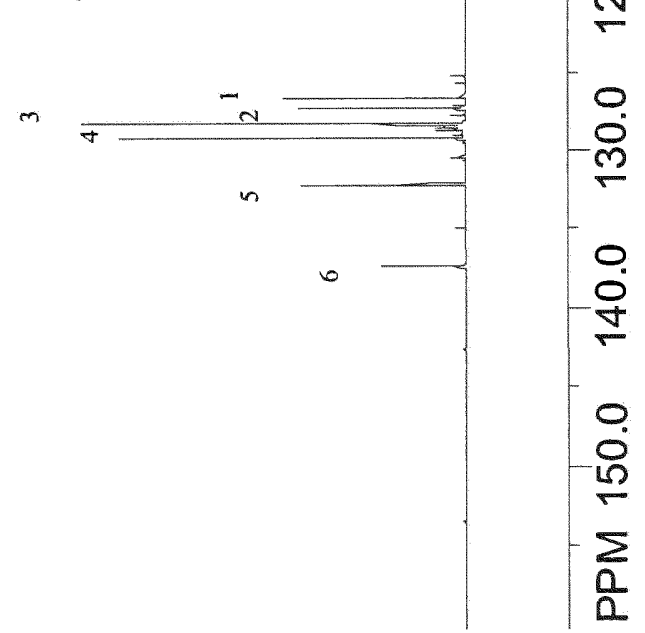




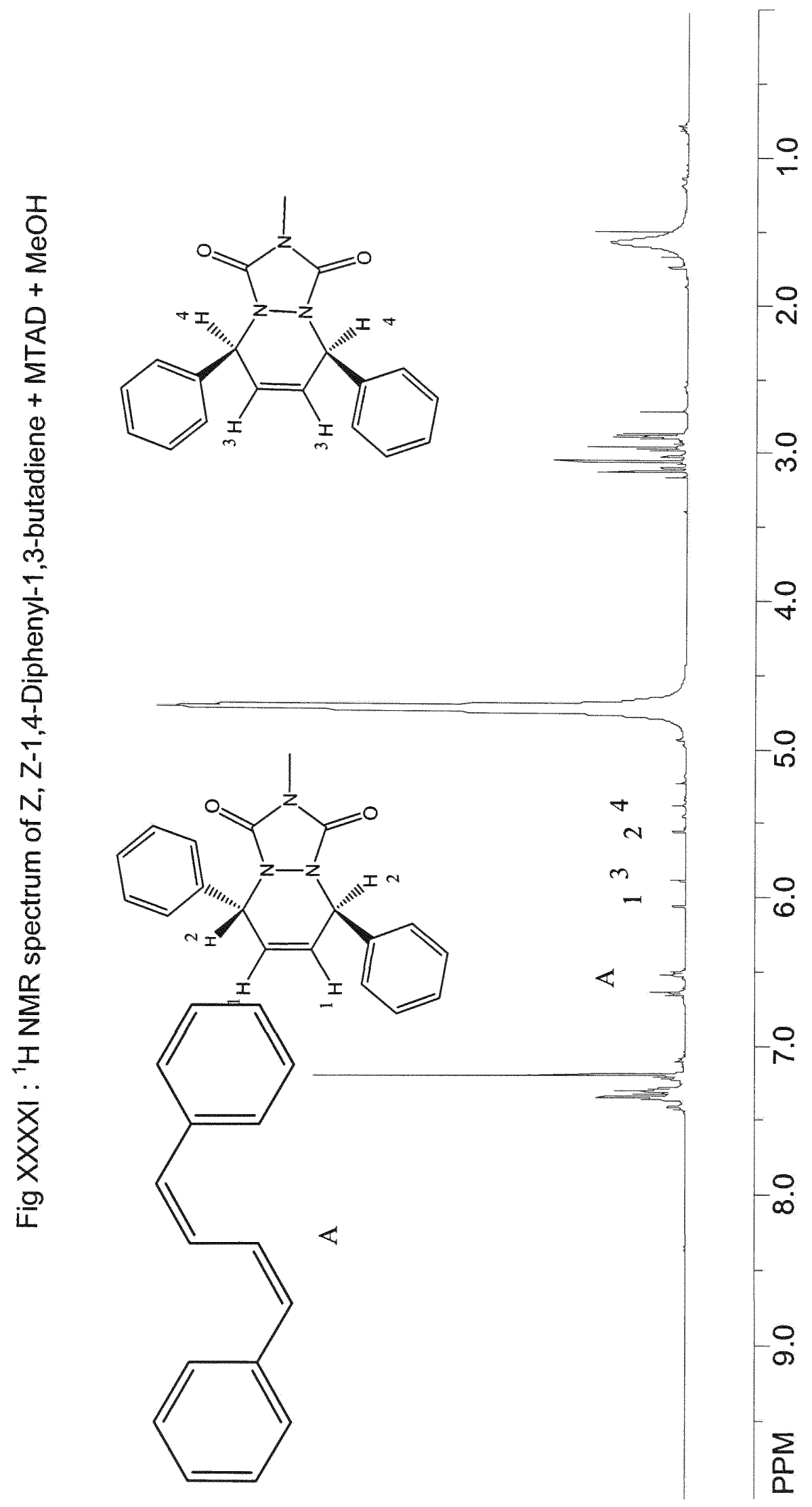


Mechanism of the MTAD reaction with Z,Z-1,4-diphenyl-1,3-butadiene:

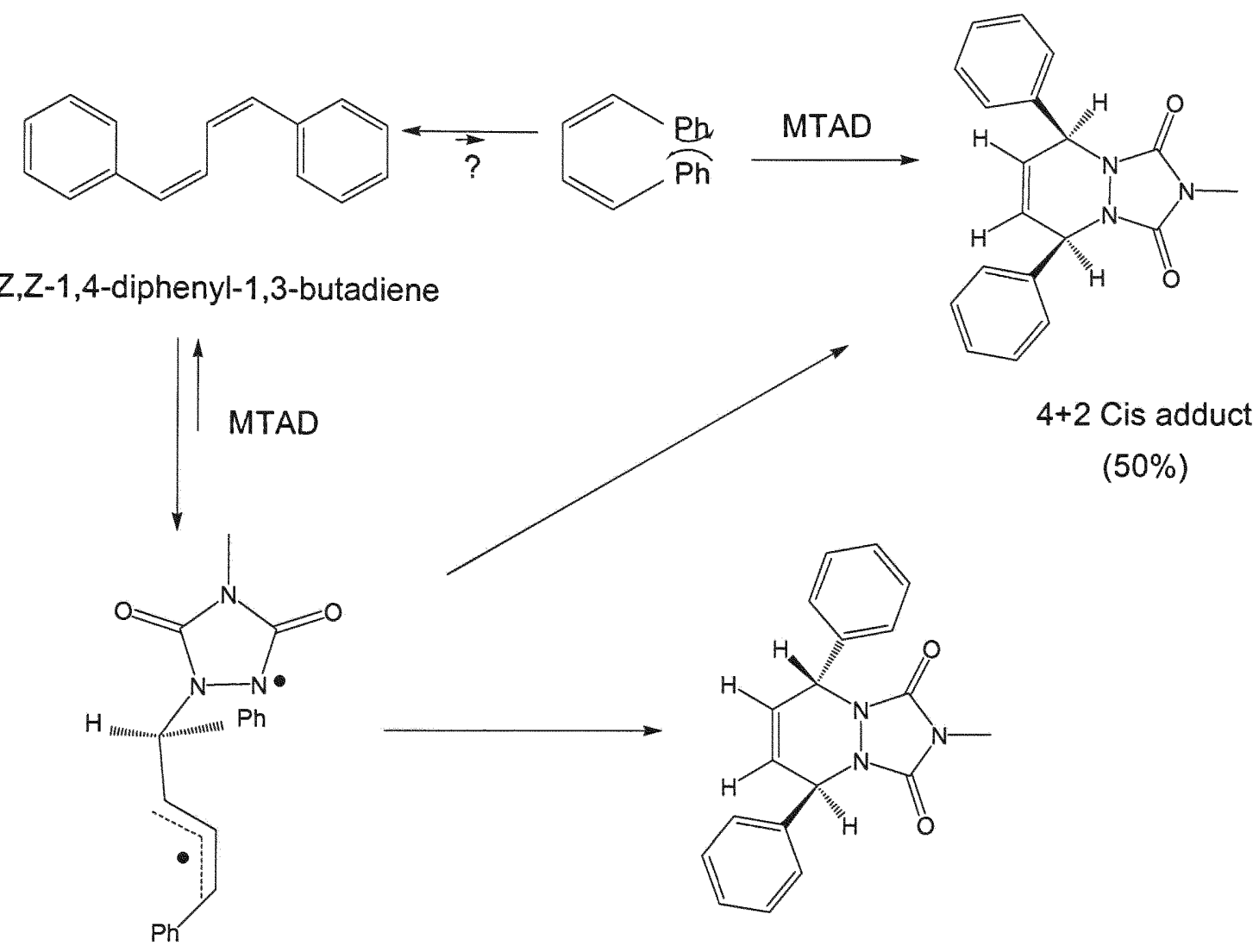

$4+2$ trans adduct

$(50 \%)$ 
Summary of results of MTAD reactions with reaction probes:

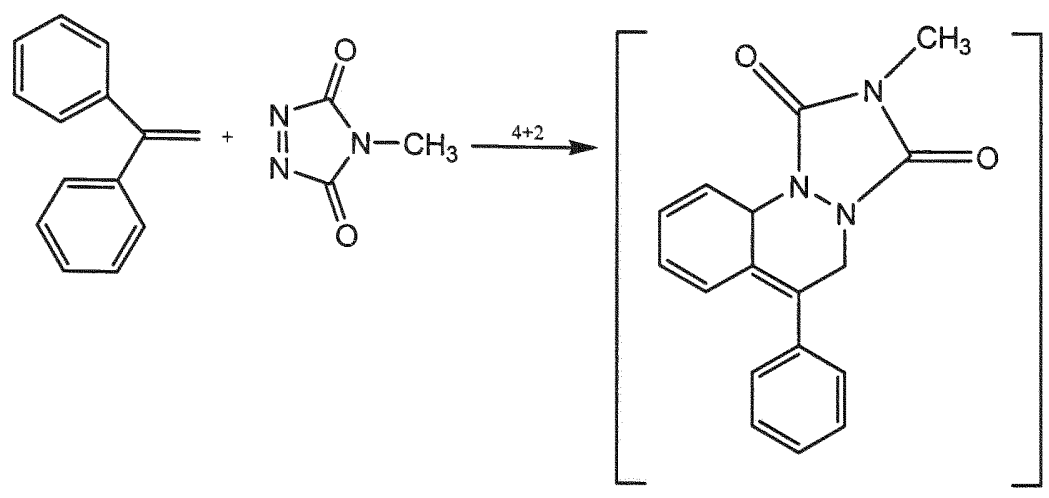
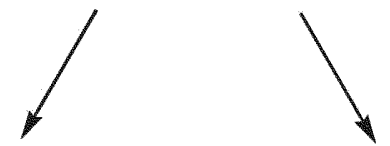<smiles>[H][Y]1([H])C(c2ccccc2)c2ccccc2-n2c(=O)n(C)c(=O)n21</smiles>

$4+2 /$ ene adduct

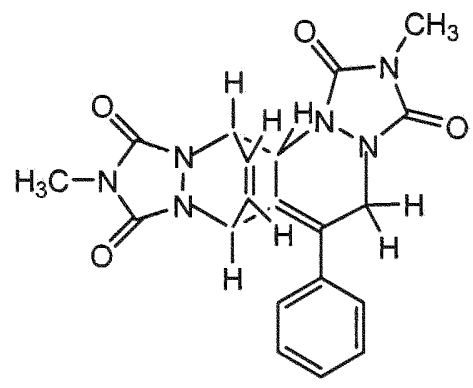

$4+2 / 4+2$ adduct

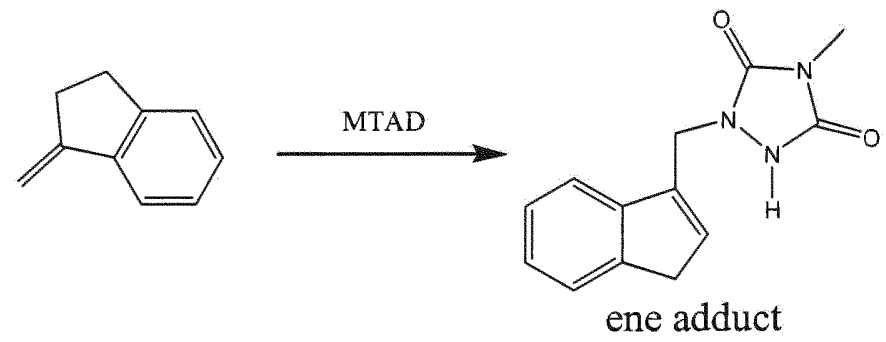<smiles>C=C1c2ccccc2-c2ccccc21</smiles>
MTAD

Complex mixture 


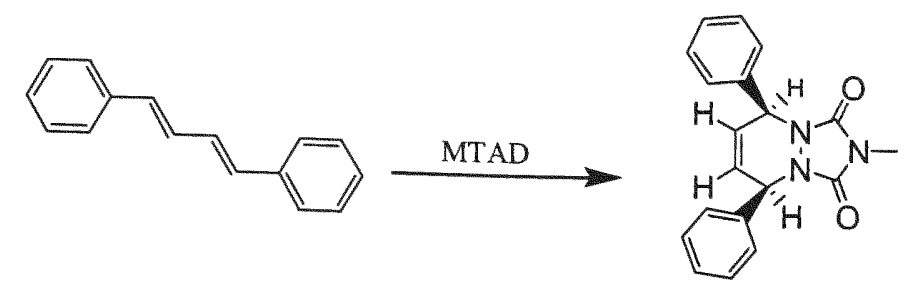

$4+2$ cis adduct $(100 \%)$
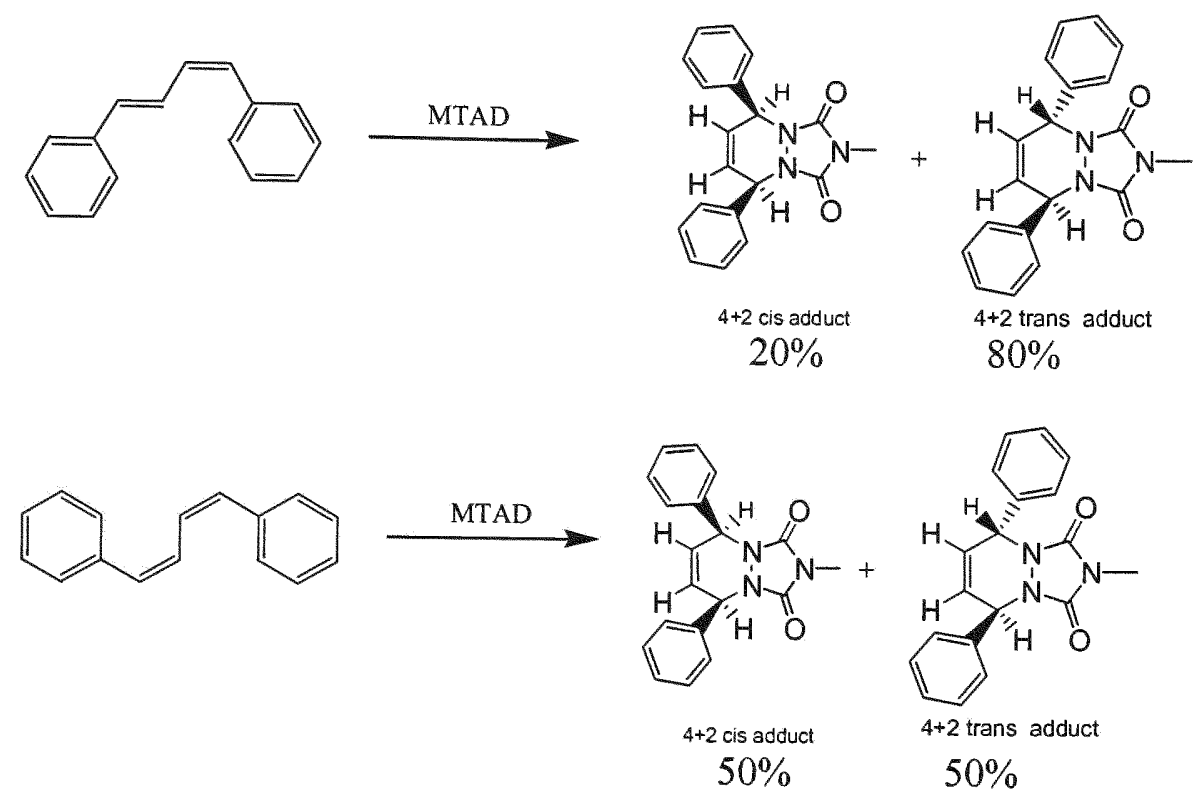

\begin{tabular}{|c|c|c|c|c|}
\hline Substrates & $\begin{array}{l}\text { cis- } 4+2 \\
\text { adduct }\end{array}$ & $\begin{array}{c}\text { trans }-4+2 \\
\text { adduct }\end{array}$ & $\begin{array}{c}2+2 \\
\text { adduct }\end{array}$ & ene \\
\hline $\begin{array}{l}E, E-1,4 \text {-diphenyl- } \\
\text { 1,3-butadiene }\end{array}$ & $100 \%$ & $0 \%$ & $0 \%$ & not observed \\
\hline $\begin{array}{l}\text { E,Z-1,4-diphenyl- } \\
\text { 1,3-butadiene }\end{array}$ & $20 \%$ & $80 \%$ & $0 \%$ & not observed \\
\hline $\begin{array}{l}\text { Z,Z-1,4-diphenyl- } \\
\text { 1,3-butadiene }\end{array}$ & $50 \%$ & $50 \%$ & $0 \%$ & not observed \\
\hline
\end{tabular}

* Exceptional results of MTAD reaction with 1,1-diphenylethylene (2:1) ratio

\begin{tabular}{|l|c|c|}
\hline Substrate & $4+2 / 4+2$ adduct & $4+2 /$ ene adduct \\
\hline $\begin{array}{l}1,1- \\
\text { Diphenylethylene }\end{array}$ & $50 \%$ & $50 \%$ \\
\hline
\end{tabular}




\section{Conclusions}

E,E-1,4-diphenyl-butadiene reacts with ${ }^{1} \mathrm{O}_{2}$ via a Diels-Alder addition to form the corresponding "cis" endoperoxide (99\%) and a small amount of " $2+2$ " product $(\sim 1 \%)$. The $E, Z$ and $Z, Z$ isomers did not exhibit any reaction with ${ }^{1} \mathrm{O}_{2}$ under our reaction conditions. These results suggest that ${ }^{1} \mathrm{O}_{2}$ reacts via a concerted reaction with $E, E-1,4$-diphenyl-butadiene and the difference in ${ }^{1} \mathrm{O}_{2}$ reactivity among these isomers is likely the result of the population of the s-cis conformation, which is restricted for the $E, Z$ and $Z, Z$ isomer (inhibiting the DielsAlder reaction). Although MTAD is often used as a singlet oxygen mimic it exhibited dramatically different reactivity than ${ }^{1} \mathrm{O}_{2}$ towards the substrates used in our study, with the exception of fluorenene. Fluorenene gives complex reaction mixture including the ene products upon react with singlet oxygen and MTAD. MTAD reacts with 1,1-diphenyl ethylene to form a mixture of $4+2 / 4+2$ and 4+2/ene 2:1 adducts. Unlike singlet oxygen, MTAD reacts with all the 1,4diphenyl-butadiene isomers; $E$, $E$ yields the stereospecific Diels-Alder Adduct; $E$, $Z$ and $Z, Z$ yield a mixture of cis and trans Diels-Alder adducts. We propose that the $E, E$ reacts with the s-cis conformation via a concerted addition, while $E, Z$ and $Z, Z$ cannot populate the s-cis conformation and hence react via radical reaction leading to non-stereospecific products. Our results clearly demonstrate that electrophile and substrate have a pronounced effect of the reaction pathways and caution must be used when using MTAD a model for singlet oxygen. 
The exceptional high yields (99\%) of endo-peroxide produced from the reaction of ${ }^{1} \mathrm{O}_{2}$ with $E, E-1,4$-diphenyl-1,3-butadiene indicate that this procedure may be valuable for making antimalarials (i.e. Artemisinin from sweet wormwood, Artemisia annua). Endoperoxides are being used for the treatment of malaria in many parts of the world.

Oxidation of vitamins is a significant aspect of photooxidative degradation of foods. Our models process the same basic structural features as vitamin $A, B_{2}$ (riboflavin), $B_{6}$ (pyridoxine), $B_{12}, C, D, E$. Degradation of these vitamins by light and oxygen should correlate to our experimental results. Exposure of milk to daylight for periods longer than 30 mins produces an objectionable flavor commonly known as "sunlight" flavor can be explained by the generation of singlet oxygen in milk by photosensitization by the potent natural photosensitizer, riboflavin. The caroteniods, natural antioxidants are excellent quenchers of singlet oxygen and/or excited sensitizers and can therefore confer protection on adjacent chemical or biochemical systems. Our study provides the fundamental mechanistic info about the photooxidation of the conjugated systems and should help to assess the impact of singlet oxygen reactions in the environment and living organisms. 


\section{References:}

1. Wasserman, H. H and Murray, R. W., Eds.; Singlet Oxygen. Academic Press: London, UK, 1979; Vol. 40, p 287.

2. Frimer, A. A. and L. M. Stephenson. The singlet oxygen ene reaction. Singlet O2, Vol. II: Reaction Modes and Products. Part I, A. A. Frimer., Eds., CRC Press, Boca Raton, FL, 1985, 67-91.

3. Horspool, W. M. and Pill-Soon, Song: CRC Handbook of Organic Photochemistry and Photobiology. CRC Press, Boca Raton, 1995; 1407.

4. Atom Yee, W.; Stephan, J.; Hug, J. S.; and Kliger, D. S. Direct and sensitized photoisomerization of 1,4-diphenylbutadienes. J. Am. Chem., Soc. $1988,110,2164-69$.

5. Kyung Duk, and O'Shea K.E. The reaction of N-Methyl-1,2,4-triazoline-3,5dione with tetracyclopropylethylene. Formation of an unusual meso-ionic product and its rearrangement to the diazetidine. J. Am. Chem. Soc. 2004, $126,700-701$.

6. Krishnamoorthy, G.; Schieffer S.; Pescatore, J.; Ulsh, R.; Liu, R. S. H.; and Liu. Photoreactions of cisoid 1,4-diphenyl-1,3-butadienes. Direct irradiation in solution and in low temperature organic glass. J. Photochem. Photobiol. Sci., 2004, 3, 1047-51.

7. Pinckard, J. H.; Wille, B.; and Zechmeister. L. A comparative study of the three stereoisomeric 1,4-Diphenylbutadienes. J. Am. Chem. Soc., 1948, $70,1938-44$.

8. Roubelakis M. M.; Vougioukalakis G. C.; Angelis Y. S.; and Orfanopoulos $M$. Solvent-dependent changes in the ene reaction of rtad with alkenes: the cyclopropyl group as a mechanistic probe. Org. Lett., 2006, 8, 39-42.

9. Singleton, D. A.; Hang, C. Isotope effects and the mechanism of triazolinedione ene reactions. aziridinium imides are innocent bystanders. J. Am. Chem. Soc., 1999, 121, 11885-11893.

10. Kim, D. K.; O'Shea, K. E. The reaction of N-methyl-1,2,4-triazoline-3,5dione with tetracyclopropylethylene. Formation of an unusual meso-ionic product and its rearrangement to the diazetidine. J. Am. Chem. Soc., 2004, $126,7000-7001$. 
11. Baran, P. S.; Guerrero, C. A.; Corey, E. Short, The first method for

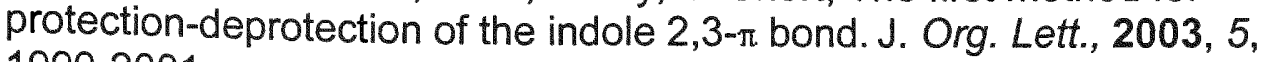
1999-2001.

12. Baran, P. S.; Guerrero, C. A.; Corey, E. J. Enantioselective total synthesis of okaramine N. J. Am. Chem. Soc., 2003, 125, 5628-5629.

13. Adam, W.; Degen, H. G.; Krebs, O.; Saha-Möller, C. R. Efficient $\pi$-facial control in the ene reaction of nitrosoarene, triazolinedione, and singlet oxygen with tiglic amides of the bornane-derived sultam as chiral auxiliary: an economical synthesis of enantiomerically pure nitrogen- and oxygenfunctionalized acrylic acid derivatives. J. Am. Chem. Soc., 2002, 124, 12938-12939.

14. Orfanopoulos, M.; Smonou, I.; Foote, C. S. Intermediates in the ene reactions of singlet oxygen and $\mathrm{N}$-phenyl-1,2,4-triazoline-3,5-dione with olefins. J. Am. Chem. Soc. 1990, 112, 3607-3614.

15. Chen. J. S.; Houk, K. N.; Foote, C. S. The nature of the transition structures of triazolinedione ene reactions. J. Am. Chem. Soc., 1997, 119, 9852-9855.

16. Adam, W.; Krebs, O.; Orfanopoulos, M.; Stratakis, M.; Vougioukalakis, G. C. Intramolecular and intermolecular kinetic isotope effects (KIE) in the nitrosoarene ene reaction: experimental evidence for reversible intermediate formation. J. Org. Chem., 2003, 68, 2420-2425.

17. Jensen. F.; Foote. C.S.; Reaction of 4-Phenyl-1,2,4-triazoline-3,5-dione with substituted butadienes. A nonconcerted diels-alder reaction. J. Amer. Chem. Soc., 1987, 109, 6376-6385.

18. O'Shea. K. E.; Foote, C. S. Chemistry of singlet oxygen. 51. Zwitterionic intermediates from 2,4-Hexadienes. J. Am. Chem. Soc., 1988, 110, 71677170 .

19. Canva, G. P.; Canva, J.J. The degradation of rubber and antioxidant action - a possible role of singlet oxygen. Rubber J., 1971, 36.

20. Carlsson, D. J.; Wiles, D. M. Importance of singlet oxygen in the degradation of rubbers and plastics. Rubber Chem Technol., 1974, 49, 991.

21. Golub, M. A.; Pure Appl. Chem., 1980, 52, 305.

22. Kearns, D. R.; J. Am. Chem. Soc., 1969, 91, 6554-6563 
23. MacCallum, J. R.; Grassie, N., Eds., Reactions of singlet oxygen with polymers. In Developments in Polymer Degradation, Applied Science, London, $1977,237$.

24. Rabek, J. F.; Singlet oxygen mechanism of photooxidation of organic compounds. Wiadom. Chem., 1971, 293, 365, 435.

25. Rabek, J. F.; Ranby, B. Role of singlet oxygen in photooxidative degradation and photostabilization of polymers. Polym. Eng. Sci., 1975, 15, 40.

26. Rabek, J. F.; Ranby, B. The role of singlet oxygen in the photo-oxidation of polymers. Photochem. Photobiol., 1978,2 8, 557.

27. Ranby, B.; Rabek, J. F. Singlet oxygen reactions with synthetic polymers, in Singlet Oxygen: Reactions with Organic Compounds and Polymers, Ranby, B.; Rabek, J. F., Eds., John Wiley \& Sons, Chichester, 1978, 211.

28. Ranby, B.; Rabek, J. F. Photodegradation, Photooxidation and Photostabilization of Polymers. John Wiley \& Sons, London, 1975.

29. Ranby, B.; Rabek, J. F. Photooxidative degradation of polymers by singlet oxygen. In Ultraviolet light Induced reactions in Polymers. ACS Symp. No. 25, Labana. S.S., Ed., American Chemical Society, Washington, D.C., 1976, 391.

30. Scott, G., The role of singlet oxygen in the photooxidation of polymers-some practical considerations, in Singlet Oxygen: Reactions with Organic Compounds and Polymers, Ranby, B.; Rabek, J. F., Eds., John Wiley \& Sons, Chichester,1978, 230.

31. Rubaltelli, F. F.; Jori, G.; Rossi, E. Evidence of minor damage occurring during phototherapy: photoinduced covalent binding of bilirubin to serum albumin. Intensive Care Newborn.,1 981,3, 79.

32. Gollnick, K.; Schenck, G. O. Oxygen as a dienophile, in 1,4-Cyclo Addition Reactions: The Diels-Alder Reaction in Heterocycilc Synthesis, Vol. 8, Hamer, J.; Ed., Organic Chemistry Monograph, Academic Press, New York, 1967, 255.

33. Gollnick, K.; Type II photoxygenation reactions in solution, in Advances in Photochemistry, Vol. 6, Noyes, W. A., Jr.; Eds., John Wiley \& Sons, New York, 1968, 1. 
34. Foote, C. S., Photosensitized oxygenations and the role of singlet oxygen. Acc. Chem. Res., 1968, 1, 104.

35. Foote, C. S., Mechanisms of photosensitized oxidation. Science., 1968, $162,953$.

36. Foote, C. S., Photosensitized oxidation and singlet oxygen: consequences in biological systems. In Free Radicals in biology, Vol. 2, Pryor, W. A., Ed., Academic Press, New York, 1976, 85.

37. Foote, C. S., Photooxidation of biological model compounds, in Oxygen and Oxy-Radicals in Chemistry and biology, Rodgers, M. A. J. and Powers, E. L.; Eds., Academic Press, New York, 1981, 425.

38. Meyer, K., On catalytic oxidations. IV. Photochemical Oxidation of some ethylenic double bonds. J. Biol. Chem., 1933, 103, 597.

39. Gollnick, K.; Kuhn, H. J. Ene-reactions with singlet oxygen, in Singlet Oxygen, Wasserman, H. H. and Murray, R. W., Eds., Academic Press, new York, 1979, 287.

40. Rabek, J. F.; Ranby, B.; Studies on the photooxidation mechanism of polymers. I. Photolysis and photooxidation of polystyrene. J. Polym. Sci., A1, 1974, 12, 273.

41. Frimer, A. A. Singlet Oxygen Vol. IV, Polymers and Biomolecules, CRC Press, Boca Raton, FL, 1985.

42. Zolotoj, N. B.; Kuznecov, M. N.; Ivanov, V. B.; Karpov, G. V.; Skurat, V. E.; Shlapintokh, V. Yu. Study of reaction of rubber with singlet oxygen by mass-spectroscopy and spectroscopical methods. Vyskomol. Soedin. Ser. A, 1976, 18, 658 .

43. Rabek, J. F.; Shur, Y. J.; Ranby, B. Photosensitized singlet oxygen oxidation of polydienes, in Singlet Oxygen: Reactions with Organic Compounds and Polymers, Ranby, B. and Rabek, J. F., Eds., John Wiley \& Sons, Chichester, 1978, 264.

44. Rabek, J. F.; Ranby, B. Studies on the photoxidation mechanism of polymers. V. Oxidation of polybutadieneby singlet oxygen from microwave discharge and in dye-photosensitized reactions. J. Polym. Sci., A1, 1976, $14,1463$.

45. Rabek, J. F.; Lucki, J.; Ranby, B. Comparative Studies of reactions of commercial polymers with molecular oxygen, singlet oxygen, atomic 
oxygen, and ozone. I. Reactions with cis-1,4-polybutadiene. Eur. Polym. J., $1979,15,1089$.

46. Morsi, S. E.; Khalifa, W. M.; Zaki, A.; Al-Sayed, M. A.; Etaiw, S. H. Effect of singlet oxygen sensitizers and quenchers on the photo-oxidation of some unsaturated polymers. Polymer., 1981, 22, 942.

47. Kaplan, M. L.; Kelleher, P. G. Polydiene oxidations with singlet oxygen. Rubber Chem. Technol., 1972, 45, 423.

48. Kaplan, M. L.; Kelleher, P. G. Photo-oxidation of polymers without light. Oxidation of polybutadiene and an ABS polyblend with singlet oxygen. J. Polym. Sci., A1, 1970, 8, 3163.

49. Kaplan, M. L.; Kelleher, P. G. Oxidation of polymer surface with gas-phase singlet oxygen. Science., 1970, 169, 1206.

50. Ivanov, V. B.; Shlyapintokh, V. Ya. Singlet oxygen and photooxidation of polymers. J. Polym. Sci., A1, 1978, 16, 899.

51. Ivanov, V. B.; Kuznecova, M. I.; Angert, L. G.; Shlyapintokh, V. Ya. Singlet oxygen and oxidation of rubber. Dokl. Akad. Nauk SSSR., 1976, 228, 1144.

52. Golub, M. A.; Gemmer, E. V.; Rosenberg, M. L. Spectroscopic study of photosensitized oxidation of 1,4-polybutadiene. In Stabilization and Degradation of Polymers, Adv. Chem. Ser. No. 169. Allara, A. L.; Hawkins, W. L., Eds., American Chemical Society, Washington, D. C., 1977.

53. Breck, A. K.; Tayler, C. L.; Russel, K. E.; wan, J. K. S. Heterogeneous reactions of singlet oxygen with solid polymers, J. Polym. Sci., A1, 1974, 12,1505

54. Fieser, L. F.; Williamson K. L. Organic Experiments, fifth edition

55. Foote, C. S.; Chang, Y. C.; Denny, R. W. Chemistry of singlet oxygen. X. Carotenoid quenching parallels biological protection, J. Am. Chem. Soc. $1970,92,5216$ 


\section{Appendix :}

\section{Control Reactions for 1,4-Diphenyl-1,3-butadienes :}

Singlet oxygen reaction without sensitizer:

None of the isomers of 1,4-Diphenyl-1,3-butadienes give any product with oxygen without sensitizer.

Singlet oxygen reaction without $410 \mathrm{~nm}$ filter:

E, E-1,4-Diphenyl-1,3-butadiene gives endoperoxide produtct as expected. E, Z1,4-Diphenyl-1,3-butadiene and Z, Z-1,4-Diphenyl-1,3-butadiene also give endoperoxide product but they get isomerized to $\mathrm{E}, \mathrm{E}-1,4-$ Diphenyl-1,3-butadiene very soon. 


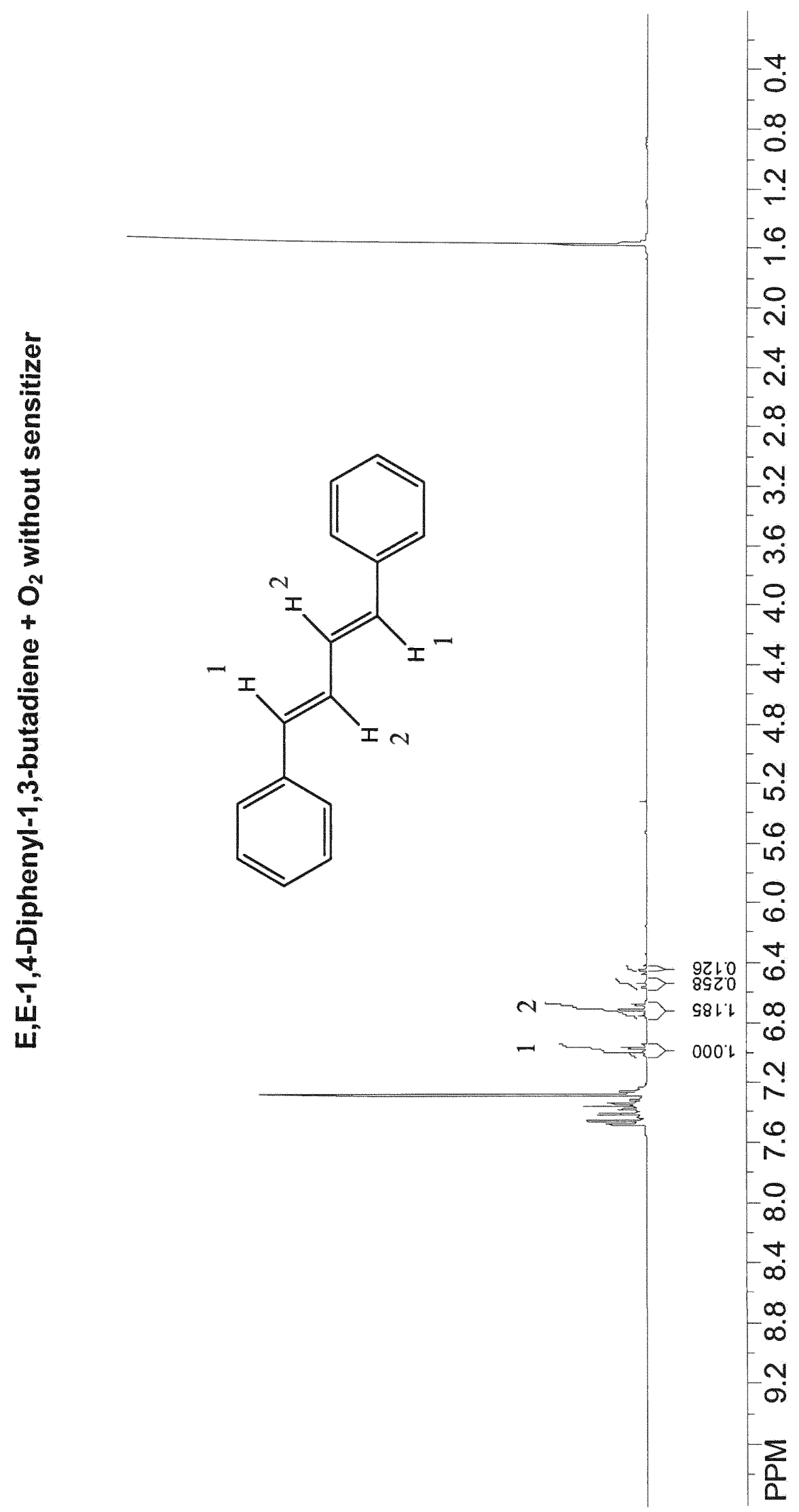




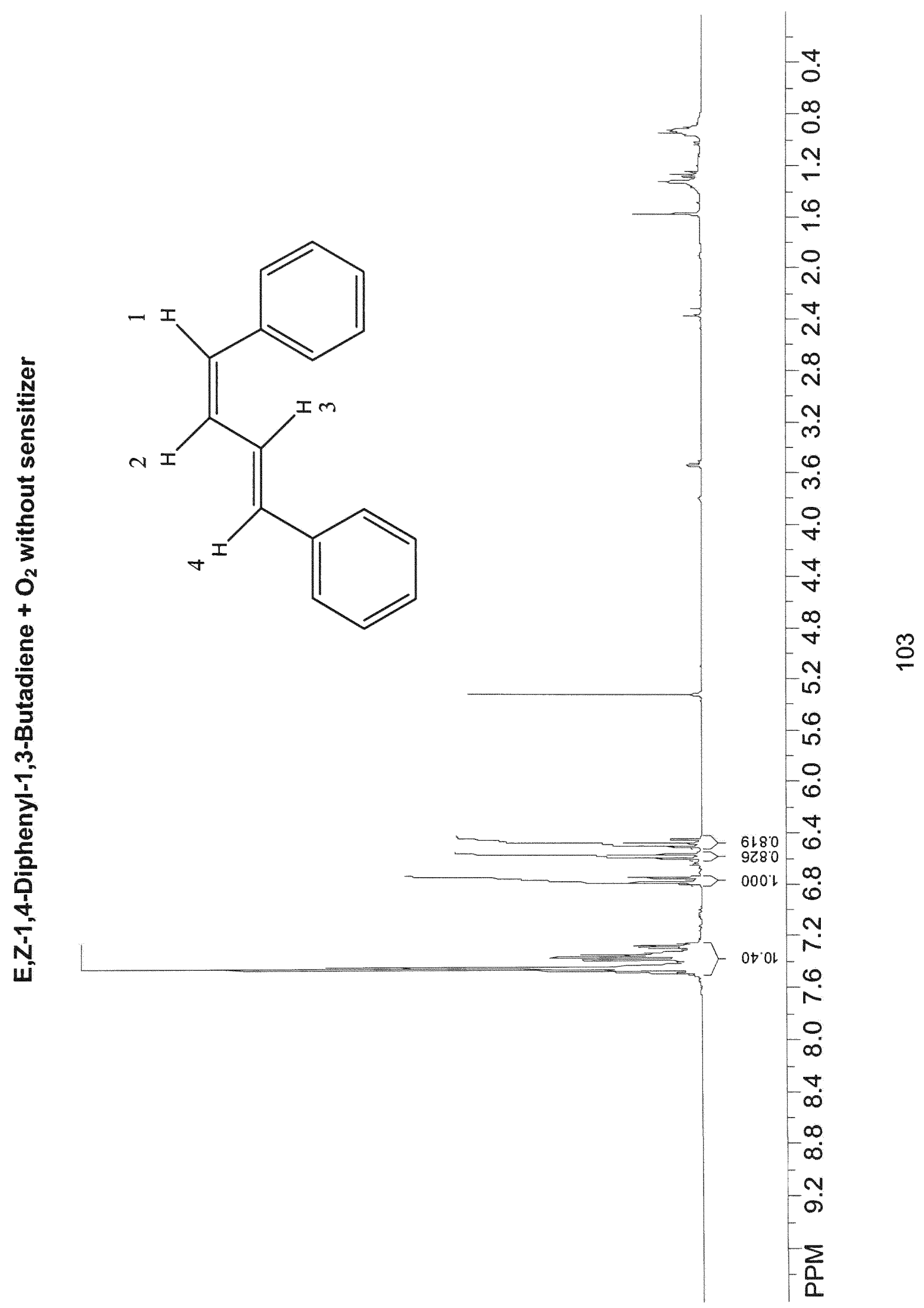




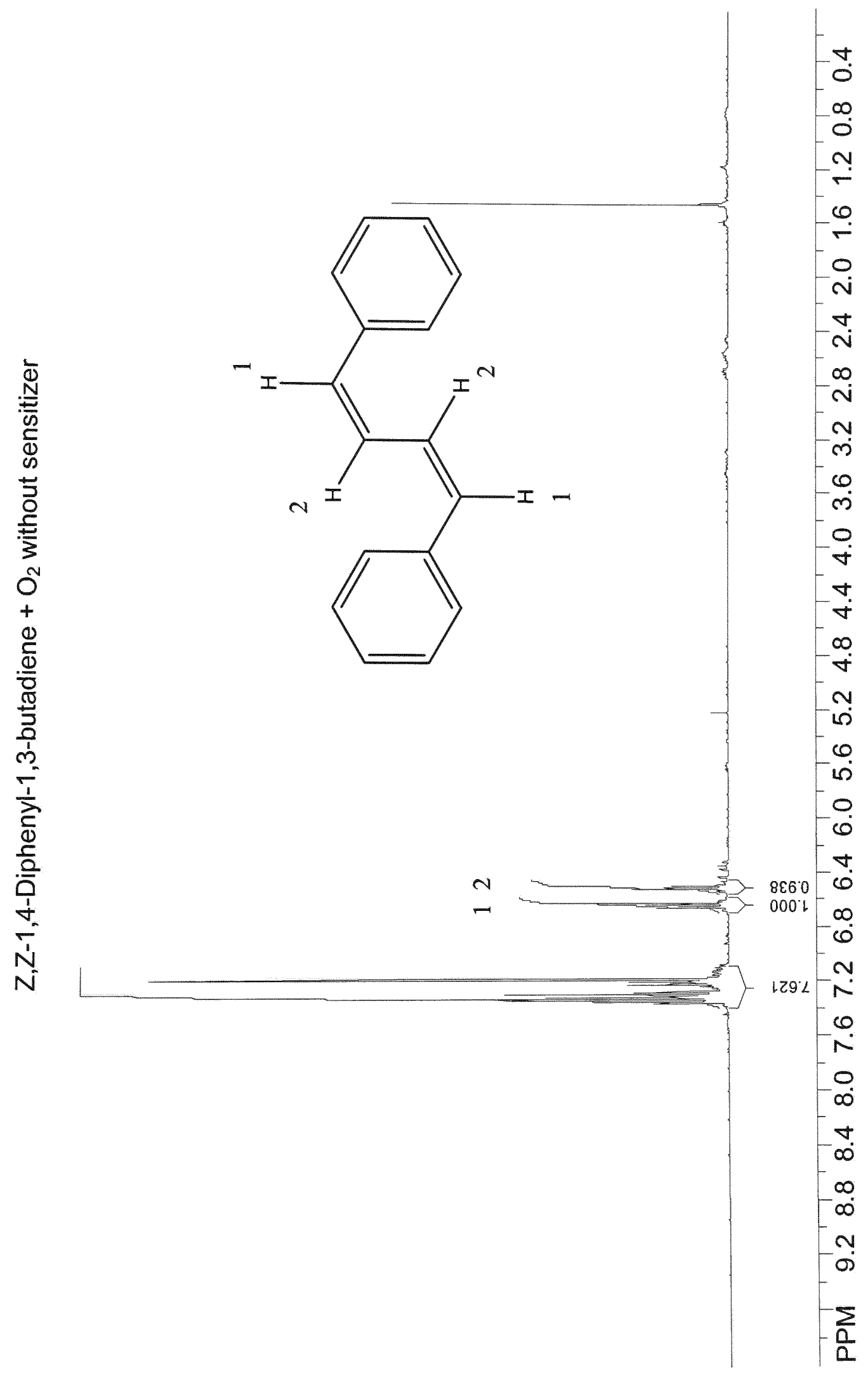




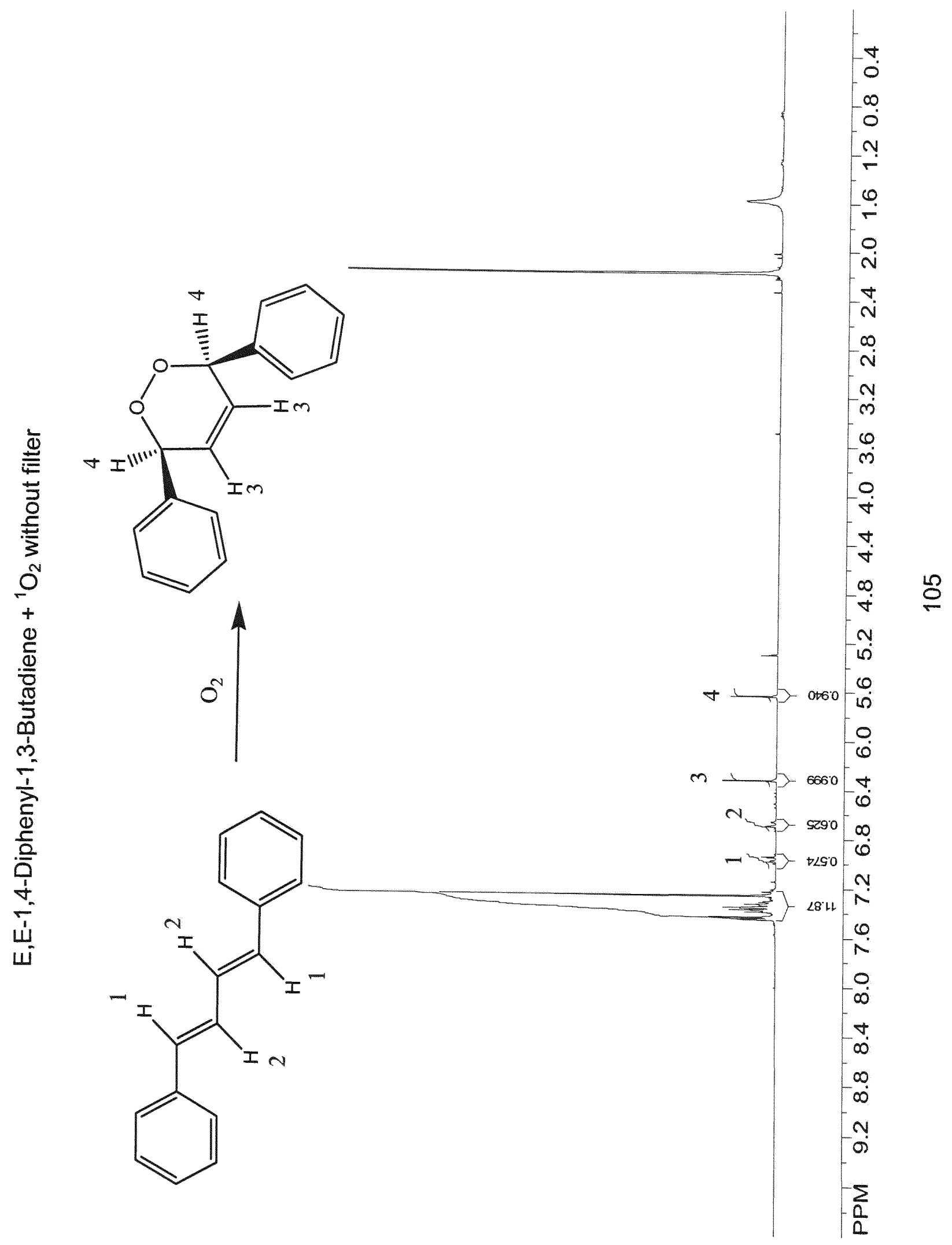


d

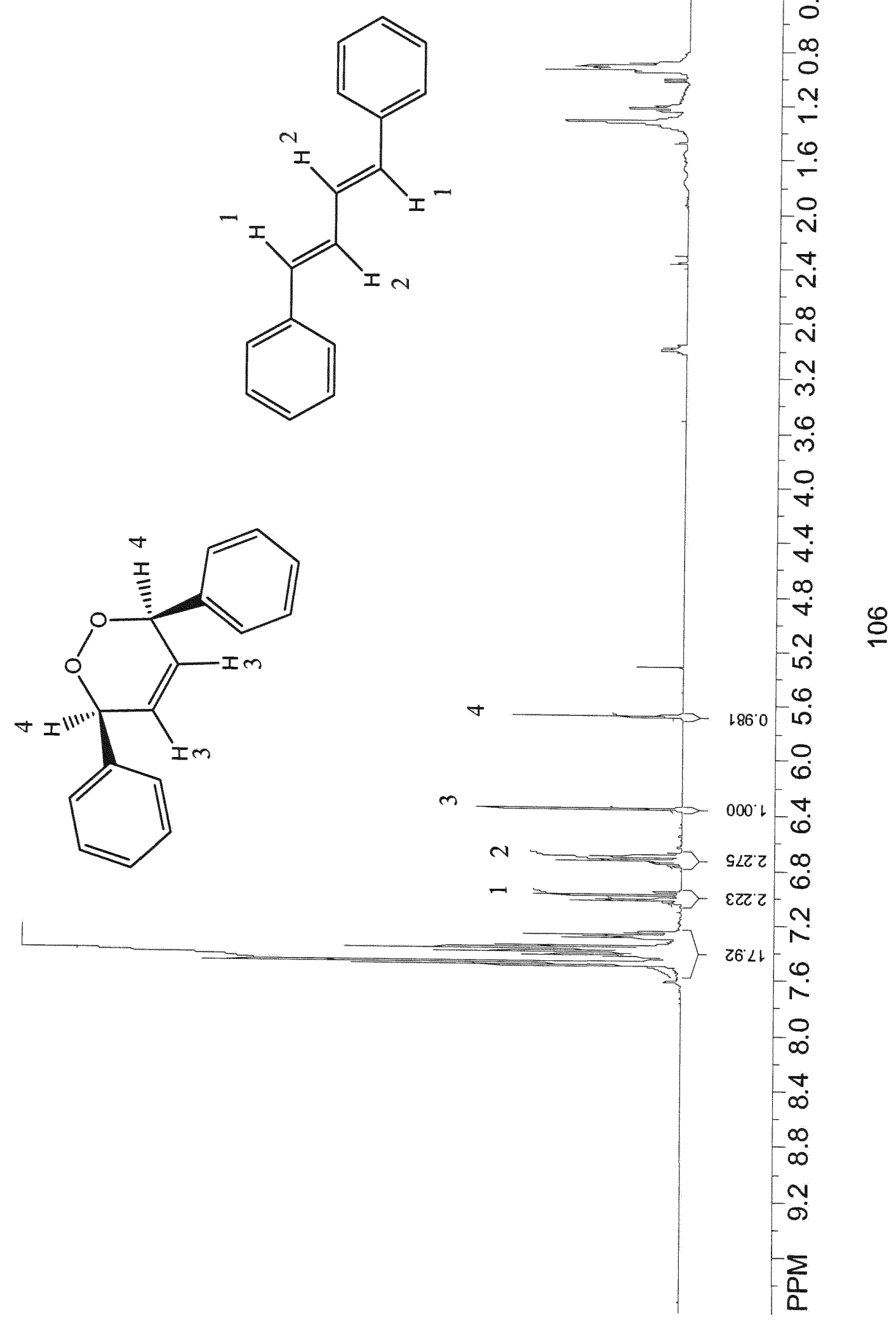




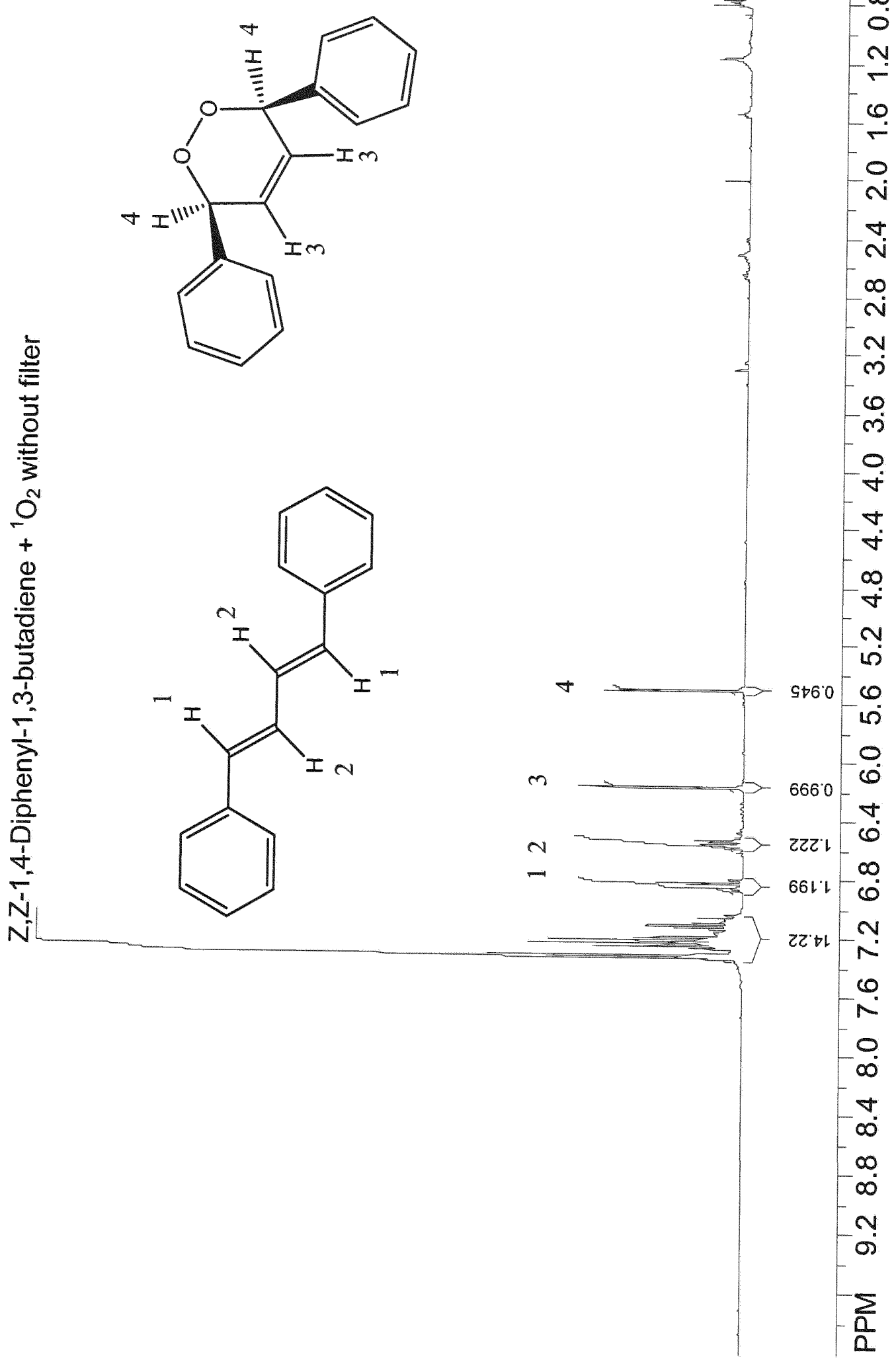




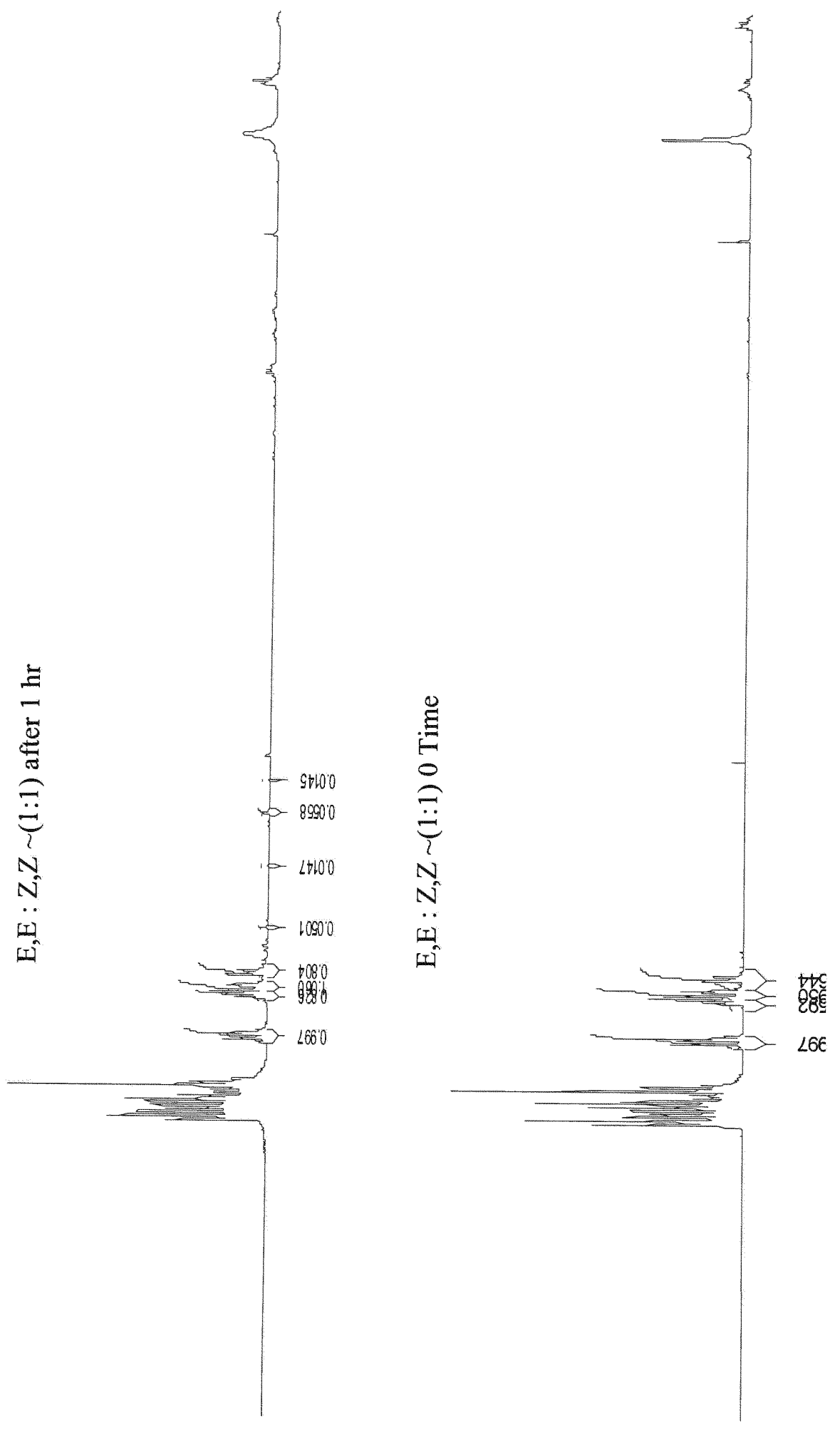



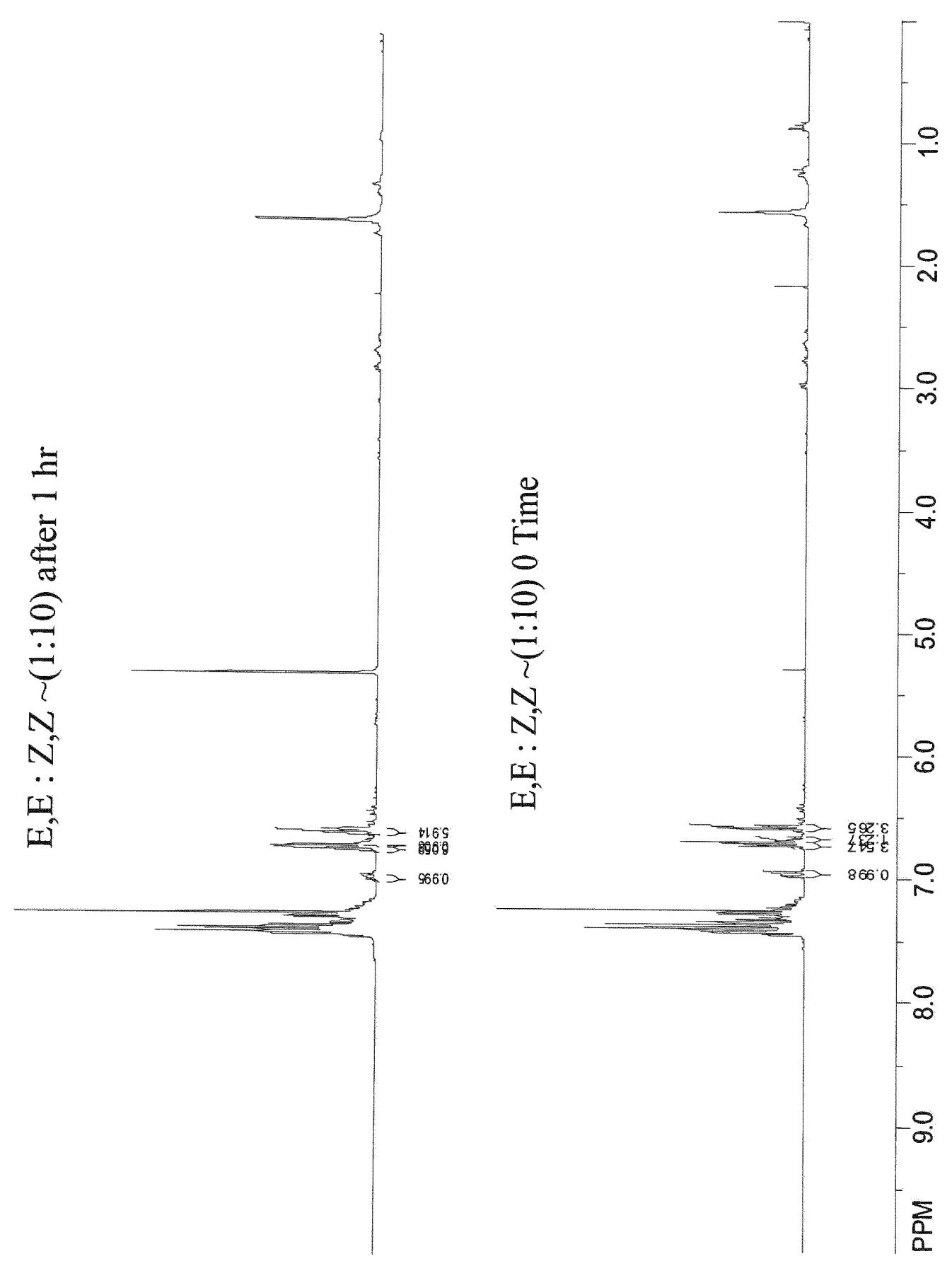

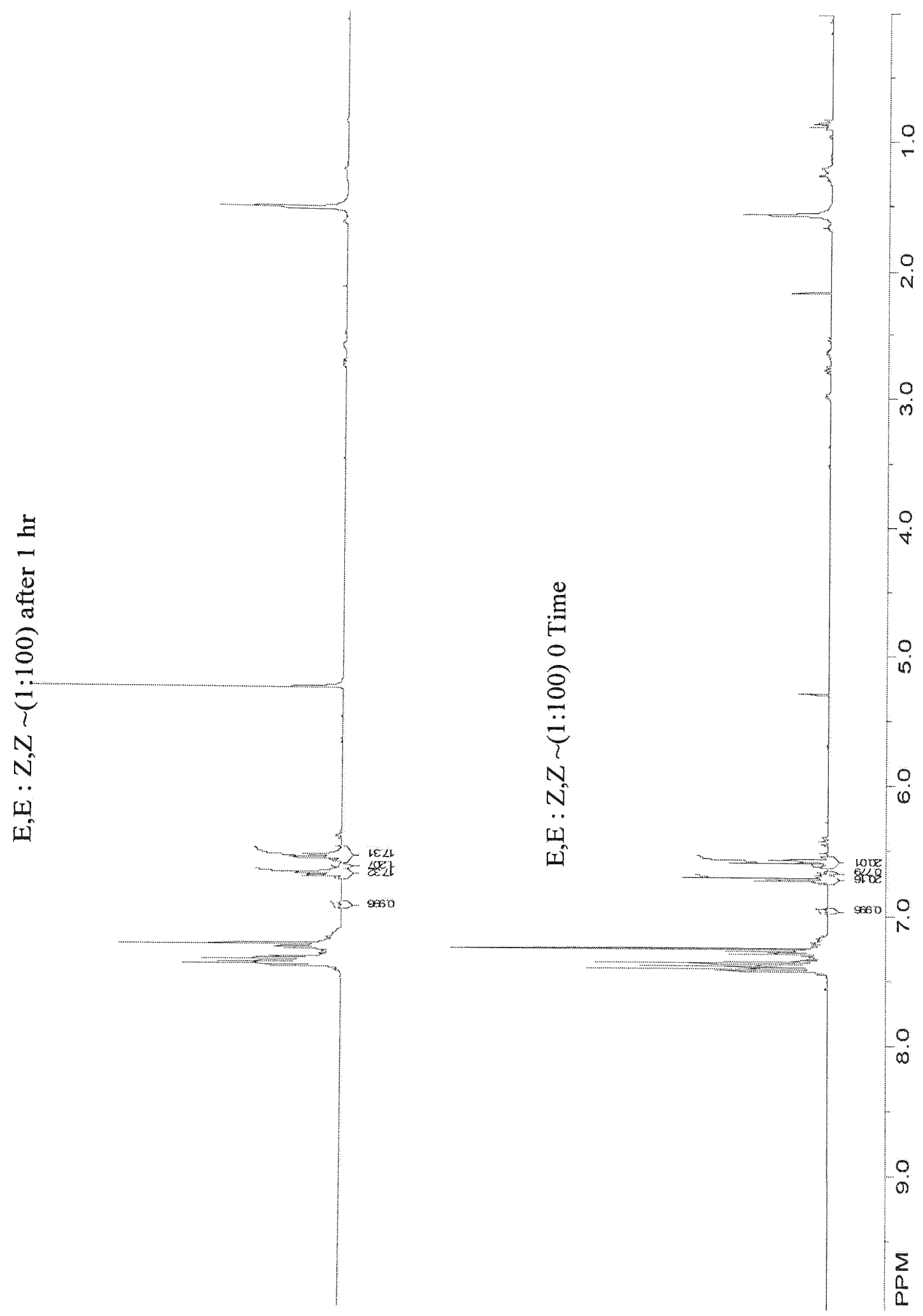